\title{
Phosphazene Superbase-Mediated Regio- and Stereoselective lodoaminocyclization of 2-(1-Alkynyl)benzamides for the Synthesis of Isoindolin-1-ones
}

\author{
Saurabh Mehta,* and Dhirendra Brahmchari \\ Department of Applied Chemistry, Delhi Technological University, Delhi, 110042 \\ India \\ saurabh.mehta@dtu.ac.in
}

\section{SUPPORTING INFORMATION}

Table of Contents

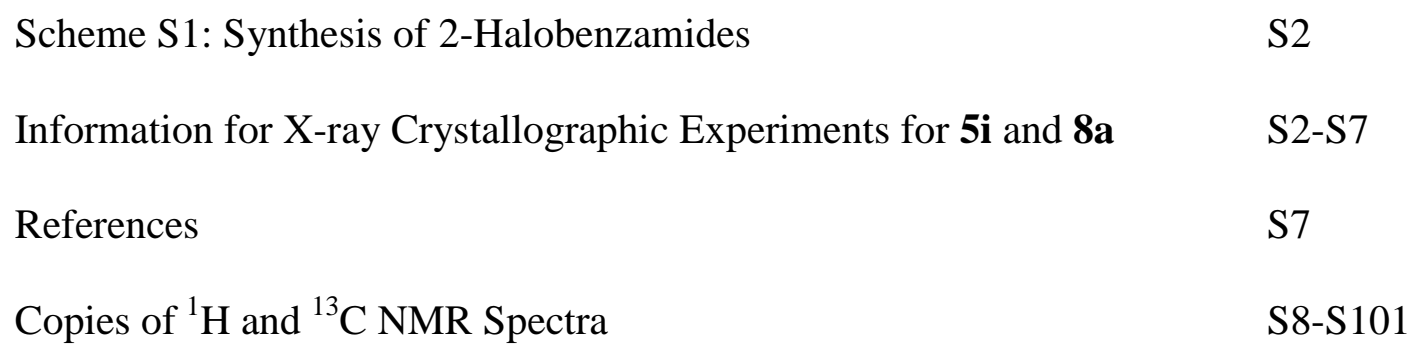




\section{Scheme S1: Synthesis of 2-Halobenzamides:}

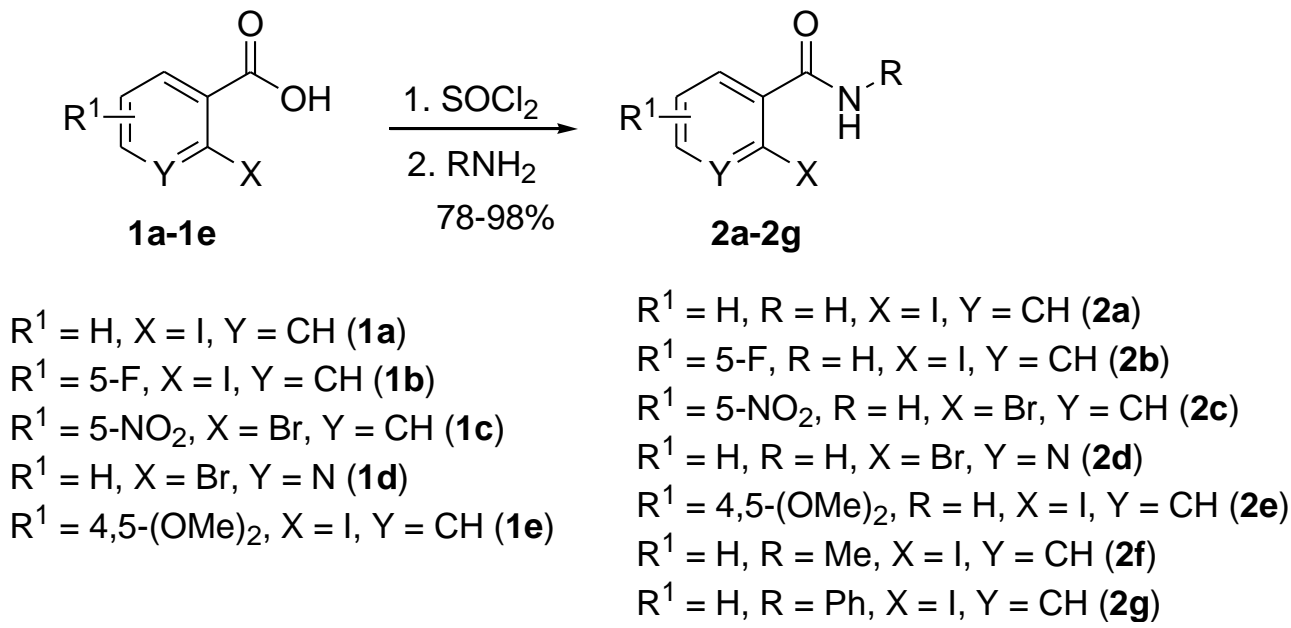

\section{X-ray Crystallographic Experimental Information of 5i and 8a.}

Single crystals of $\mathbf{5 i}$ of suitable quality were grown by slow evaporation of the solvent mixture of dichloromethane and diethyl ether $(\mathrm{v}: \mathrm{v}=2: 5)$ solvent solutions containing $\mathbf{5 i}$ at room temperature. Compound $\mathbf{5 i}$ was dissolved in dichloromethane at room temperature. Subsequently, diethyl ether was added carefully on top of the dichloromethane solution and two layers were observed. The vial was kept to allow slow evaporation of solvents until crystals were formed which were suitable for X-ray diffraction analysis. Crystallographic data have been deposited in the Cambridge Crystallographic Data Centre and CCDC deposit number for $\mathbf{5 i}$ is 1864768 .

Single crystals of 8a of suitable quality were grown by slow evaporation of the mixture solvent of dichloromethane and diethyl ether (v:v $=2: 5)$ solvent solutions containing 8a at room temperature. Compound 8a was dissolved in dichloromethane at room temperature. Subsequently, diethyl ether was added carefully on top of the dichloromethane solution and two layers were observed. The vial was kept to allow slow evaporation of solvents until crystals were formed which were suitable for X-ray diffraction analysis. 
Crystallographic data have been deposited in the Cambridge Crystallographic Data Centre and CCDC deposit number for $\mathbf{8 a}$ is 1865767.

X-ray data collection was performed with Oxford Xcalibur, Sapphire3 Diffractometer equipped Mo $(\mathrm{K} \alpha)(\lambda=0.71073 \AA)$ radiation. Cell refinement and data reduction were carried out using CrysAlisPro 1.171.38.46 (Rigaku OD, 2015) program. Empirical absorption correction was performed using spherical harmonics, implemented in SCALE3 ABSPACK scaling algorithm. Crystal structures were solved by SHELXT -2014 (Sheldrick, 2014) and refined by full-matrix least squares techniques using SHELXL-2014 (Sheldrick, 2014) computer program using the WinGX graphical user interface. ${ }^{1}$ Molecular graphics were drawn using ORTEP3. ${ }^{2}$ The relevant details of data collection and refinement are given in Table (please provide the Table). All aromatic hydrogens were fixed geometrically at calculated positions and refined as riding model with $\mathrm{C}-\mathrm{H}$ distance of $0.93 \AA$, Uiso $(\mathrm{H})=$ 1.2Ueq $(\mathrm{C})$, whereas the hydrogen on Nitrogen atom was located from the electron density peaks and refined freely with N-H distance restrained at $0.85 \AA$ within an allowed standard deviation of $0.02 \AA ̊$

[CCDC 1864768 (5i) and CCDC 1865767 (8a) contain the supplementary crystallographic data for this paper. These data can be obtained free of charge from The Cambridge Crystallographic Data Centre via www.ccdc.cam.ac.uk/data_request/cif.] 
X-ray Crystallographic Data for (Z)-3-((2-Bromophenyl)iodomethylene)isoindolin-1-one (5i), CCDC 1864768. Displacement ellipsoids are drawn at $40 \%$ probability level for non-hydrogen atoms.

\section{Figure S1. Molecular structure}

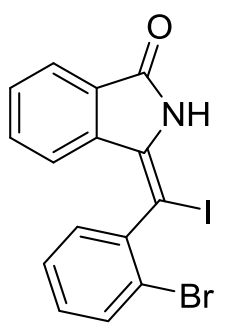

$5 \mathbf{i}$

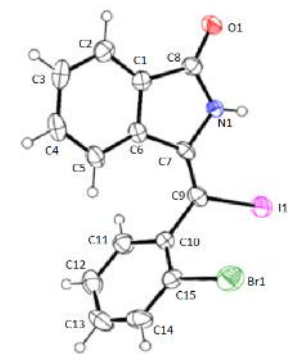

Table S1. Crystal data and structure refinement for Compound $5 \mathrm{i}$.

Identification code

Empirical formula

Formula weight

Temperature

Wavelength

Crystal system

Space group

Unit cell dimensions

Volume

$\mathrm{Z}$

Density (calculated)

Absorption coefficient

$\mathrm{F}(000)$

Crystal size
DHB-167

C15H9BrINO

426.04

293(2) K

$0.71073 \AA$

Triclinic

P-1

$a=7.3441(4) \AA$ $\alpha=77.358(7)^{\circ}$.

$\mathrm{b}=8.1078(6) \AA$ $\beta=82.035(7)^{\circ}$.

$\mathrm{c}=13.4140(8) \AA$ $\gamma=63.503(10)^{\circ}$

$696.73(10) \AA^{3}$

2

$2.031 \mathrm{Mg} / \mathrm{m}^{3}$

$5.156 \mathrm{~mm}^{-1}$

404

$0.200 \times 0.150 \times 0.100 \mathrm{~mm}^{3}$ 


$\begin{array}{ll}\text { Theta range for data collection } & 3.406 \text { to } 24.999^{\circ} . \\ \text { Index ranges } & -8<=\mathrm{h}<=8,-9<=\mathrm{k}<=9,-15<=\mathrm{l}<=15 \\ \text { Reflections collected } & 8386 \\ \text { Independent reflections } & 2454 \text { [R(int) }=0.0728] \\ \text { Completeness to theta }=24.999^{\circ} & 99.7 \% \\ \text { Absorption correction } & \text { Semi-empirical from equivalents } \\ \text { Max. and min. transmission } & 0.657 \text { and } 0.457 \\ \text { Refinement method } & \text { Full-matrix least-squares on } \mathrm{F}^{2} \\ \text { Data / restraints / parameters } & 2454 / 1 / 176 \\ \text { Goodness-of-fit on } \mathrm{F}^{2} & 1.070 \\ \text { Final R indices [I }>2 \text { sigma(I)] } & \mathrm{R} 1=0.0599, \mathrm{wR} 2=0.1440 \\ \text { R indices (all data) } & \mathrm{R} 1=0.0754, \mathrm{wR} 2=0.1561 \\ \text { Extinction coefficient } & \mathrm{n} / \mathrm{a} \\ \text { Largest diff. peak and hole } & 0.982 \text { and }-0.740 \text { e. } \AA^{-3}-3\end{array}$

X-ray Crystallographic Data for Dibenzo[cd,f]indol-4(5H)-one (8a), CCDC 1865767. Displacement ellipsoids are drawn at $\mathbf{4 0 \%}$ probability level for non-hydrogen atoms.

Figure S2. Molecular structure
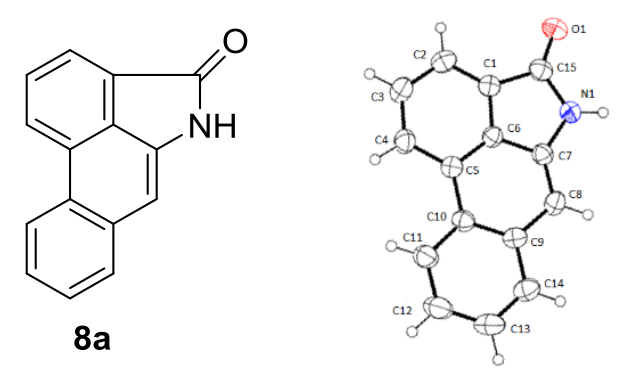

Table S2. Crystal data and structure refinement for Compound 8a.

Identification code

Empirical formula
292

C15H9NO 
Formula weight

Temperature

Wavelength

Crystal system

Space group

Unit cell dimensions

Volume

\section{Z}

Density (calculated)

Absorption coefficient

$\mathrm{F}(000)$

Crystal size

Theta range for data collection

Index ranges

Reflections collected

Independent reflections

Completeness to theta $=24.980^{\circ}$

Absorption correction

Max. and min. transmission

Refinement method

Data / restraints / parameters

Goodness-of-fit on $\mathrm{F}^{2}$

Final R indices [I $>2 \operatorname{sigma}(\mathrm{I})]$
219.23

293(2) K

$0.71073 \AA$

Monoclinic

$\mathrm{P} 2{ }_{1} / \mathrm{n}$

$$
\begin{array}{ll}
\mathrm{a}=9.3645(6) \AA & \alpha=90^{\circ} . \\
\mathrm{b}=6.7110(5) \AA & \beta=96.720(6)^{\circ} . \\
\mathrm{c}=17.1210(10) \AA & \gamma=90^{\circ} .
\end{array}
$$

1068.58(12) $\AA^{3}$

4

$1.363 \mathrm{Mg} / \mathrm{m}^{3}$

$0.086 \mathrm{~mm}^{-1}$

456

$0.250 \times 0.200 \times 0.200 \mathrm{~mm}^{3}$

3.744 to $24.980^{\circ}$.

$-11<=\mathrm{h}<=11,-7<=\mathrm{k}<=7,-20<=1<=20$

12321

$1872[\mathrm{R}(\mathrm{int})=0.0641]$

$99.8 \%$

Semi-empirical from equivalents

1.0 and 0.938

Full-matrix least-squares on $\mathrm{F}^{2}$

1872 / 0 / 159

1.063

$\mathrm{R} 1=0.0528, \mathrm{wR} 2=0.1054$ 

$\mathrm{R}$ indices (all data)
$\mathrm{R} 1=0.1052, \mathrm{wR} 2=0.1377$
Extinction coefficient
$0.0070(17)$
Largest diff. peak and hole
0.197 and -0.154 e. $\AA^{-3}$

\section{References:}

(1) Farrugia, L. J. WinGX Suite for Small-Molecule Single-Crystal Crystallography. J. Appl. Cryst. 1999, 32, 837-838.

(2) Farrugia, L. J. ORTEP-3 for Windows - a Version of ORTEP-III with a Graphical User Interface (GUI). J. Appl. Cryst. 1997, 30, 565-565. 


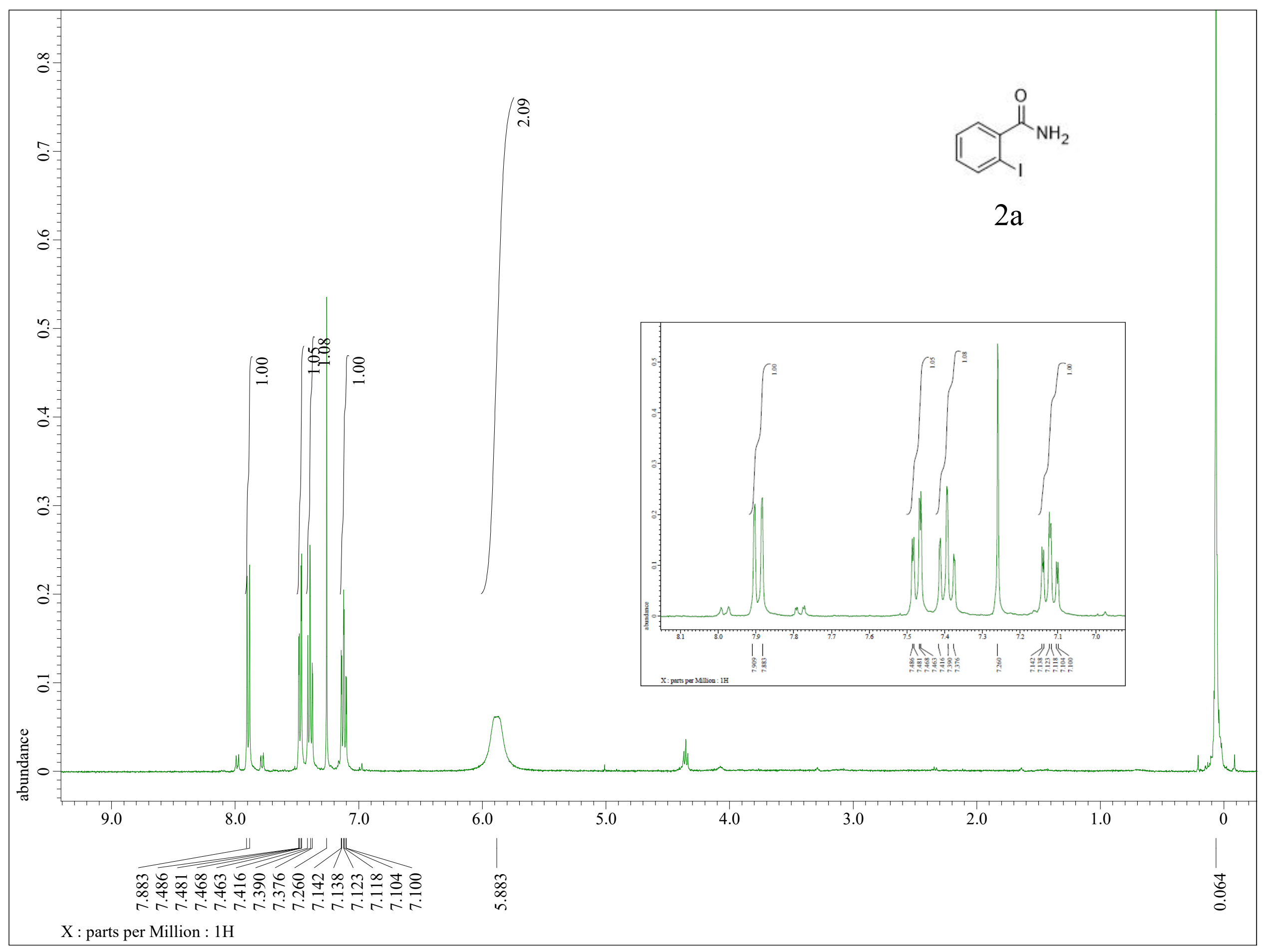




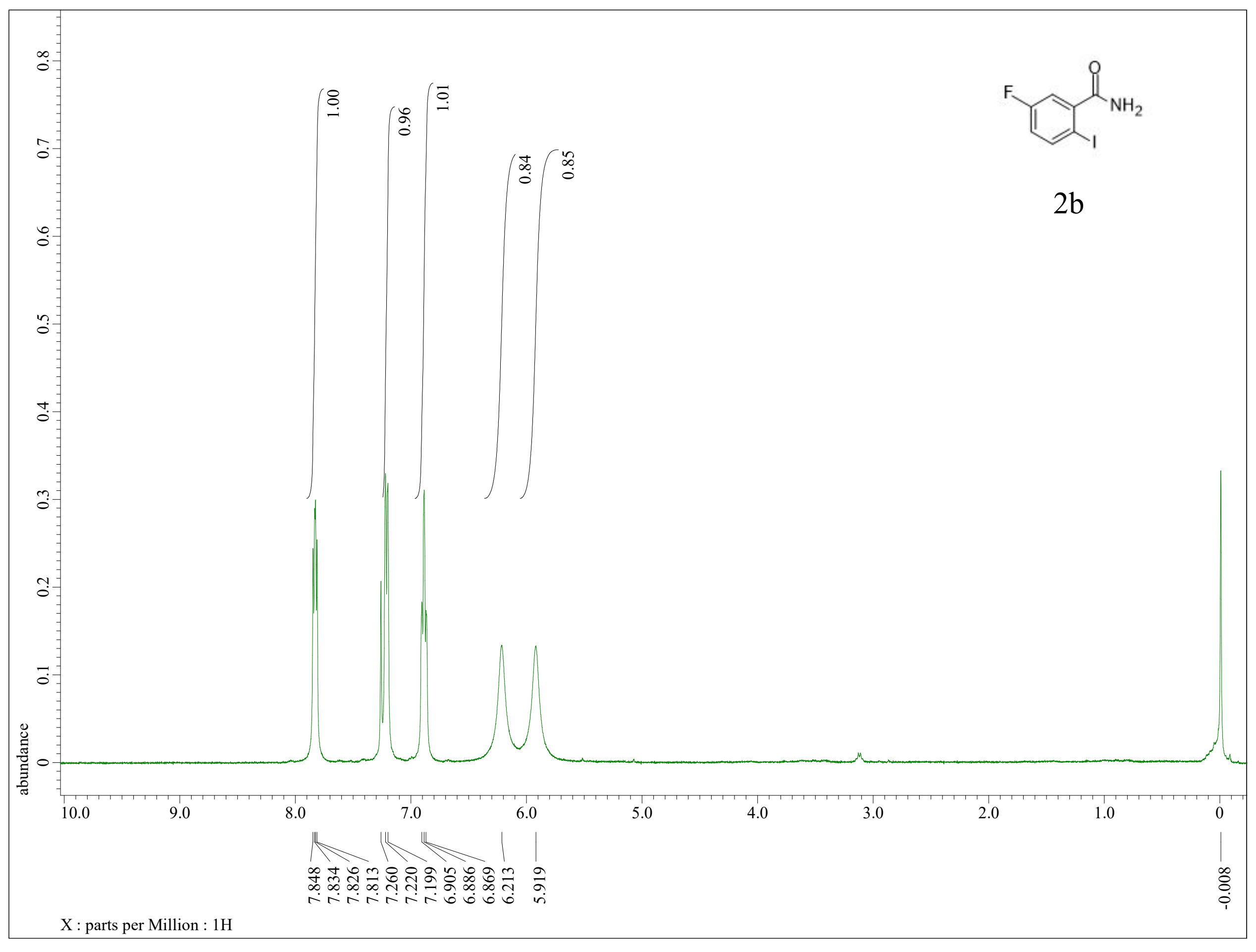




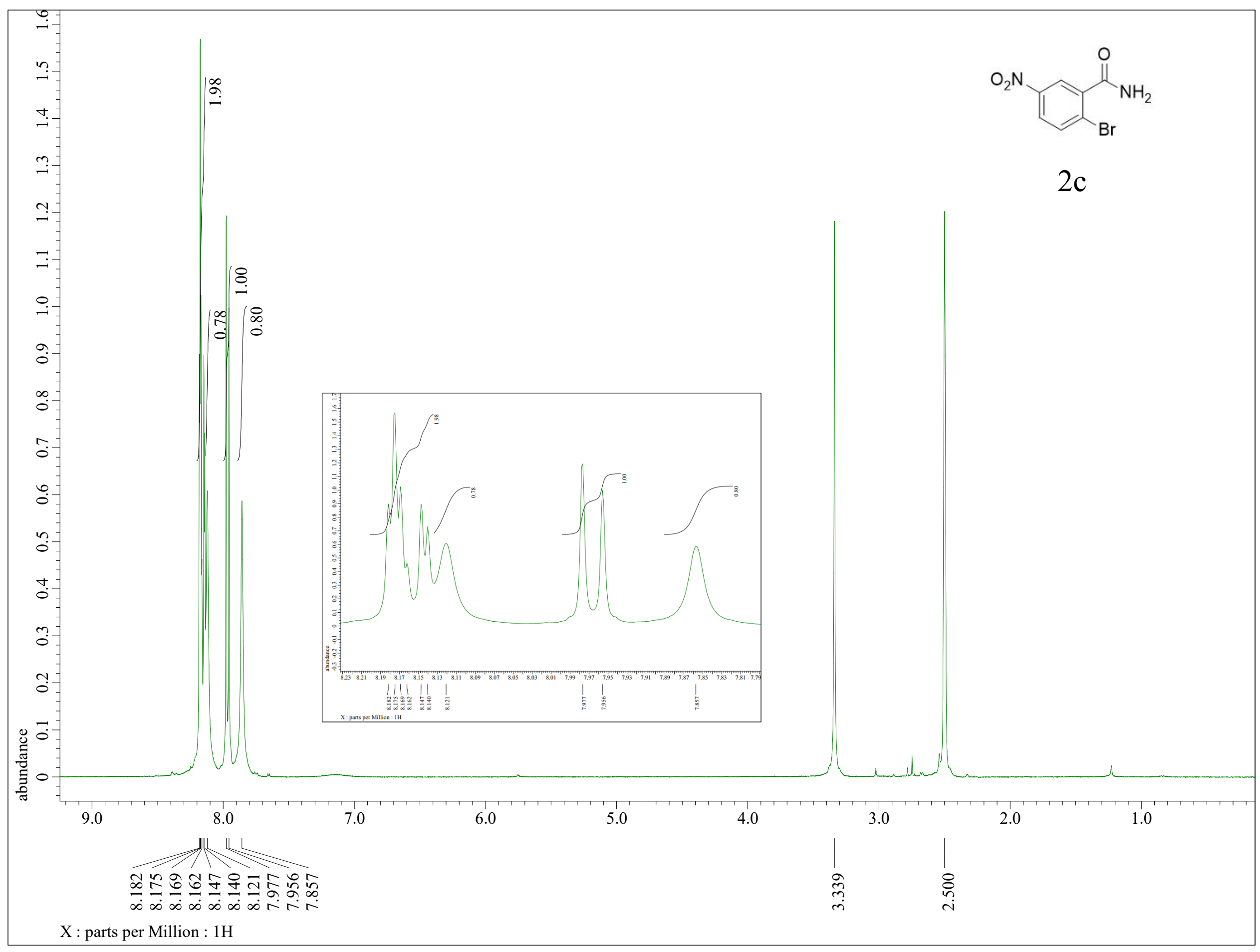




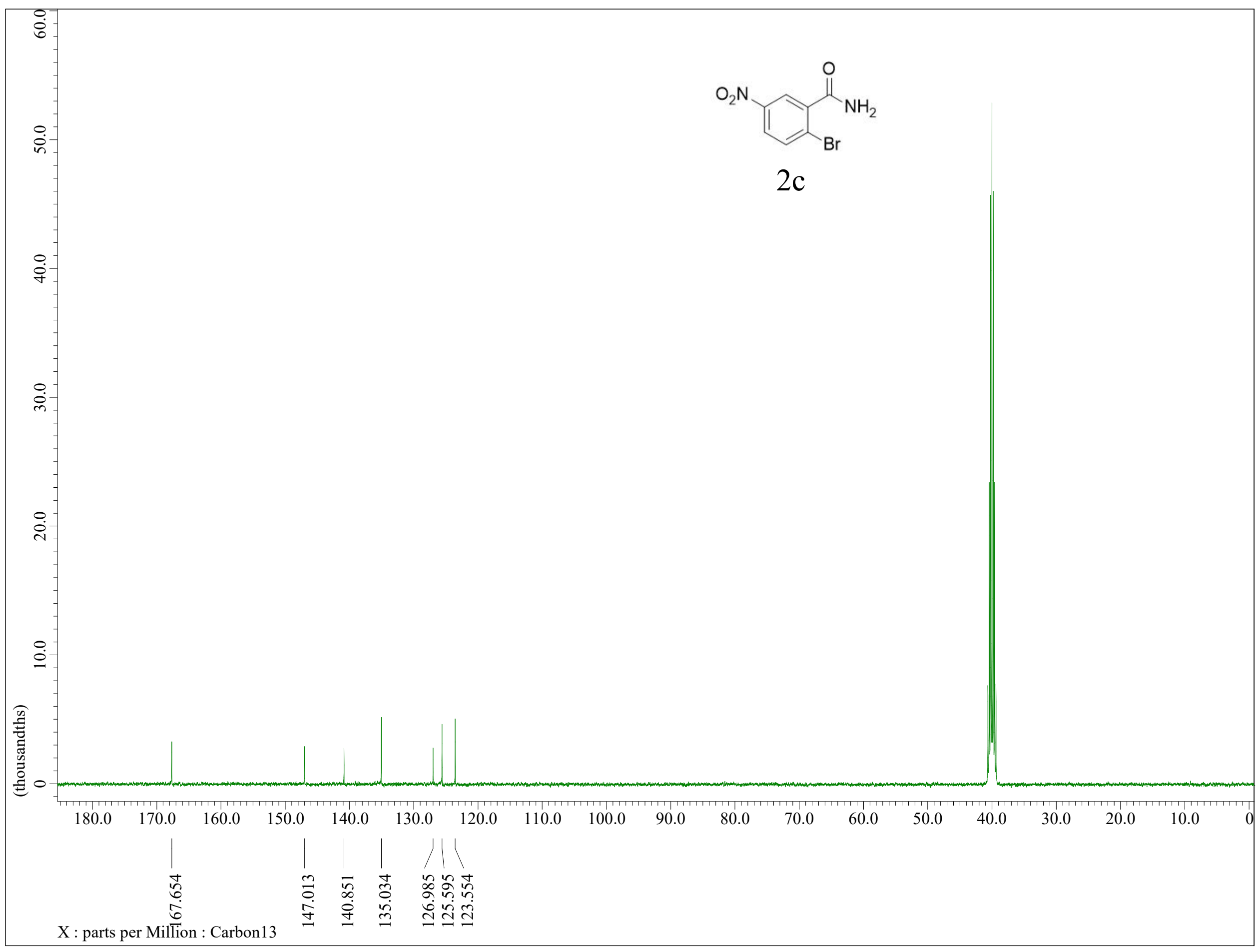




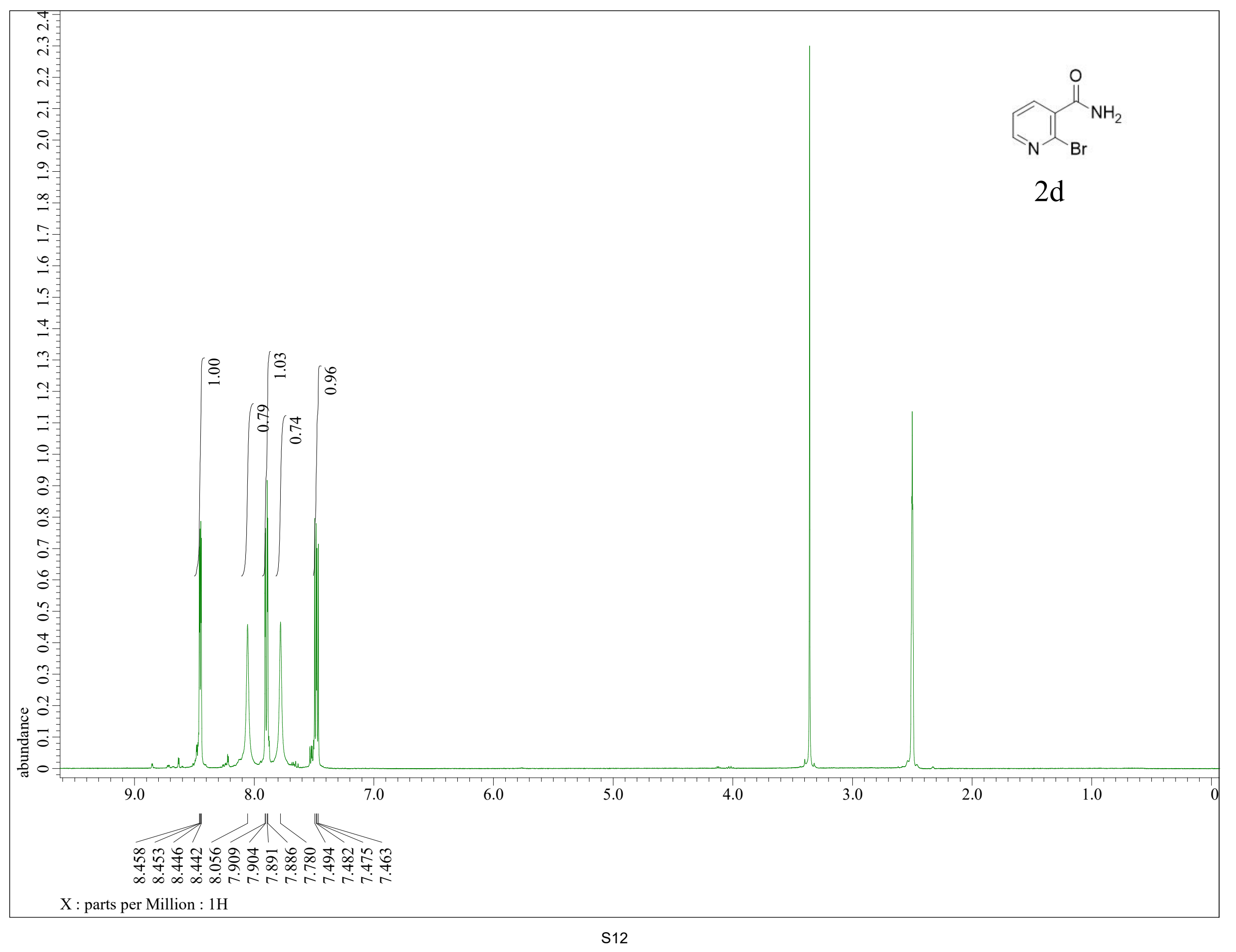




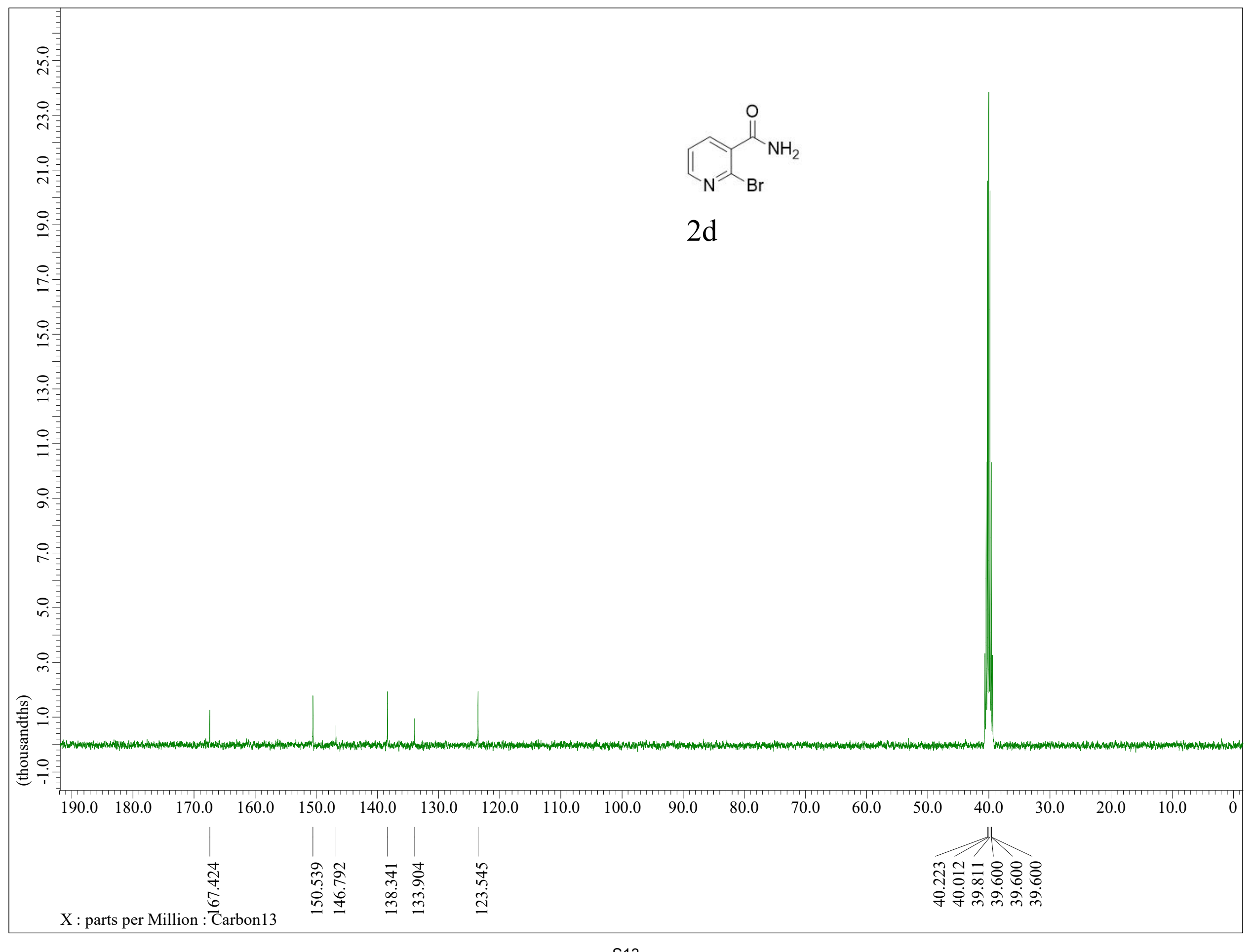




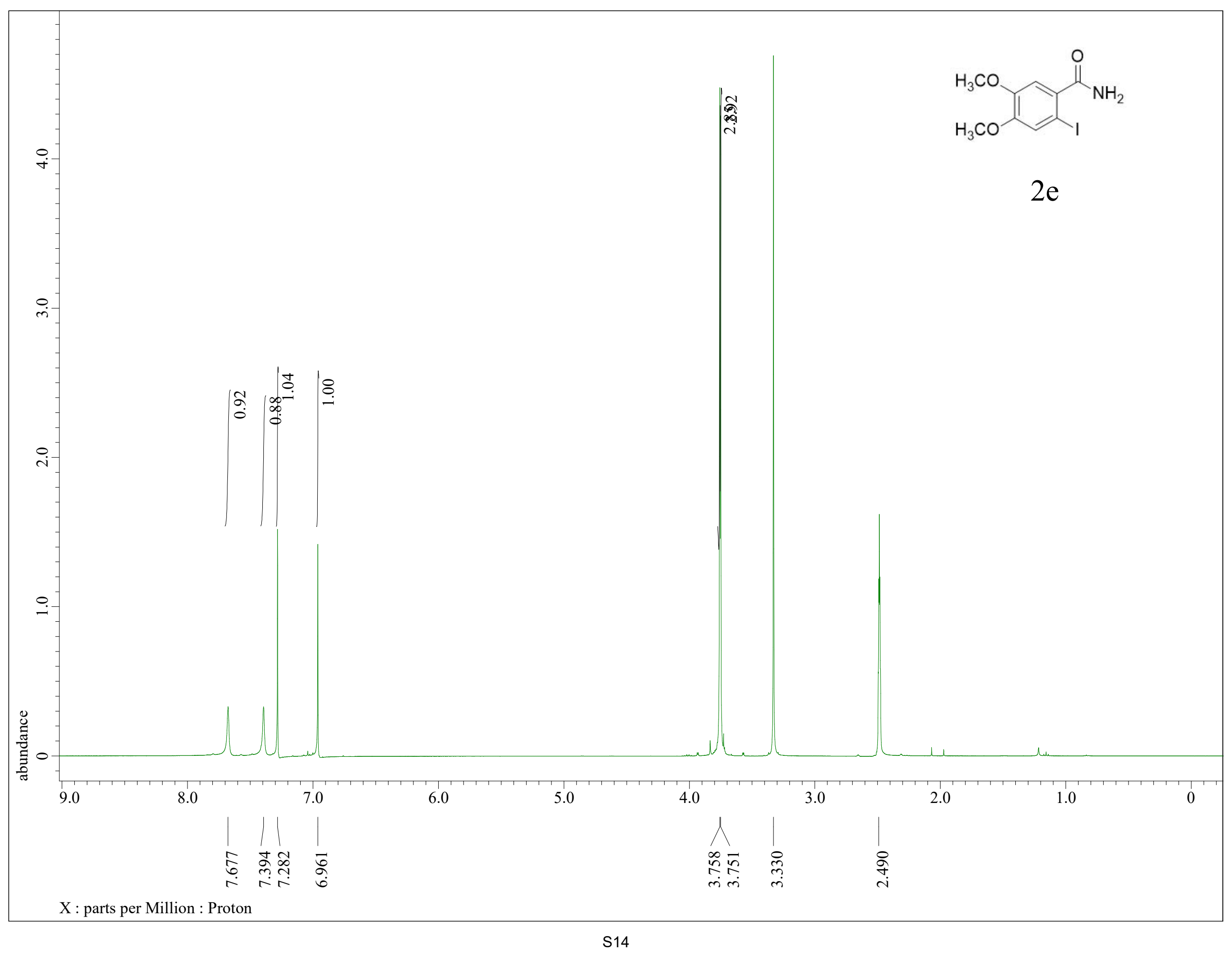




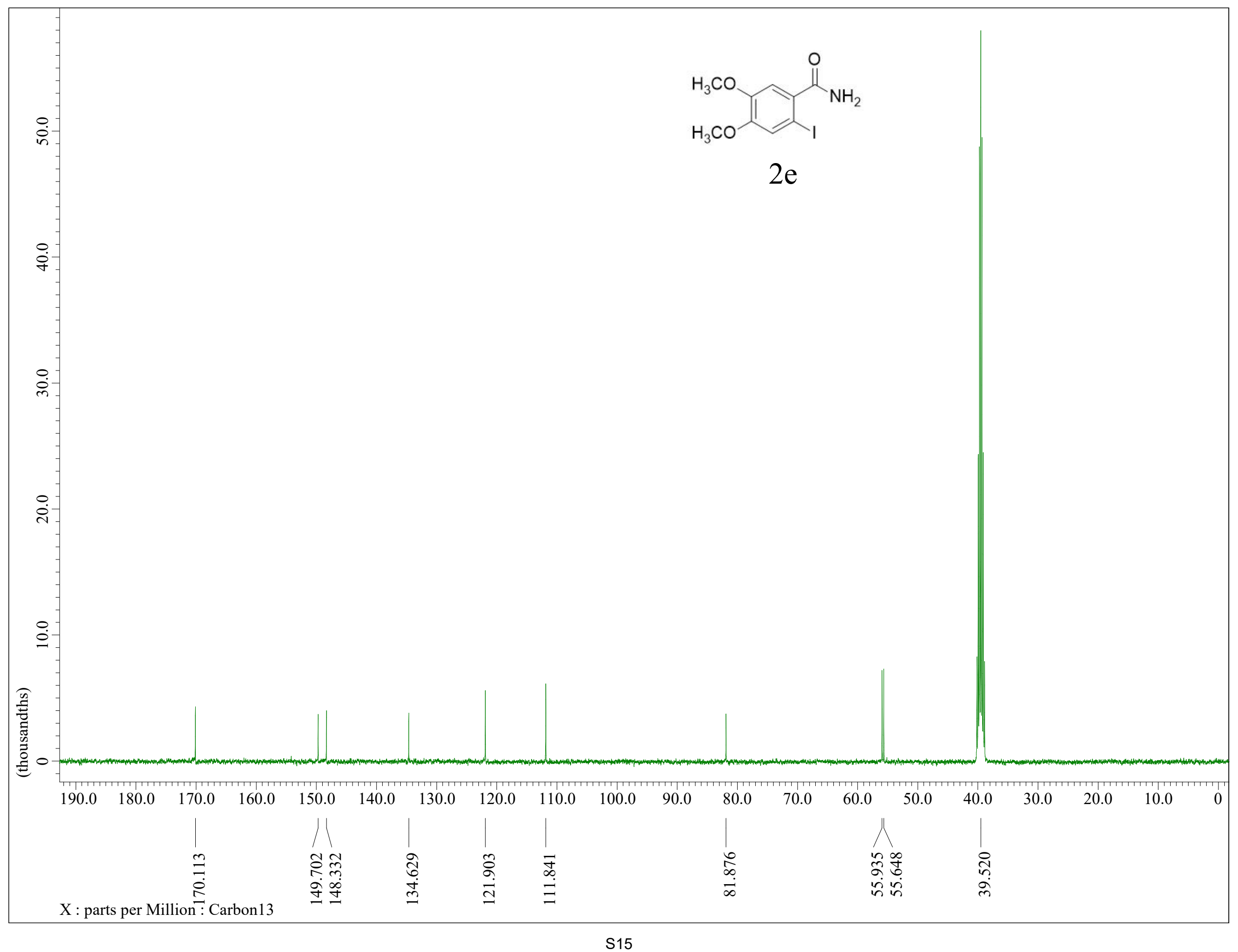




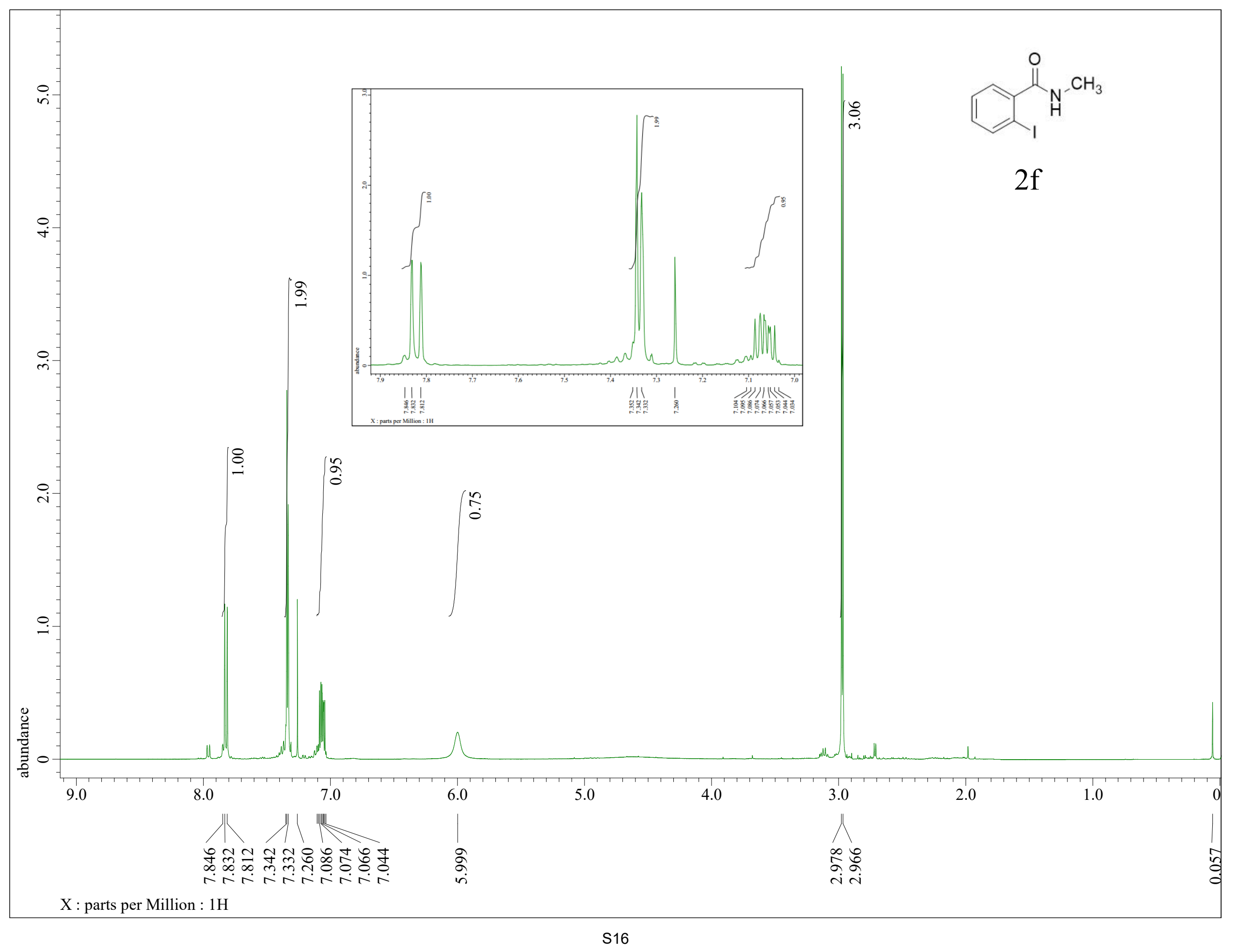




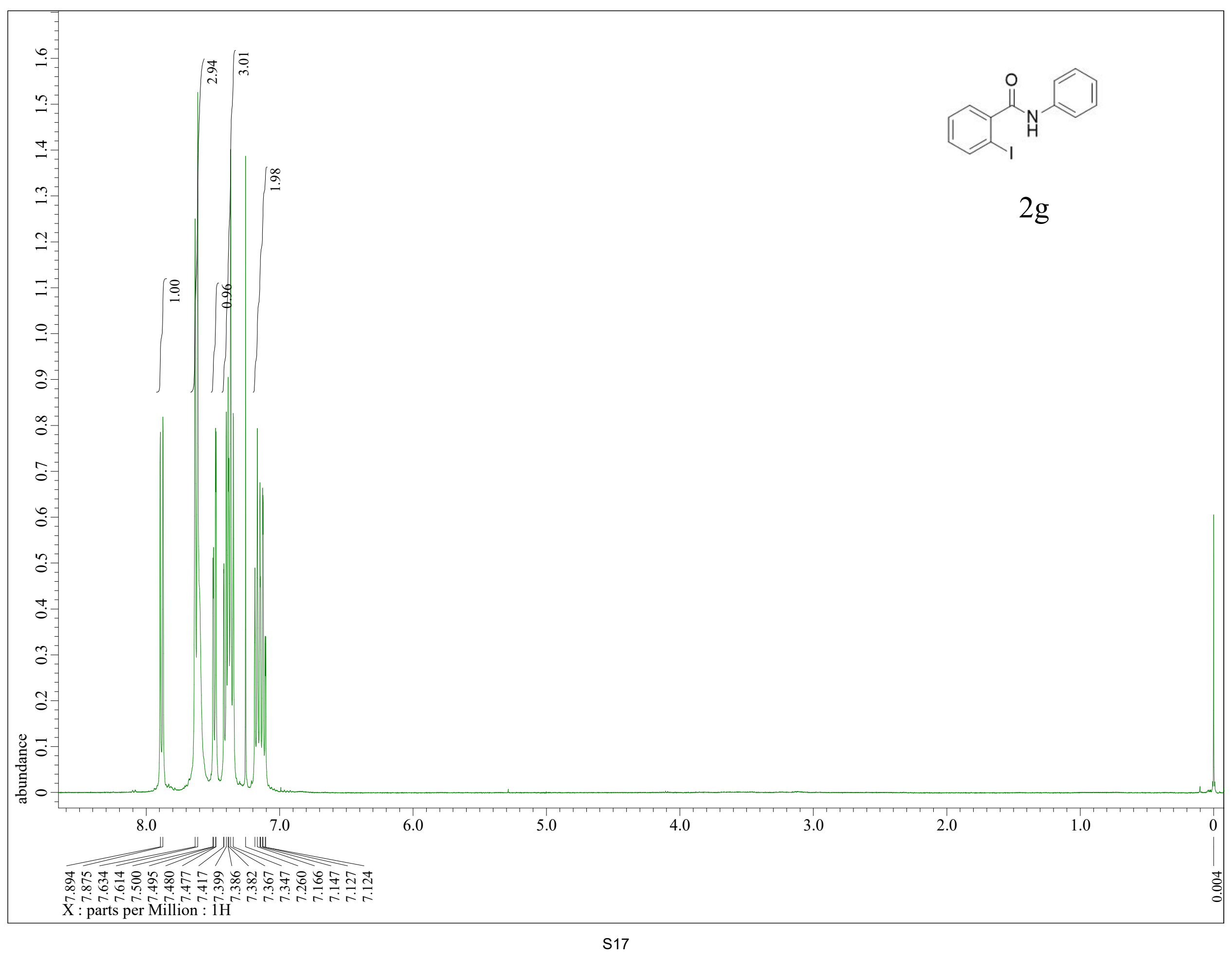




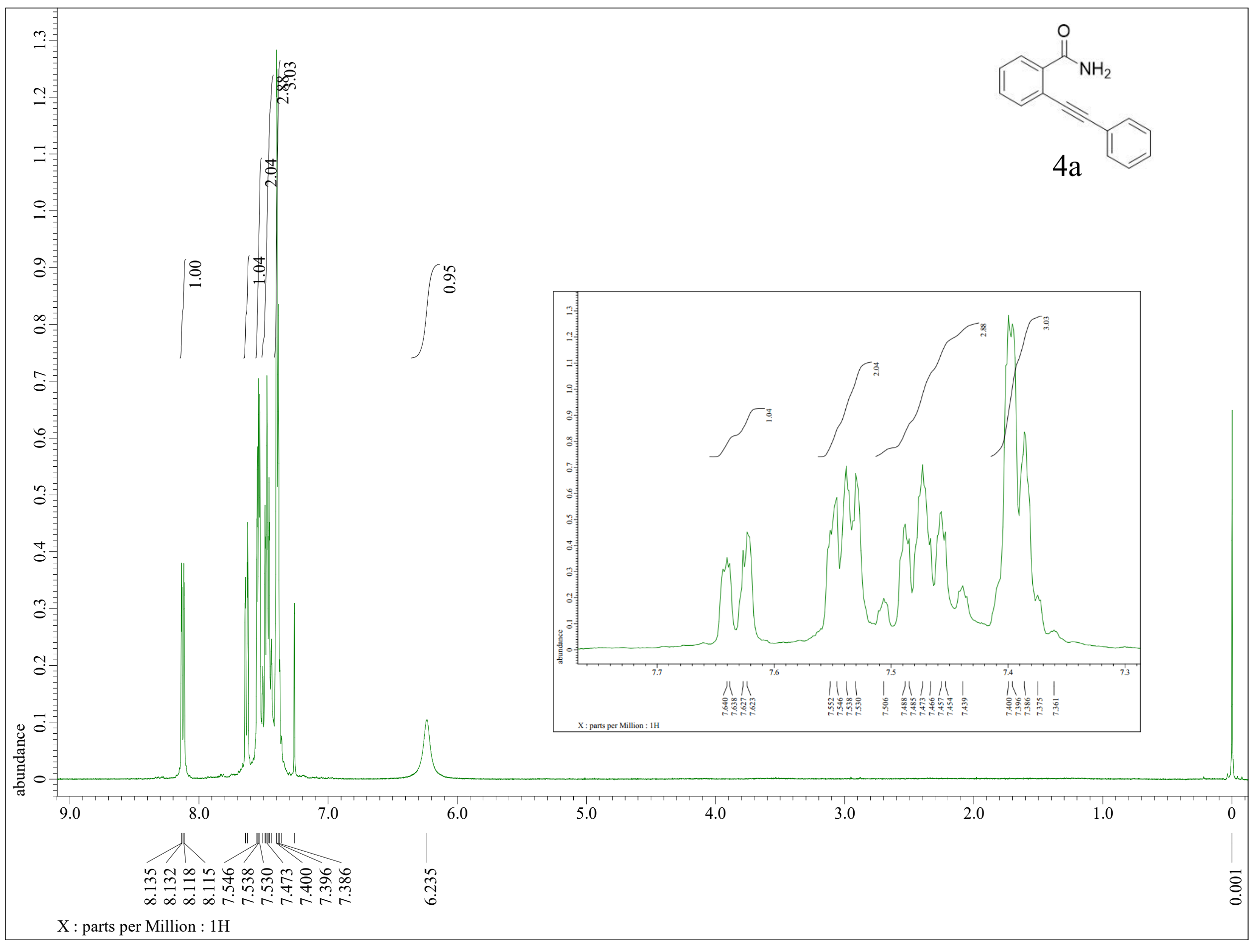




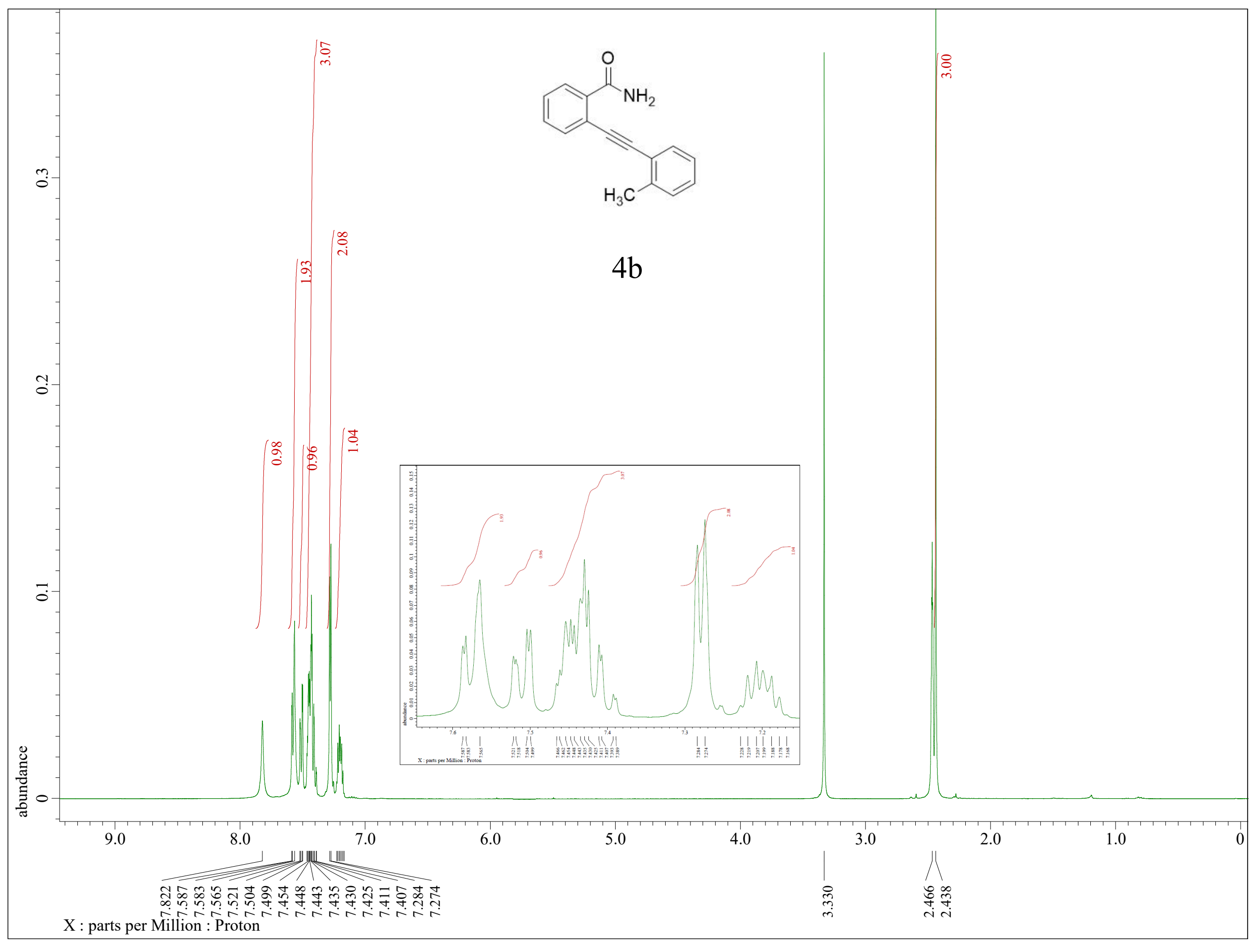




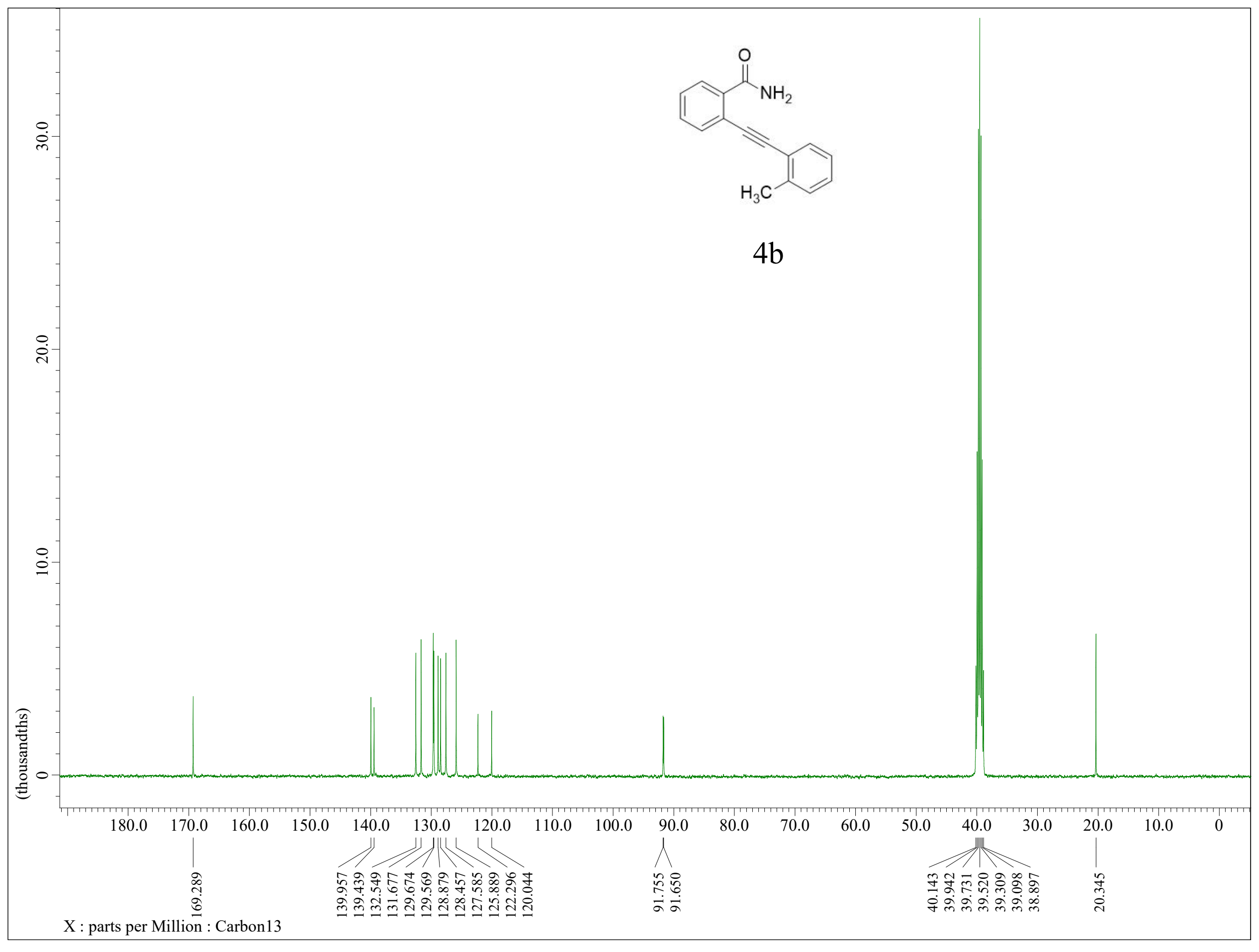




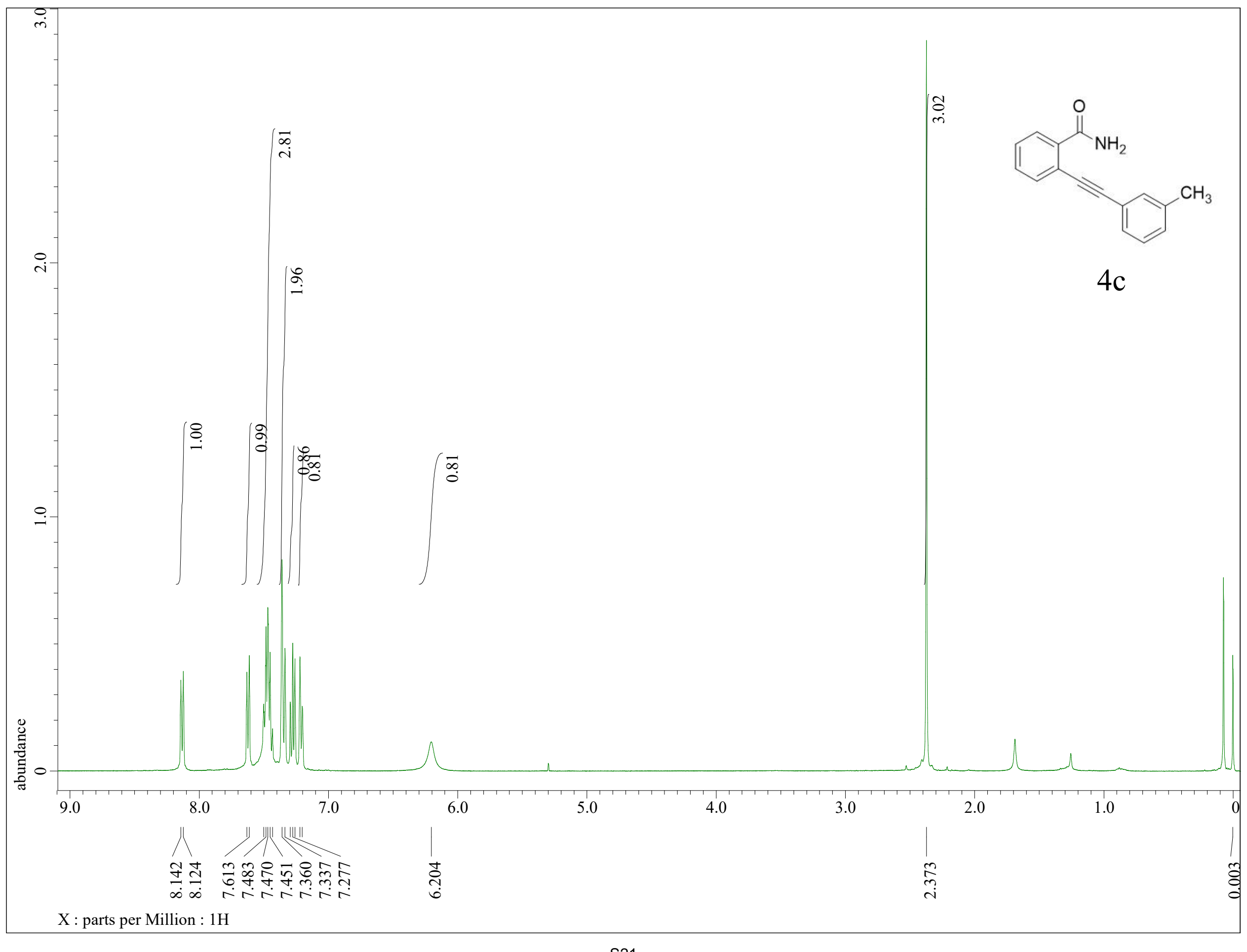




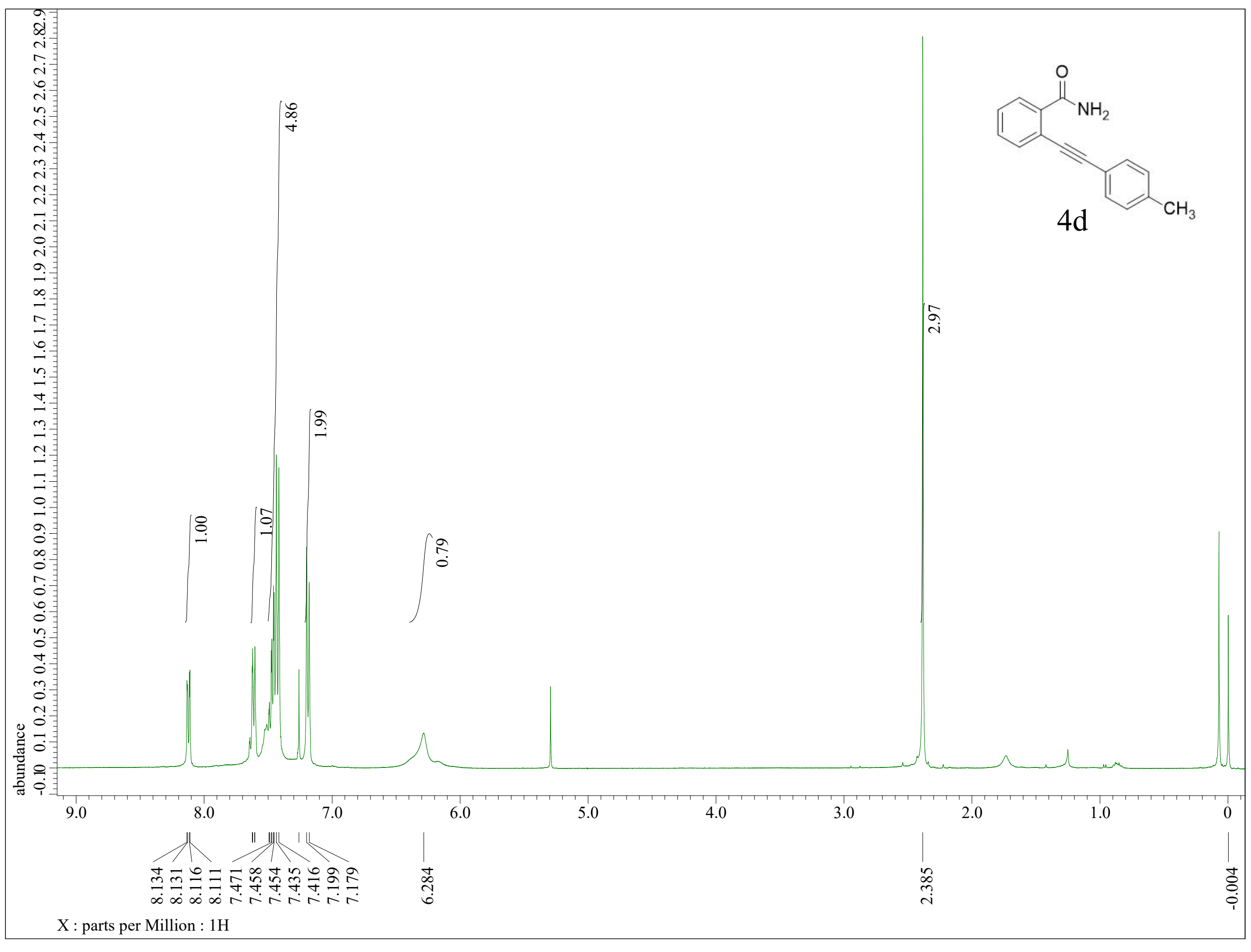




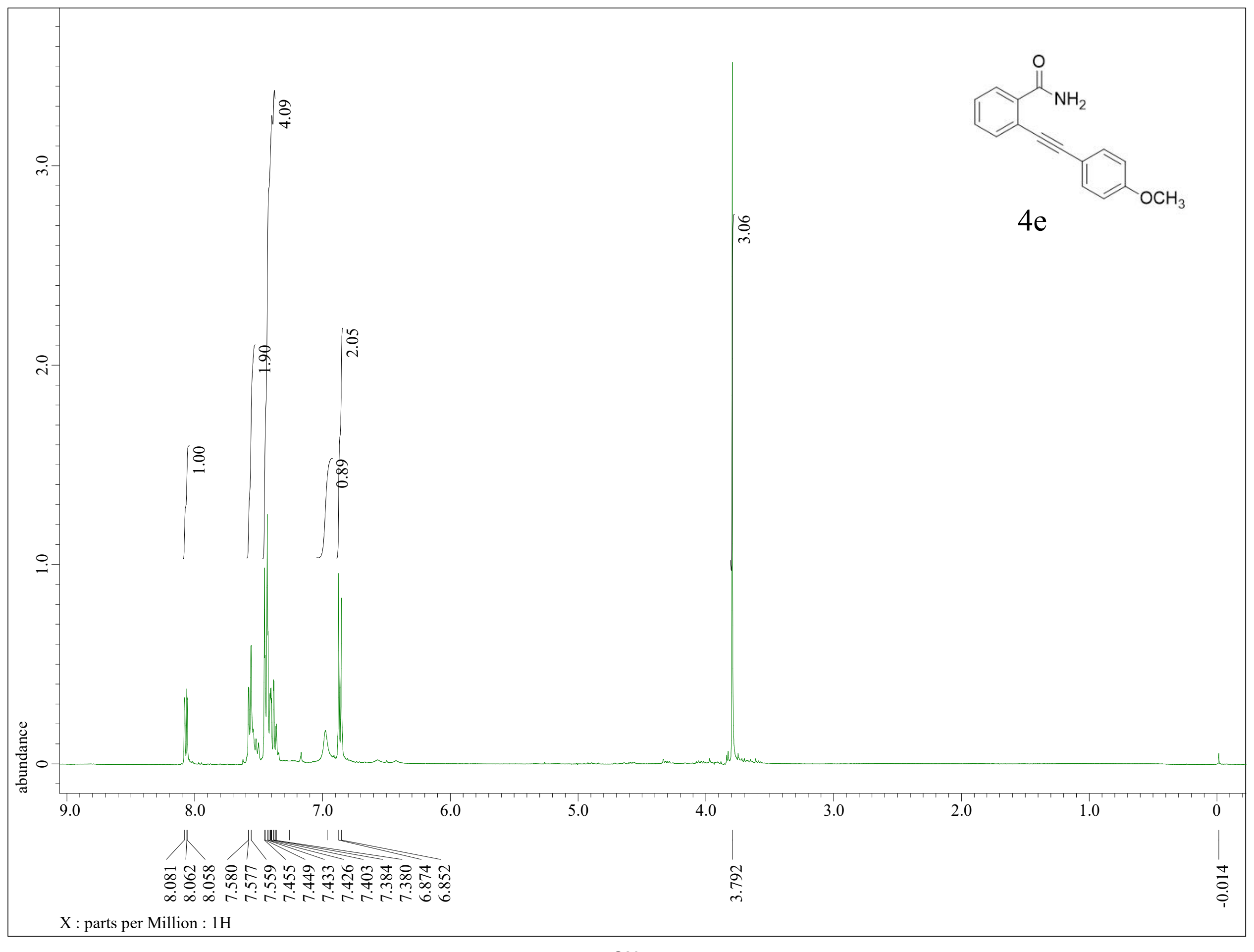




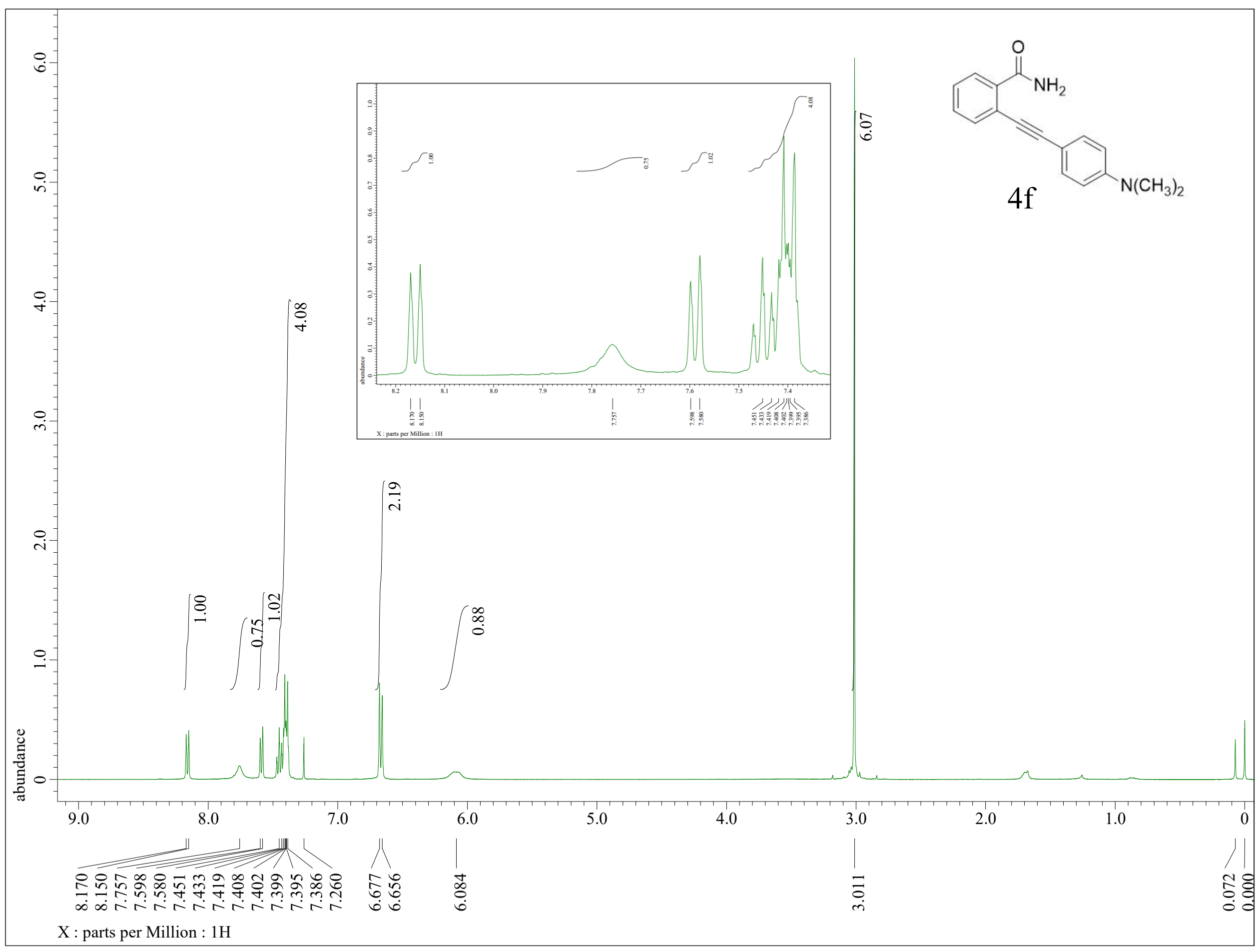




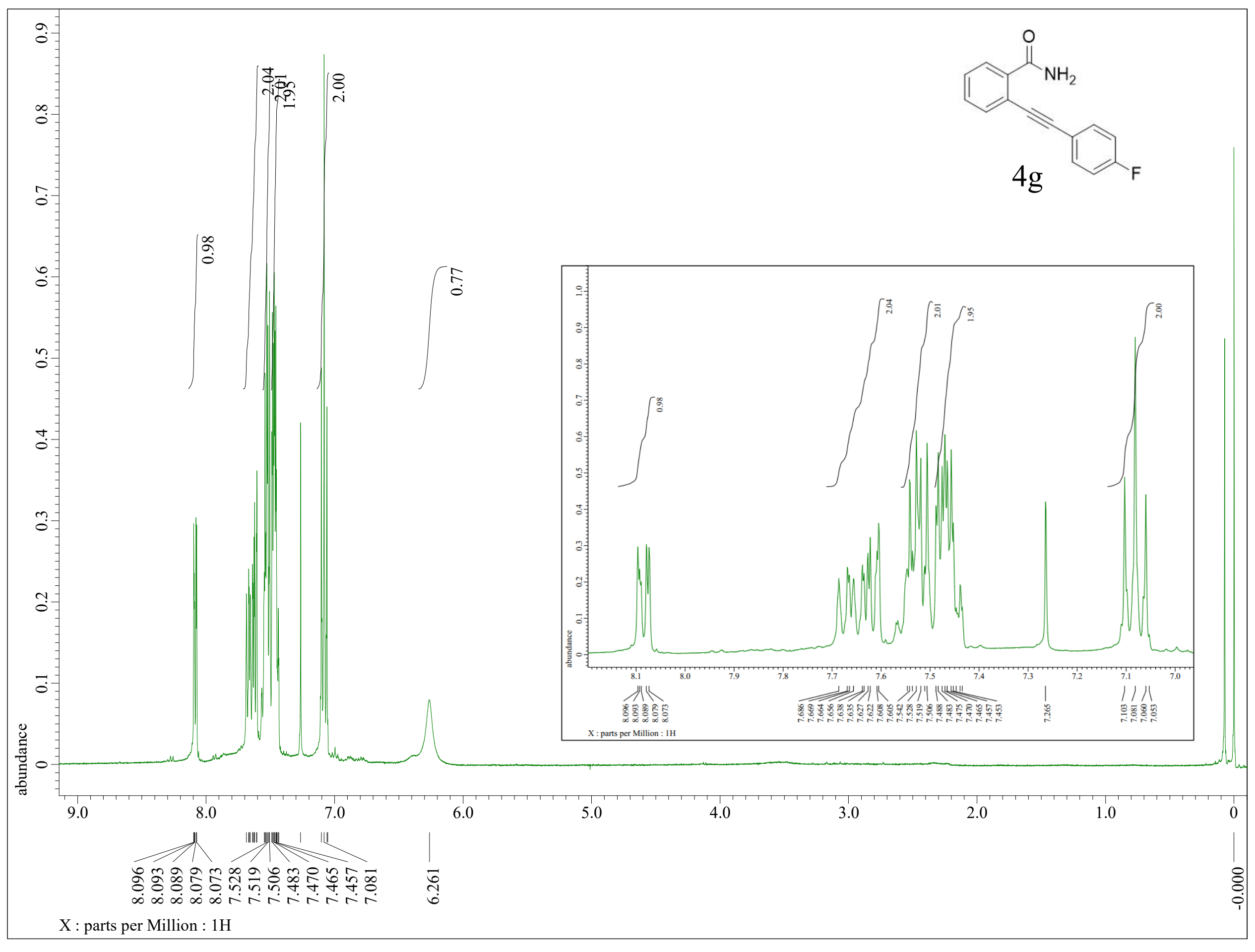




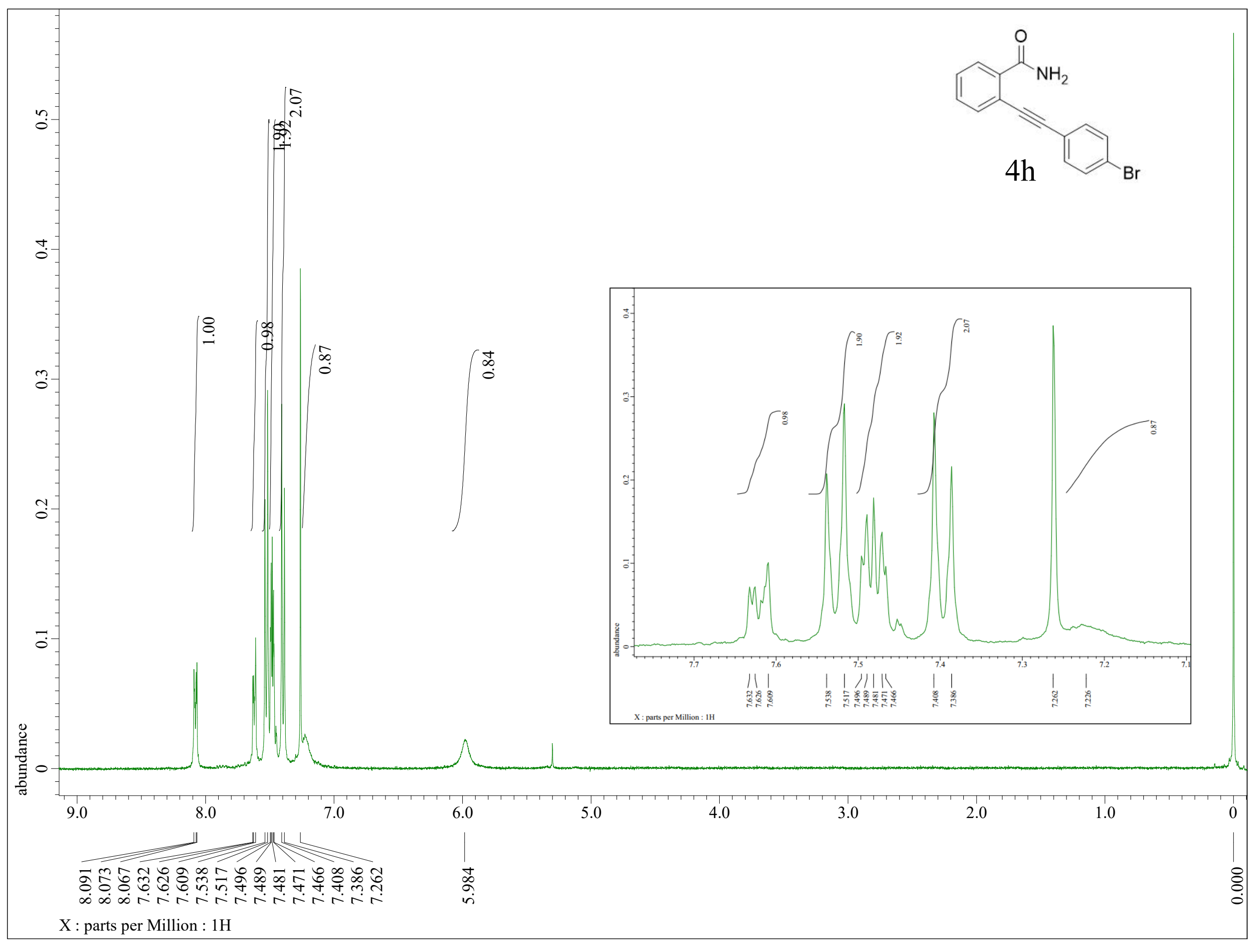




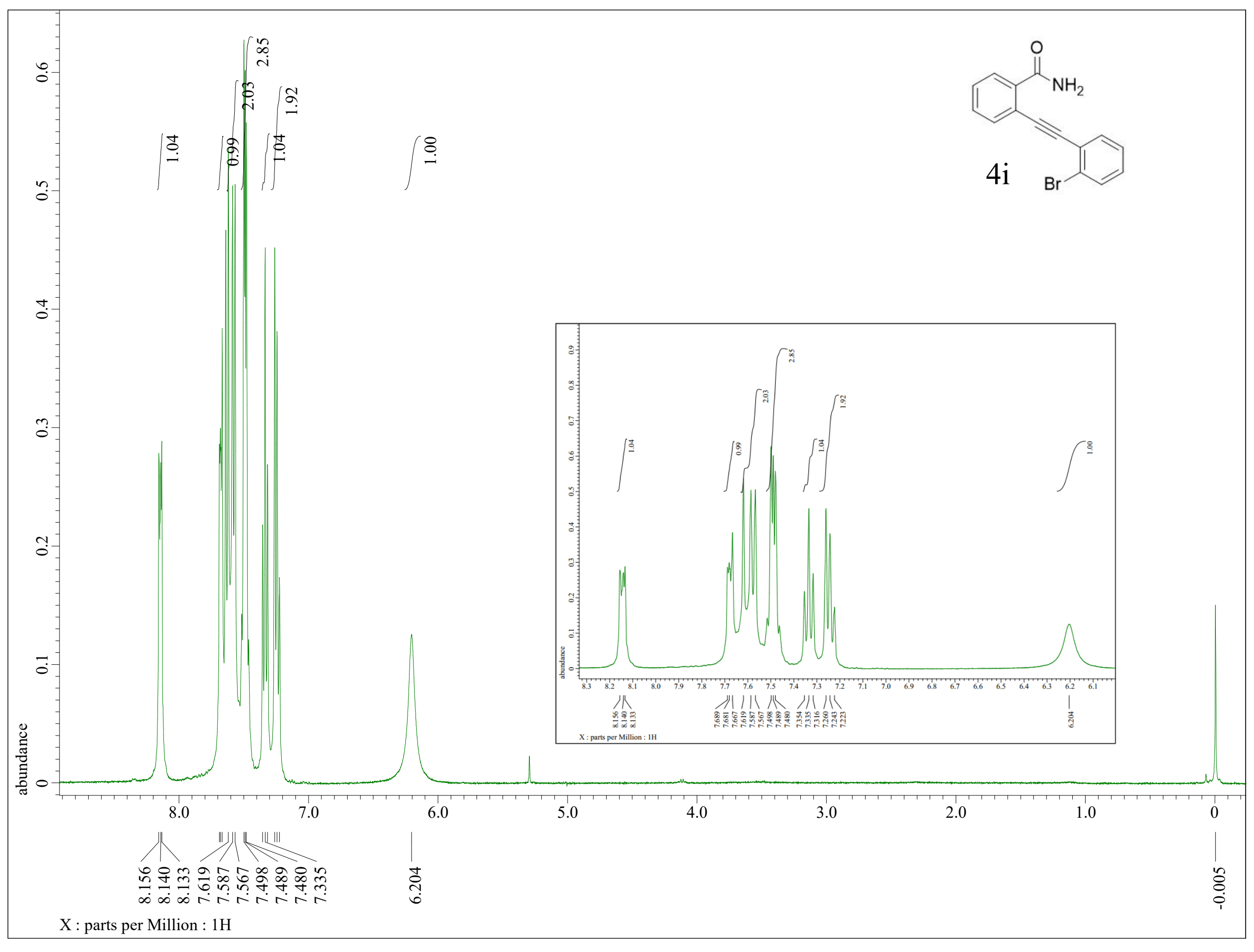




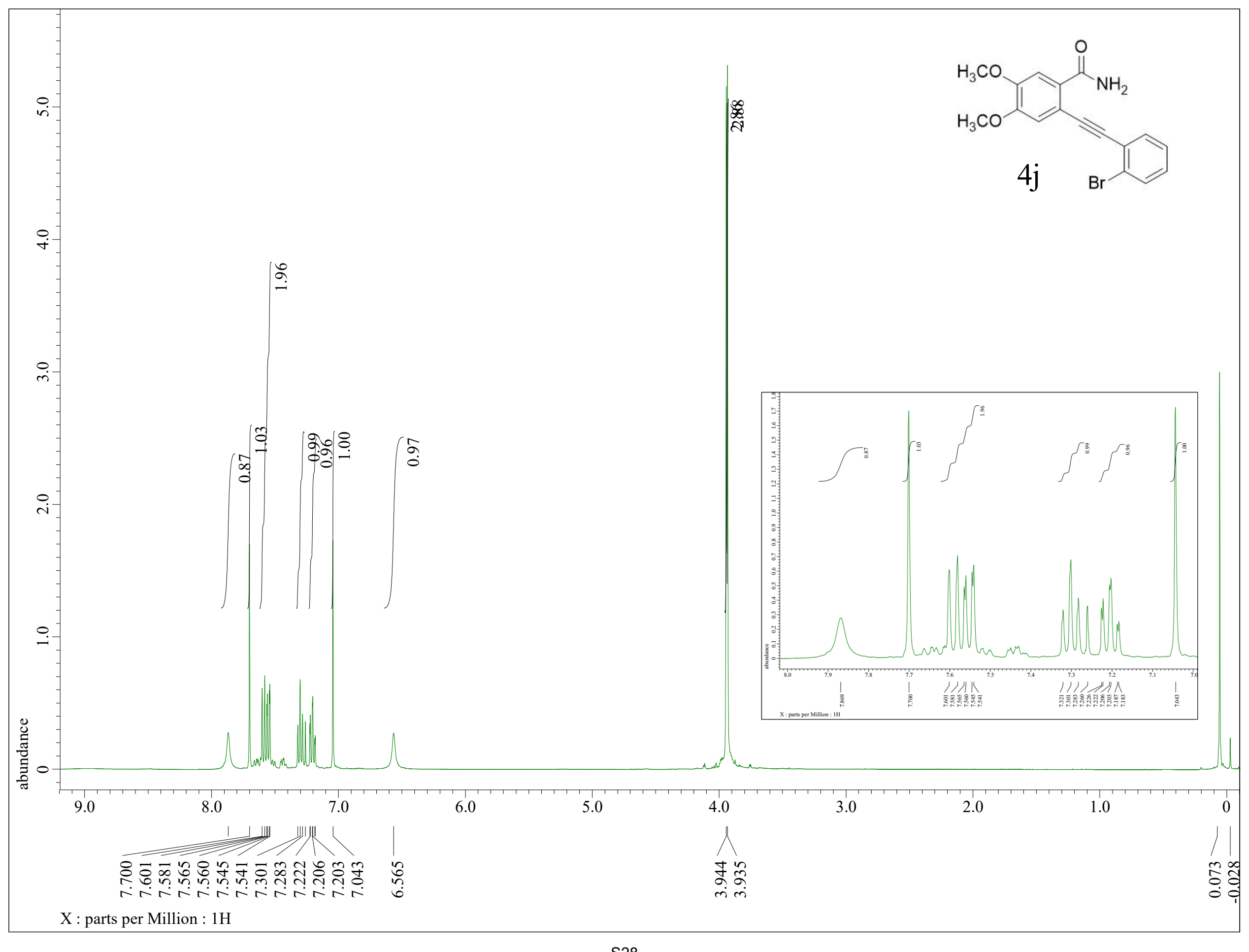




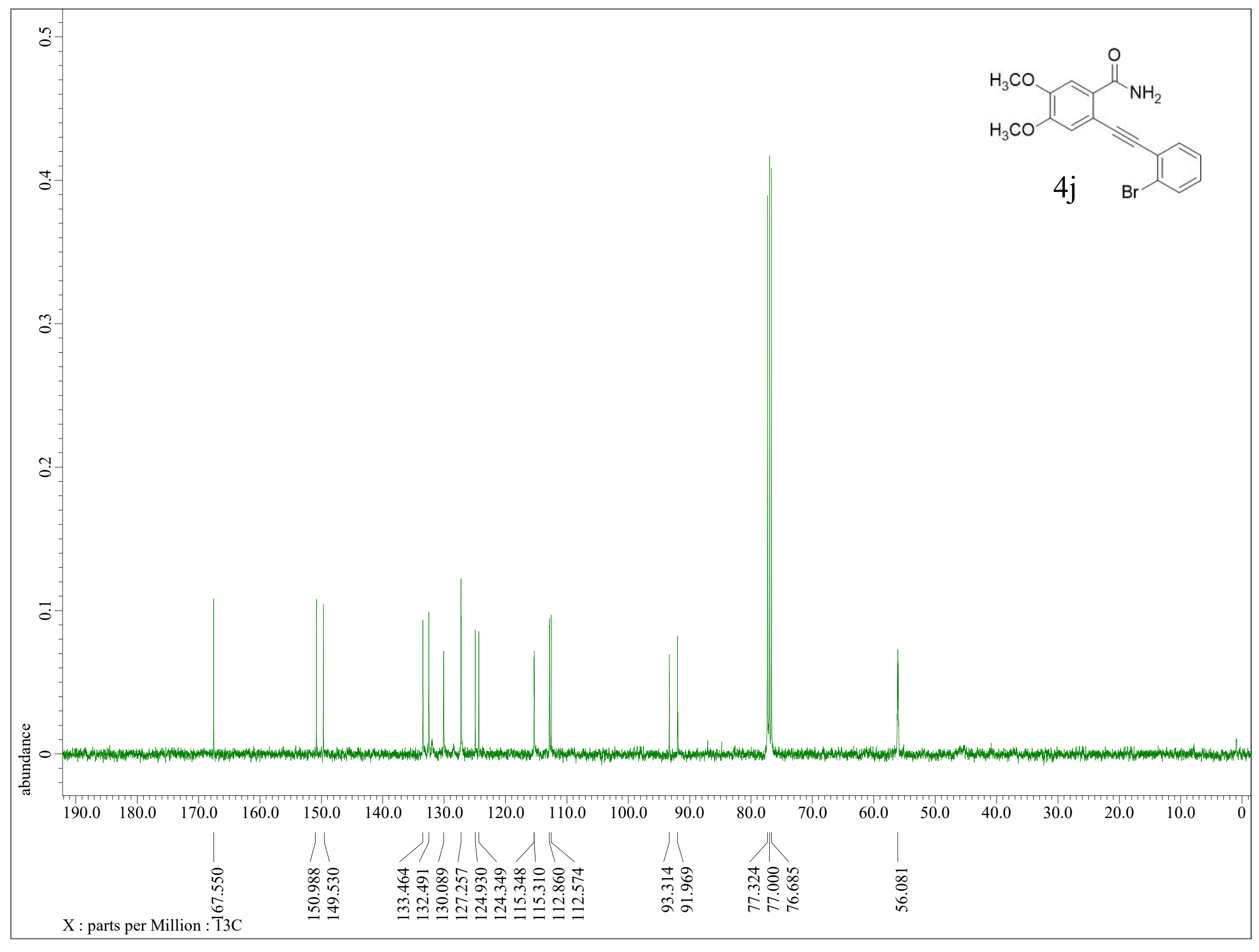




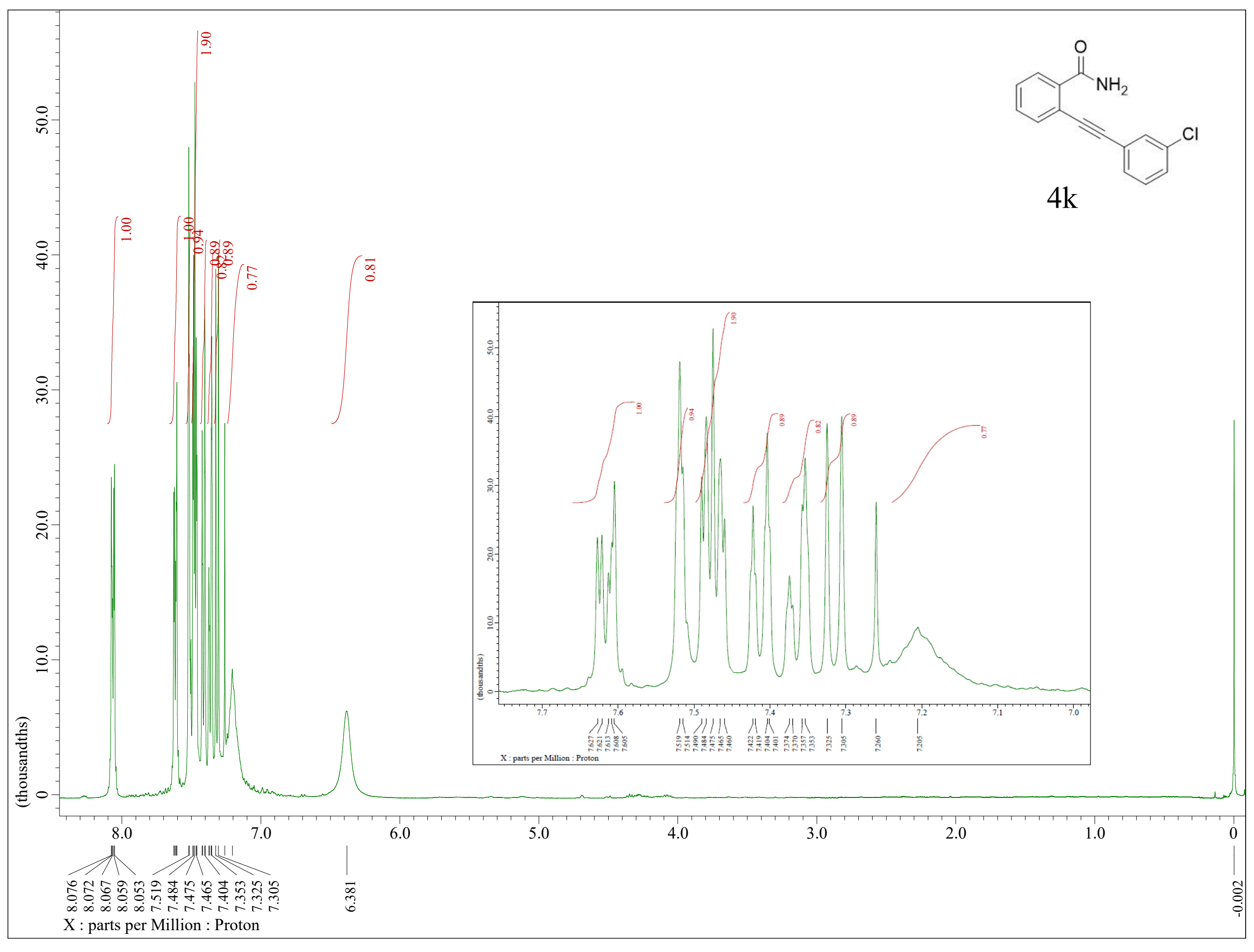




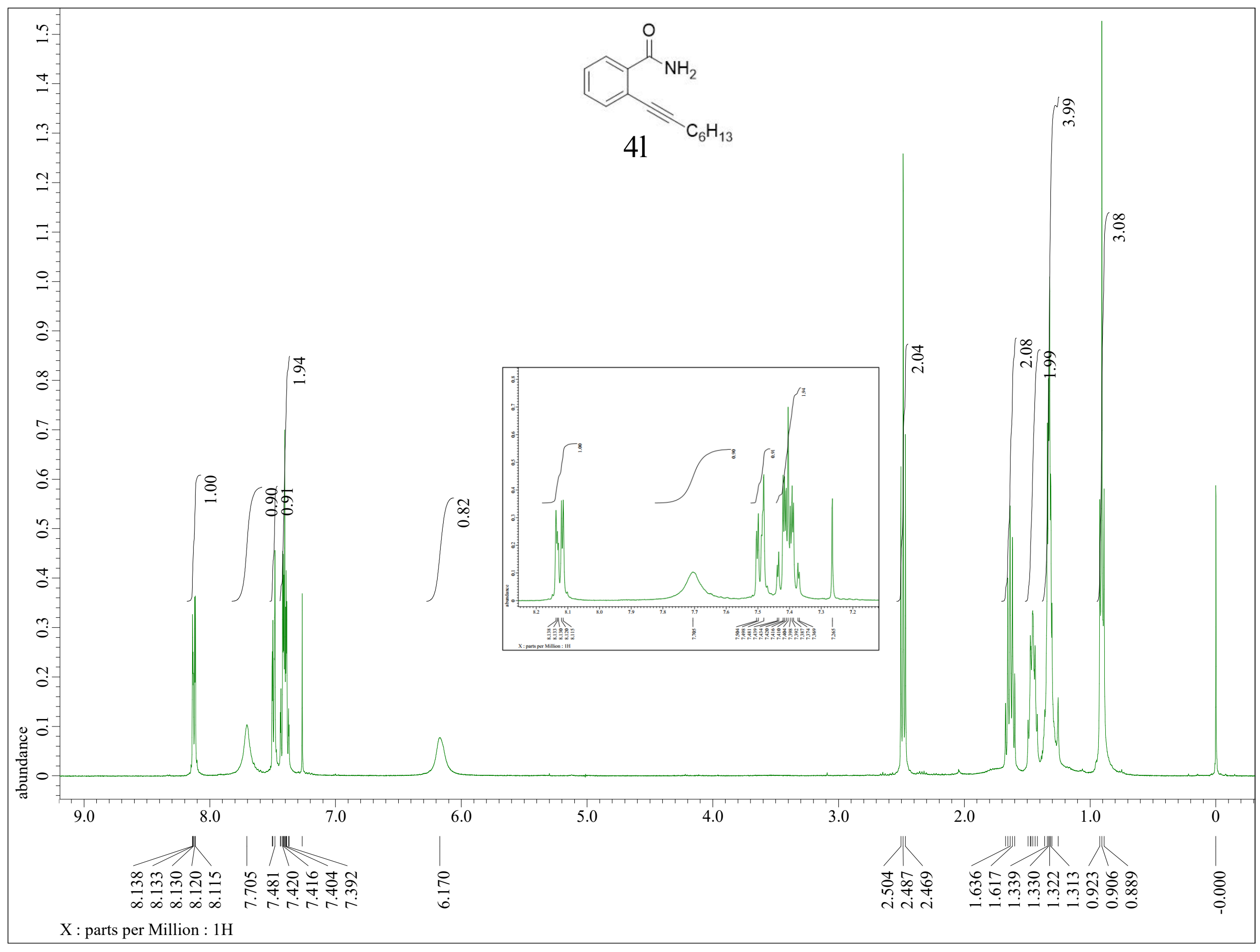




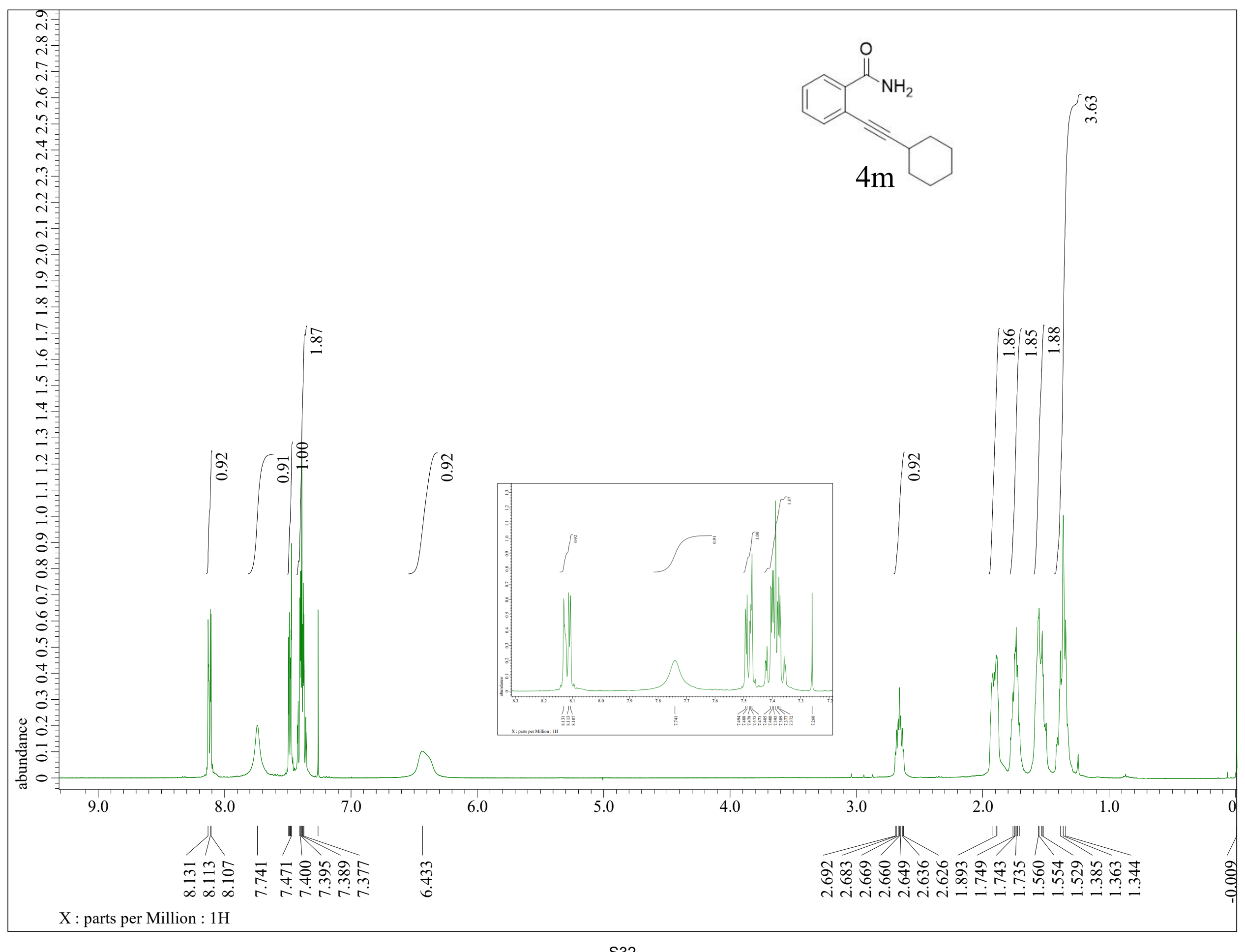




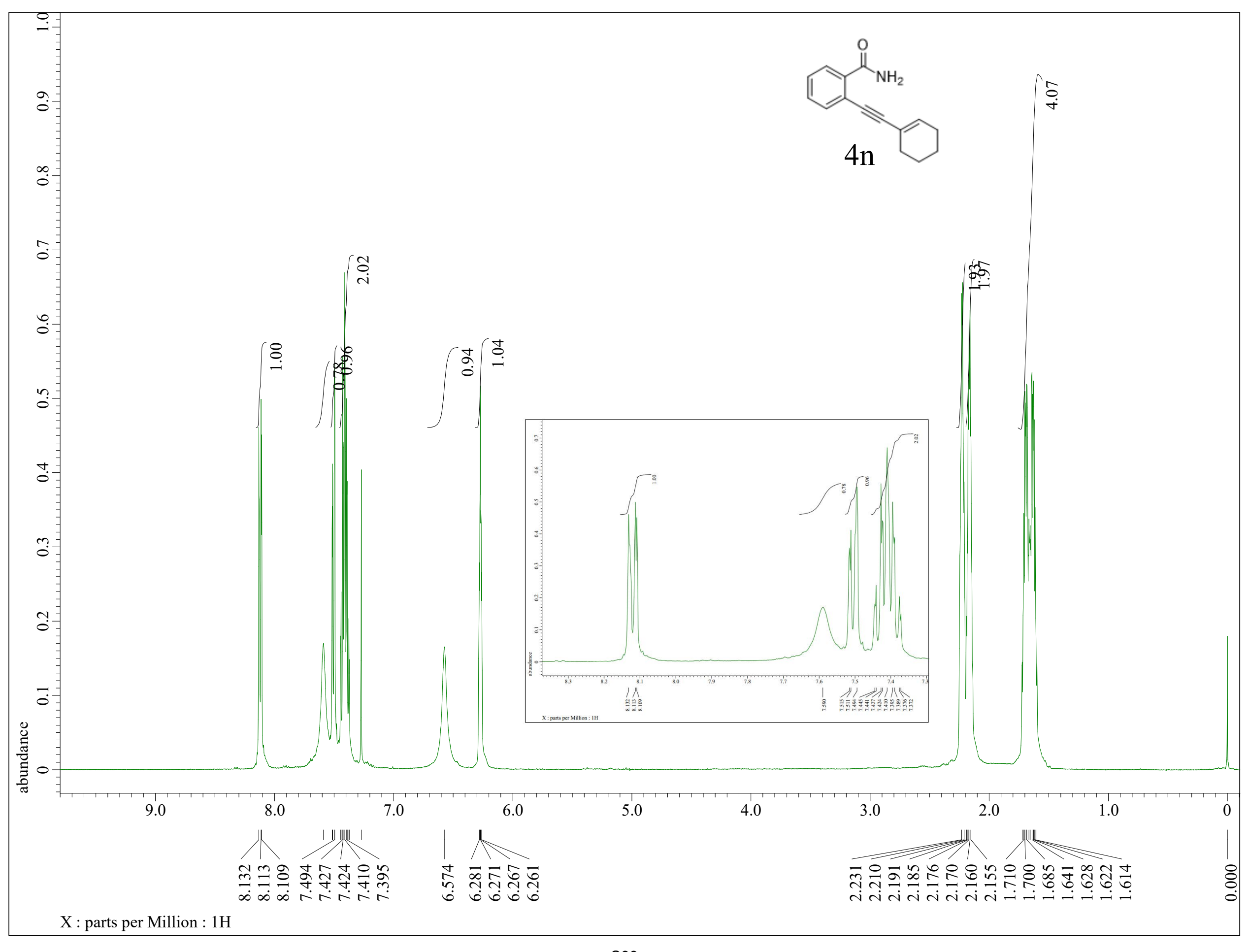




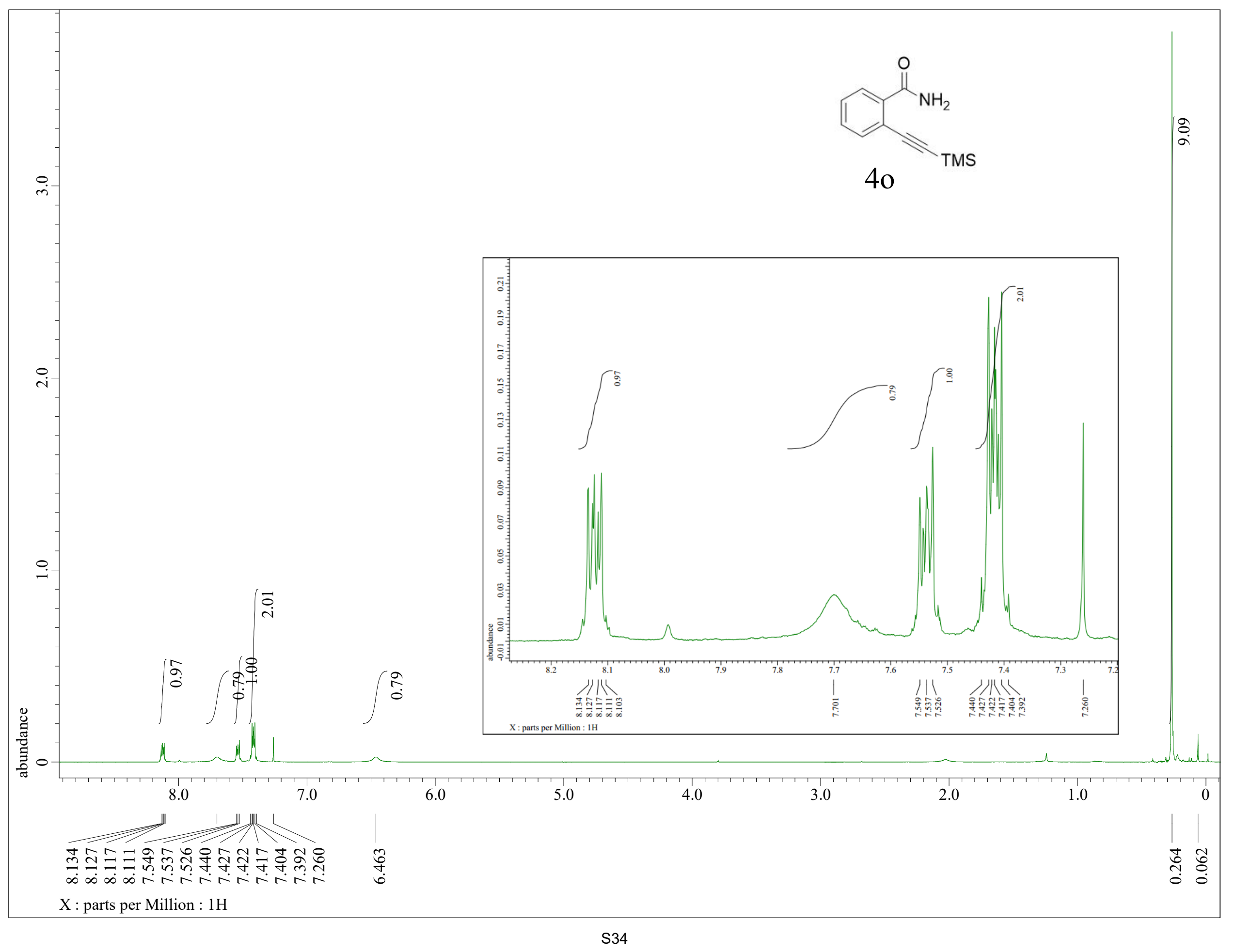




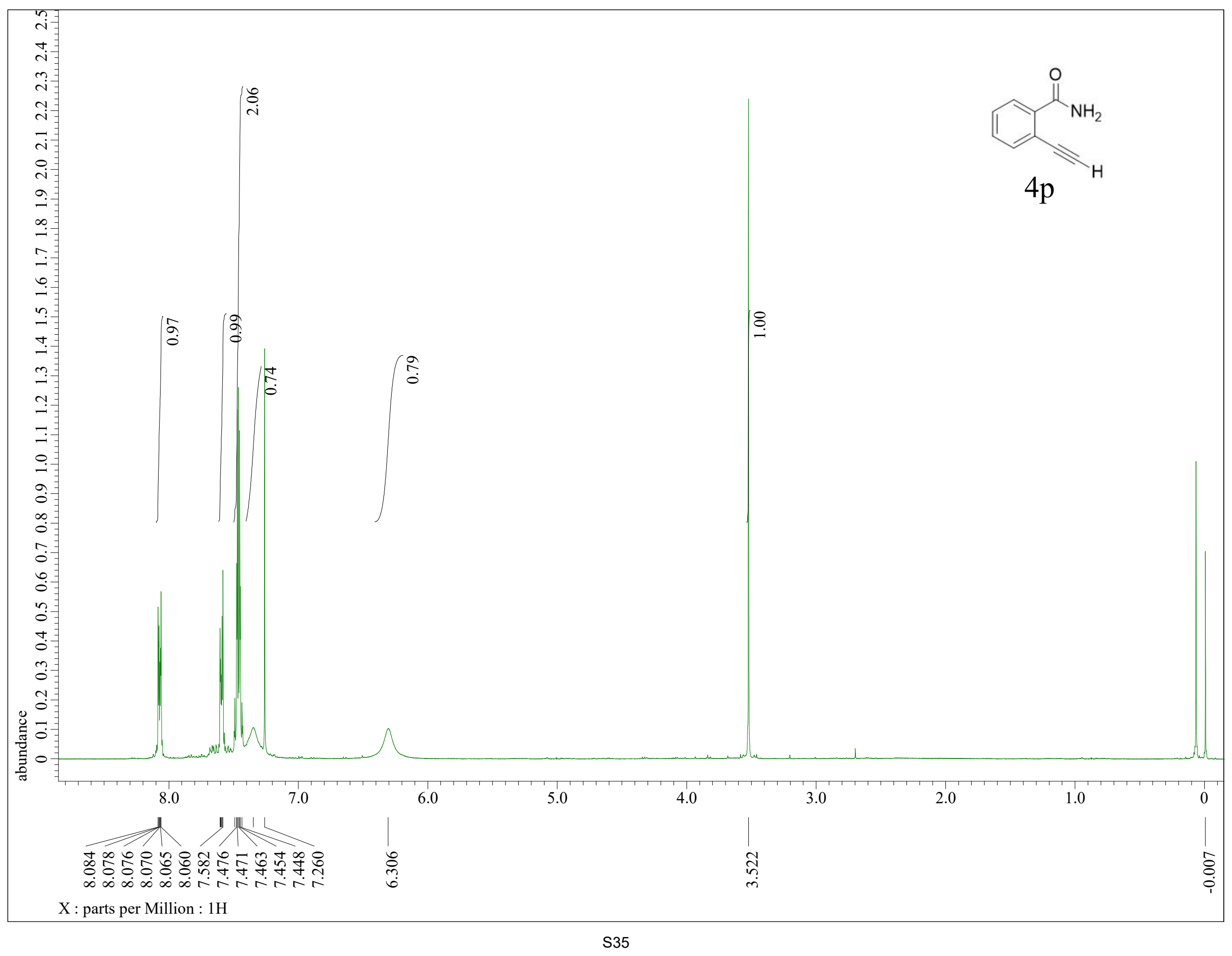




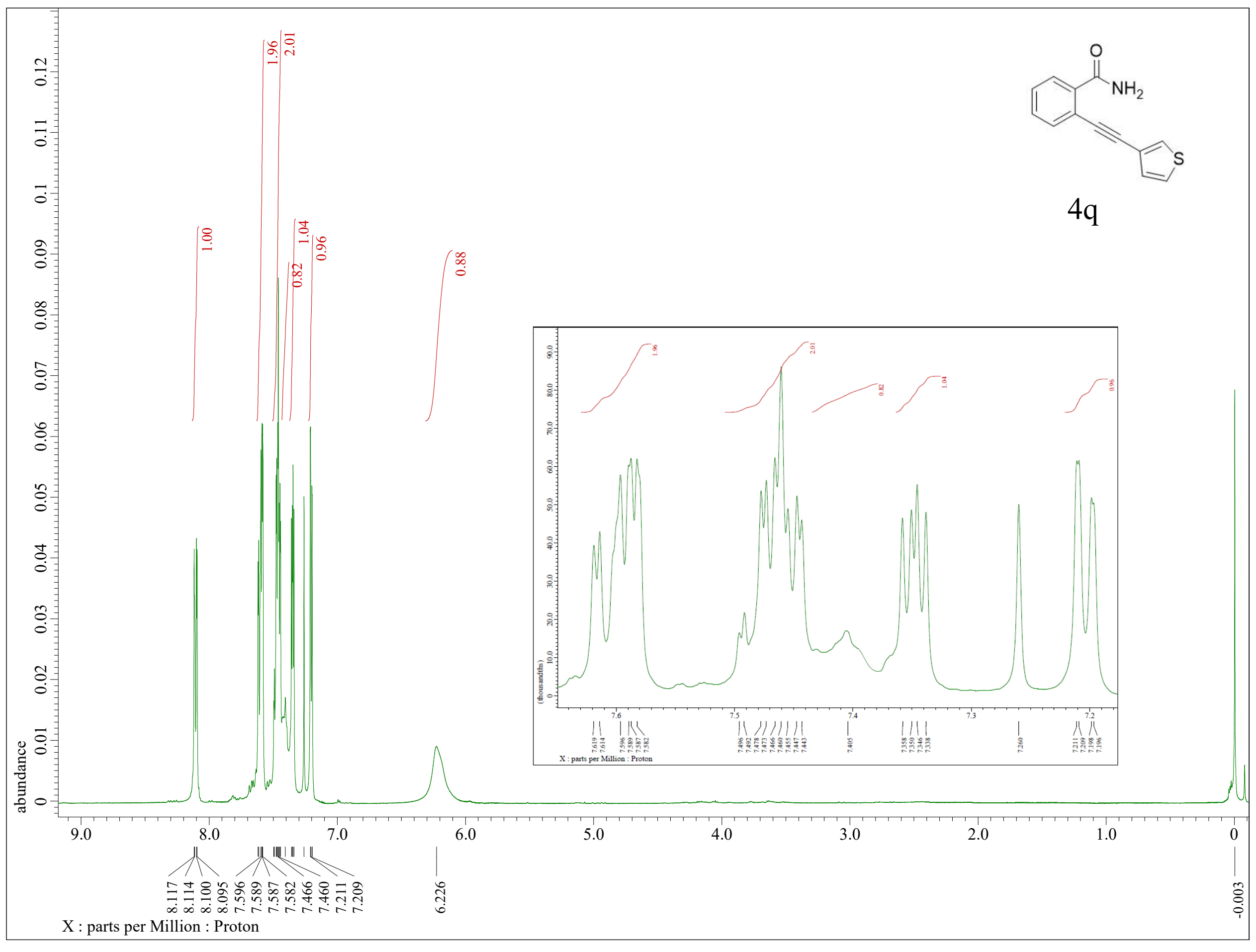




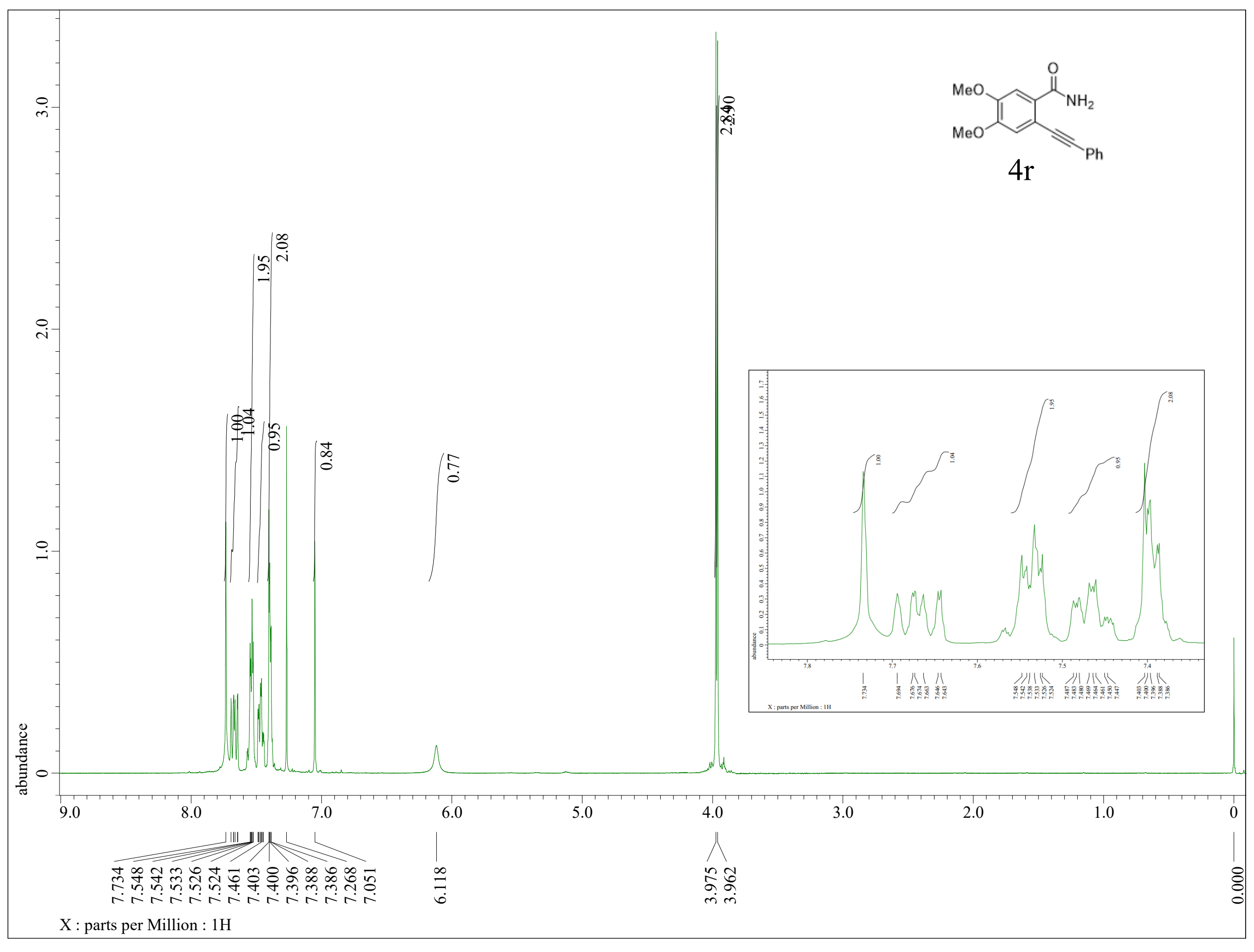




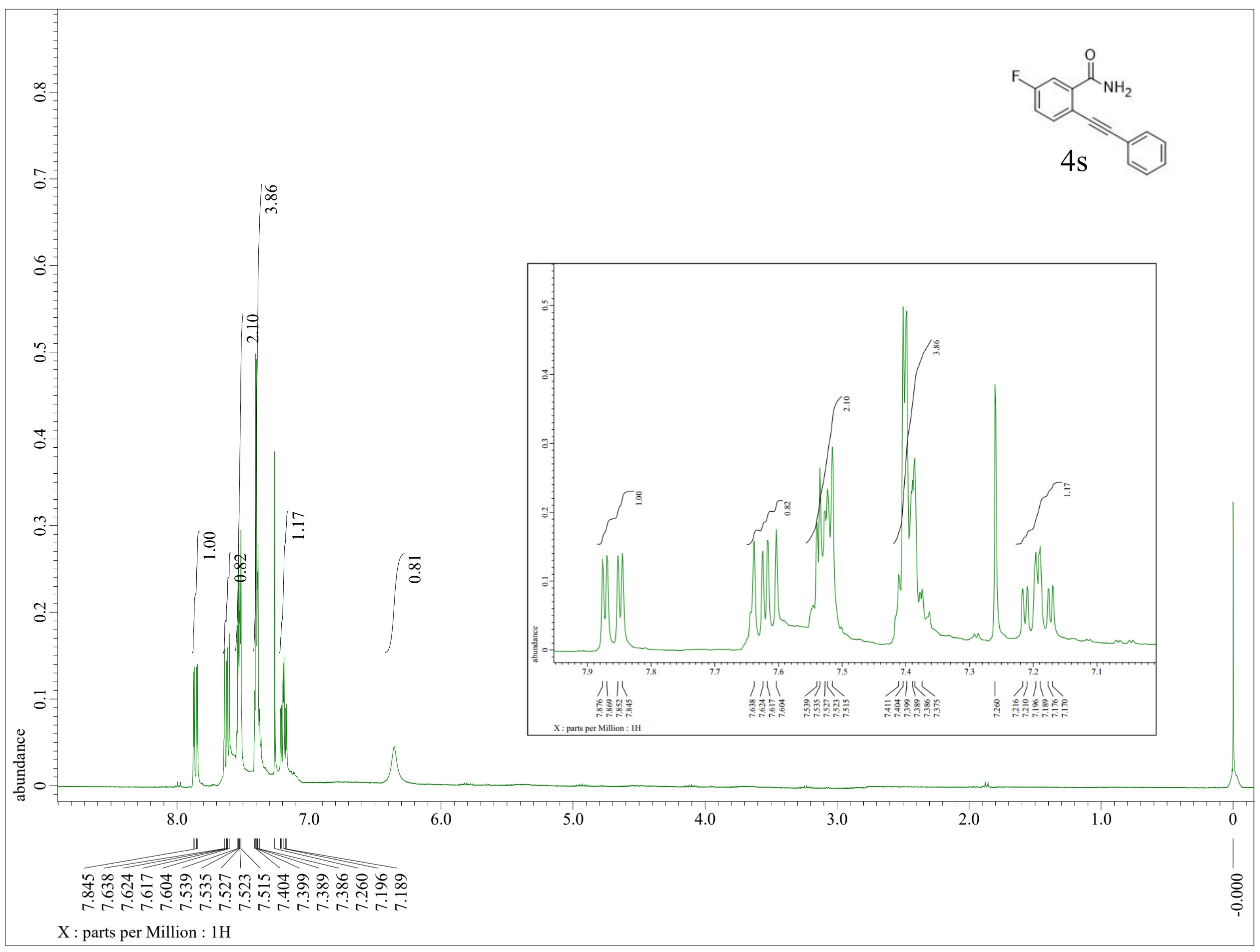




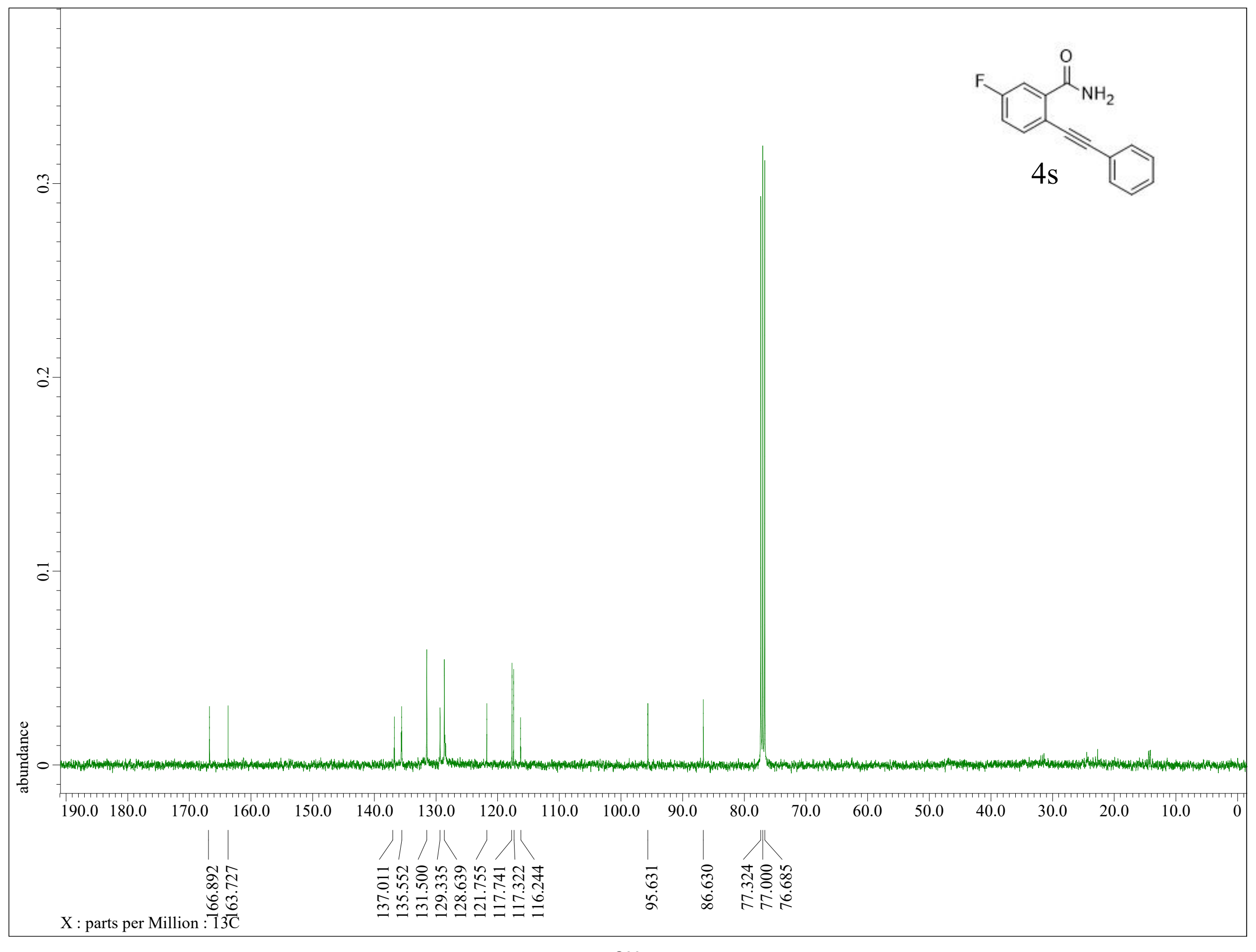




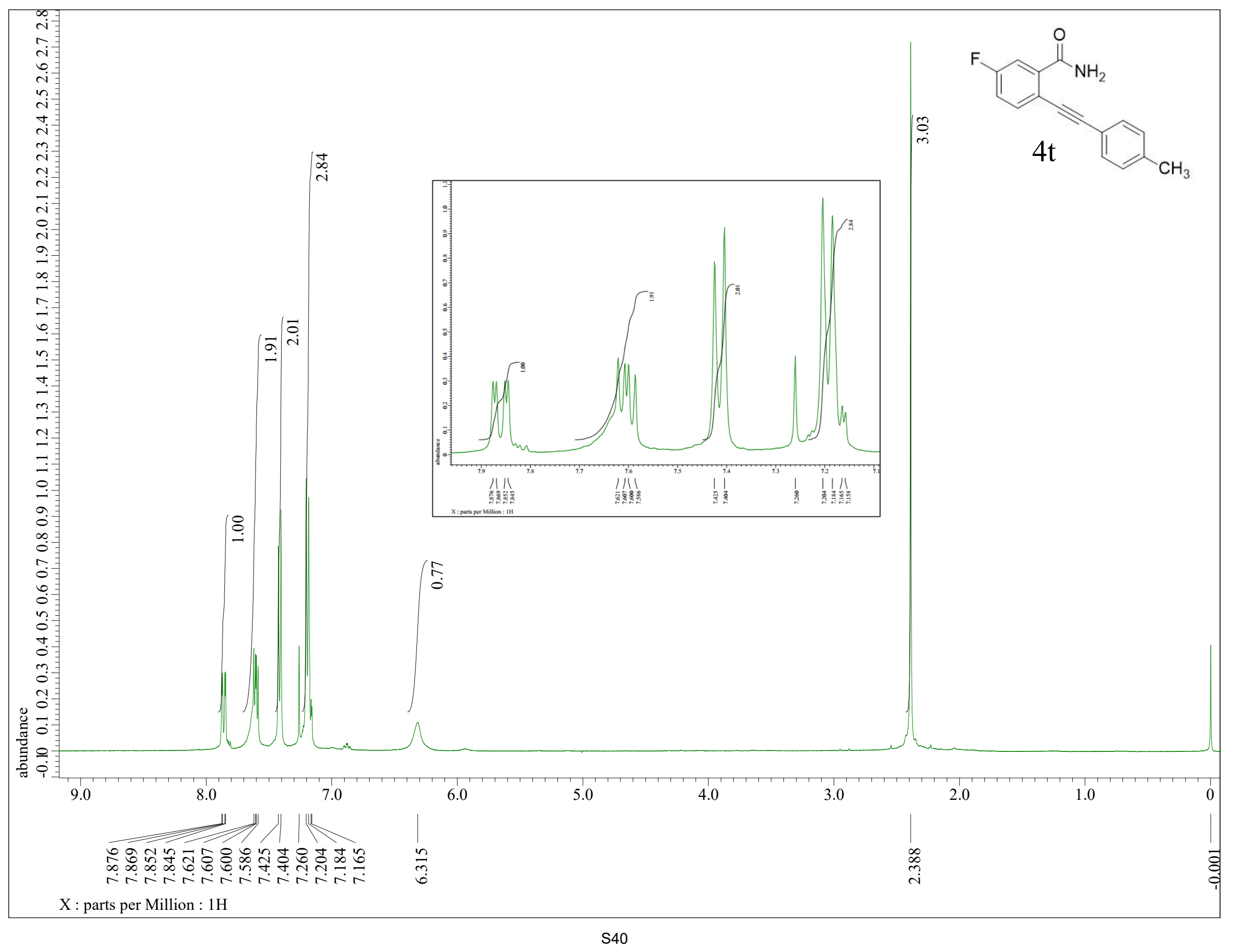




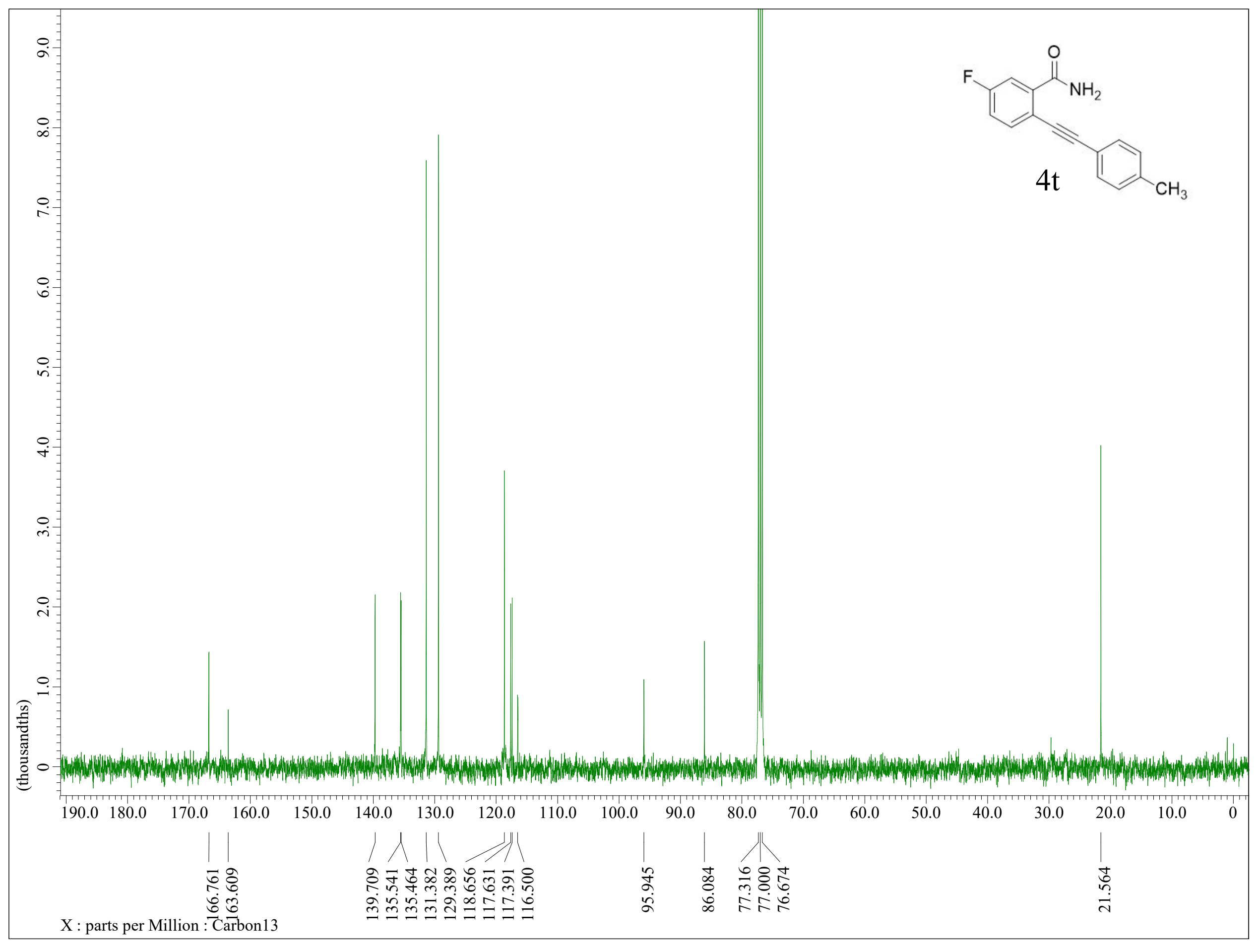




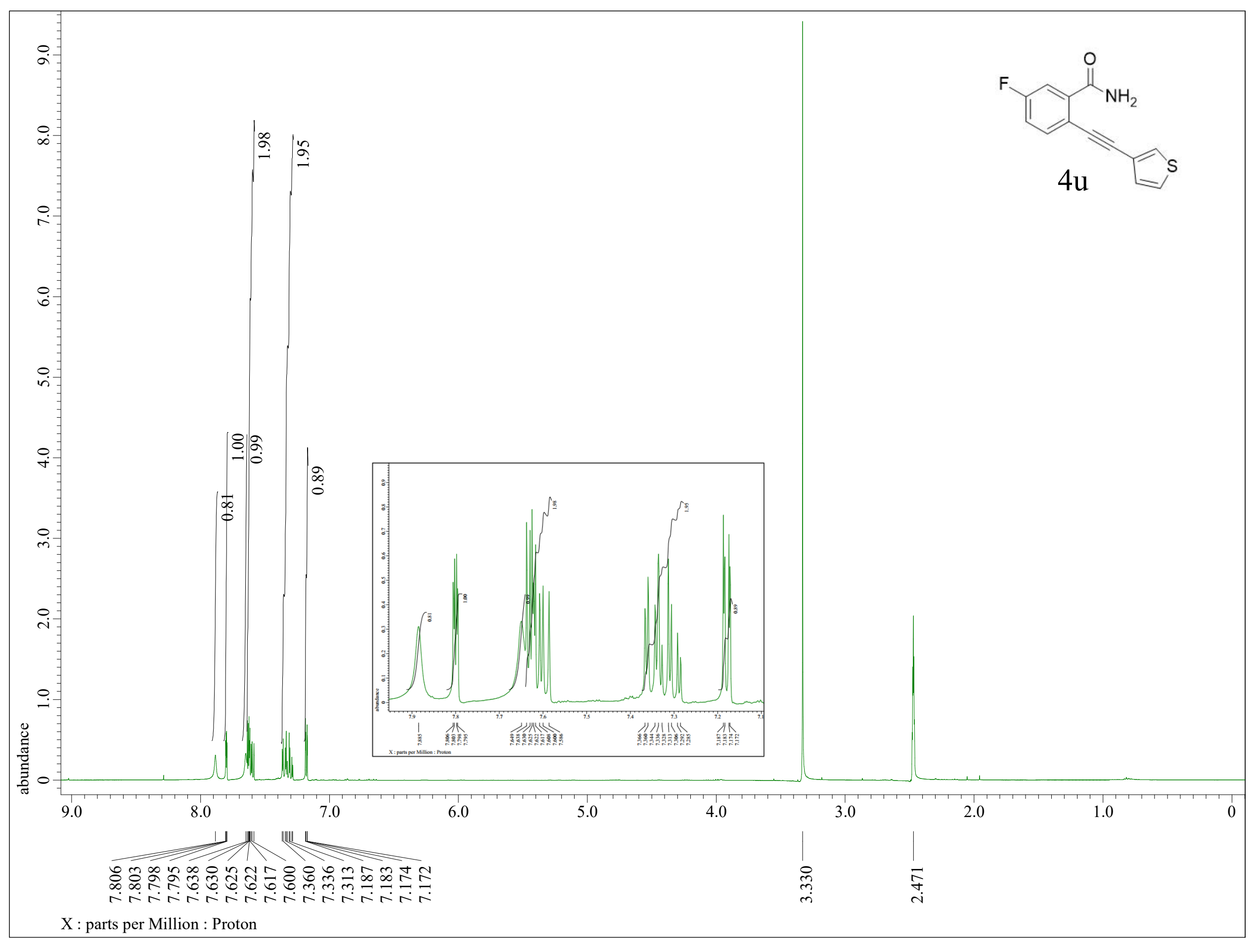




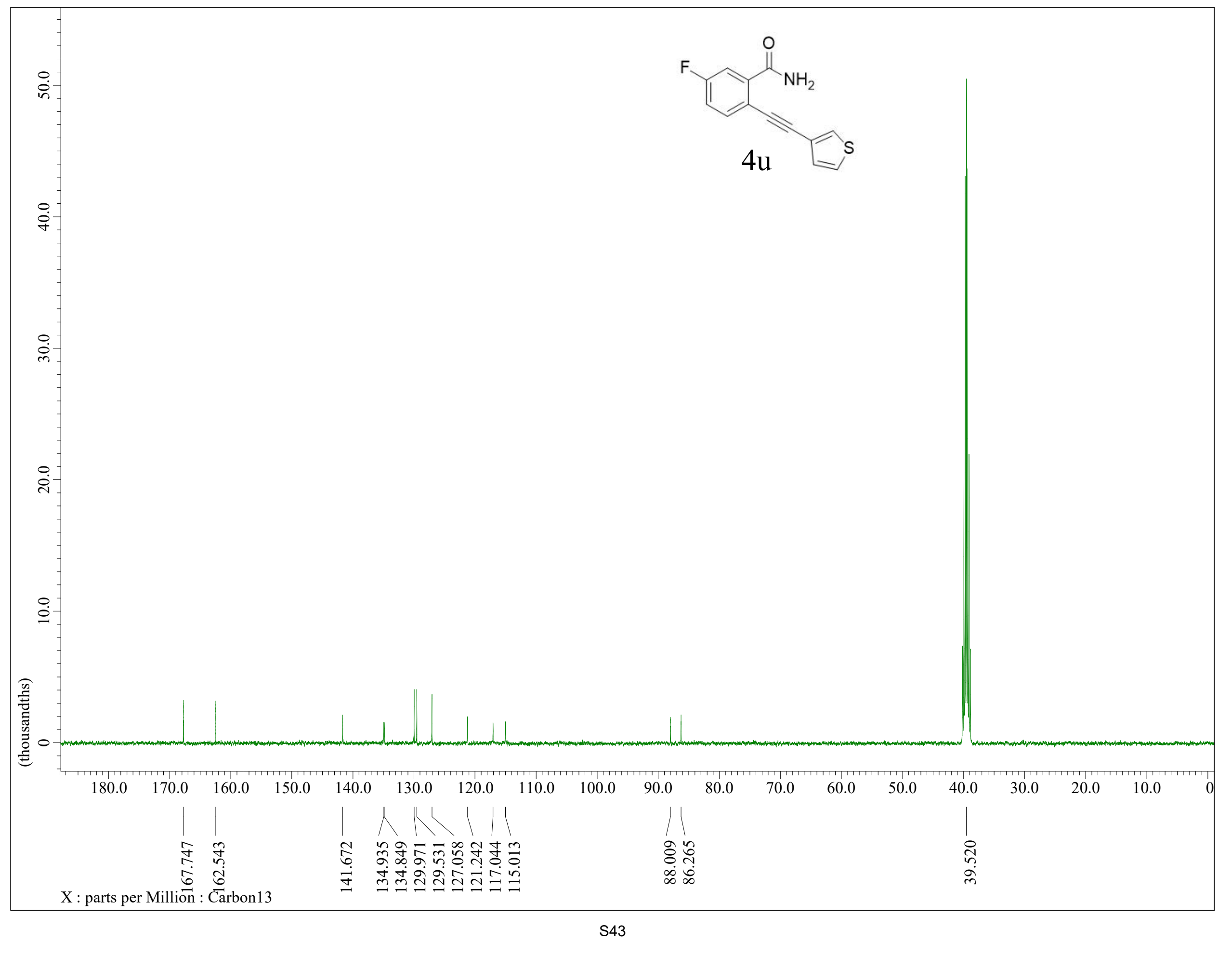




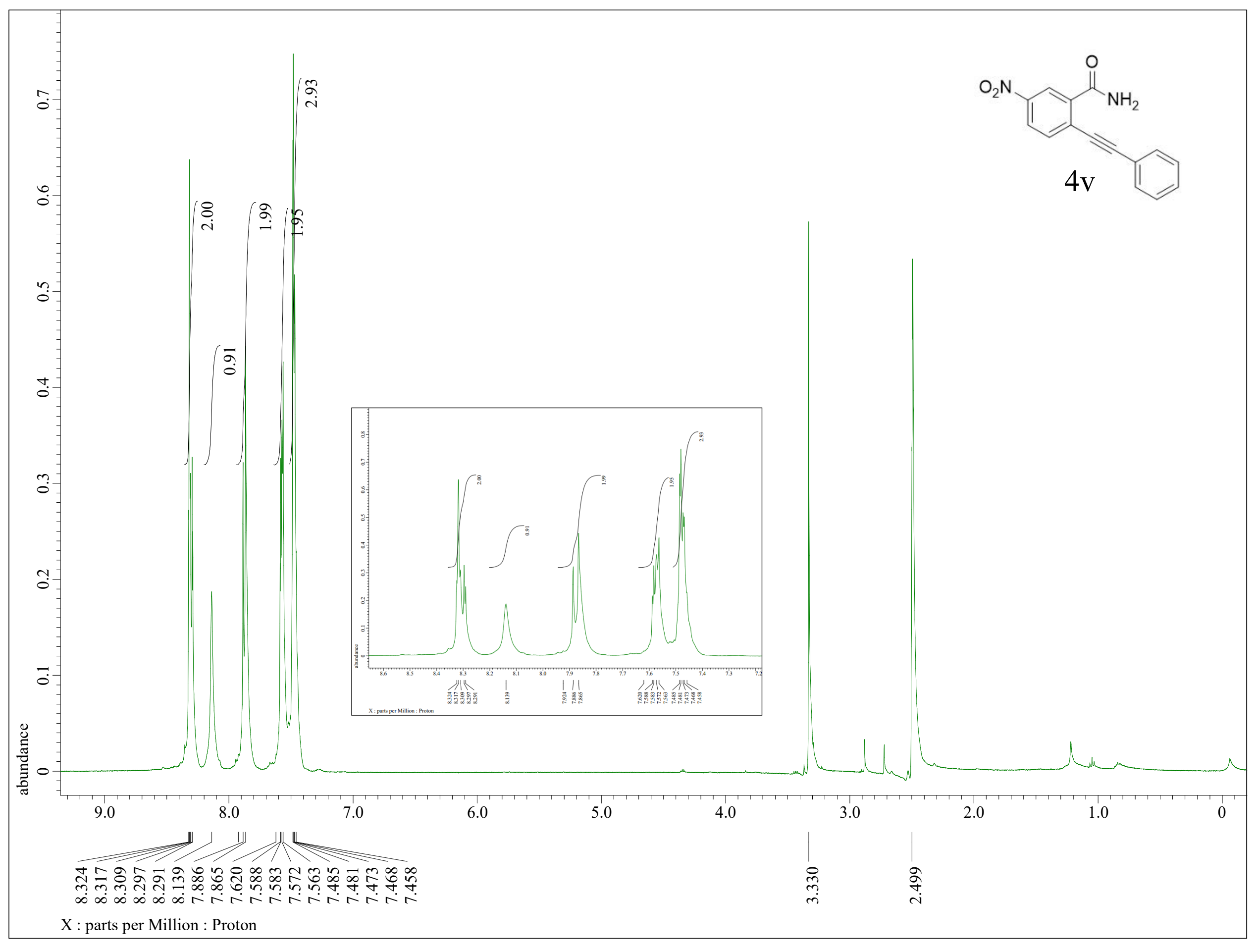




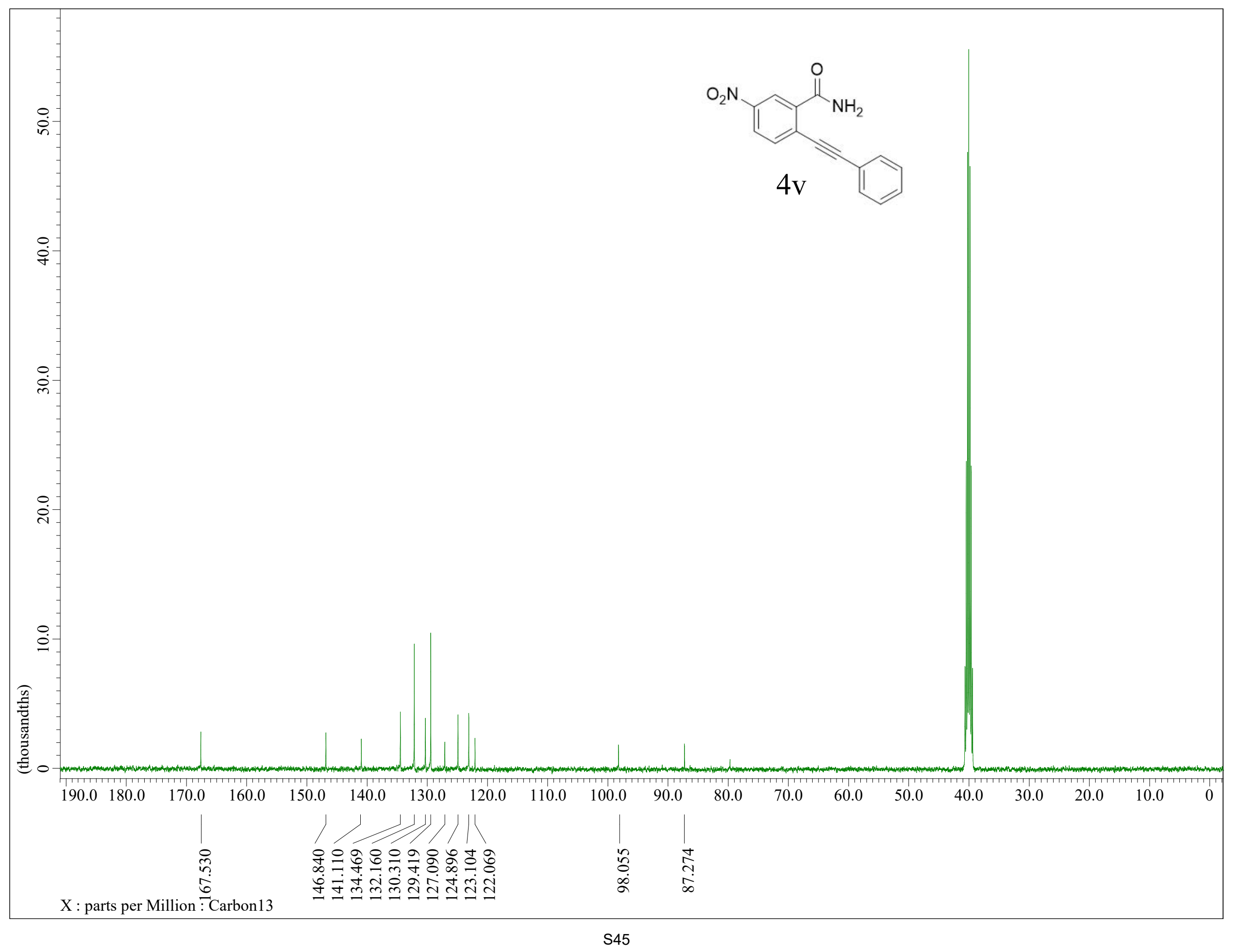




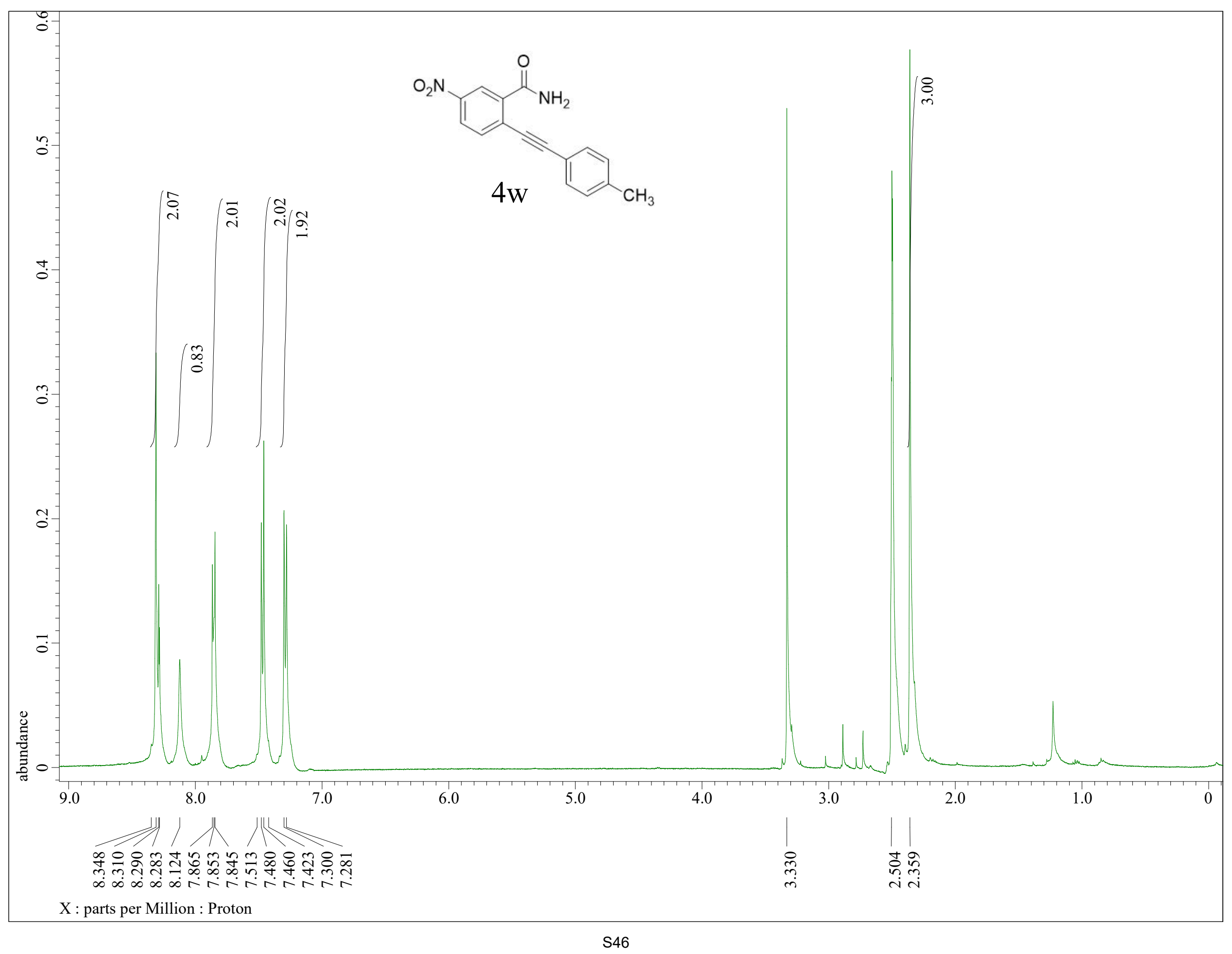




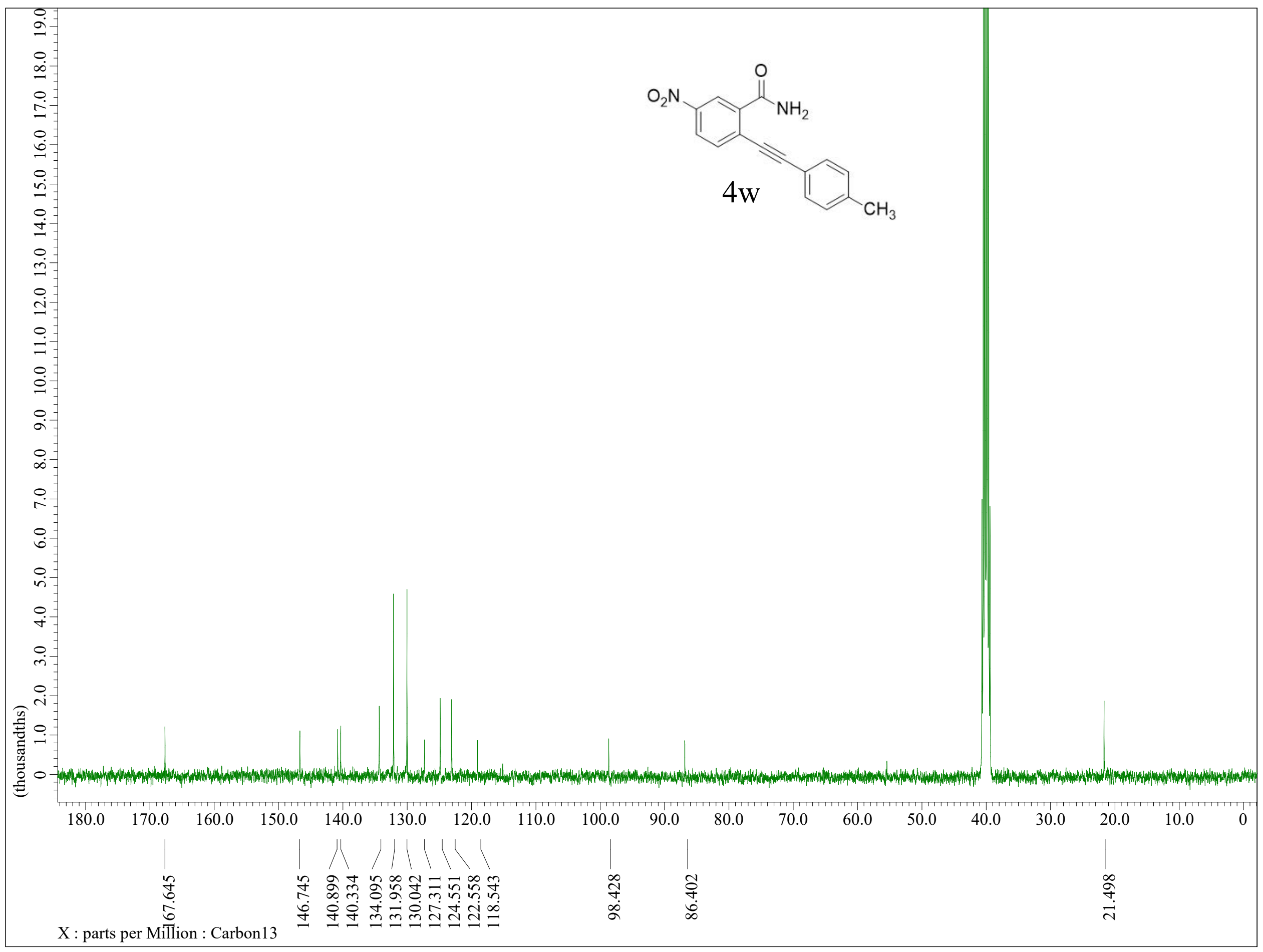




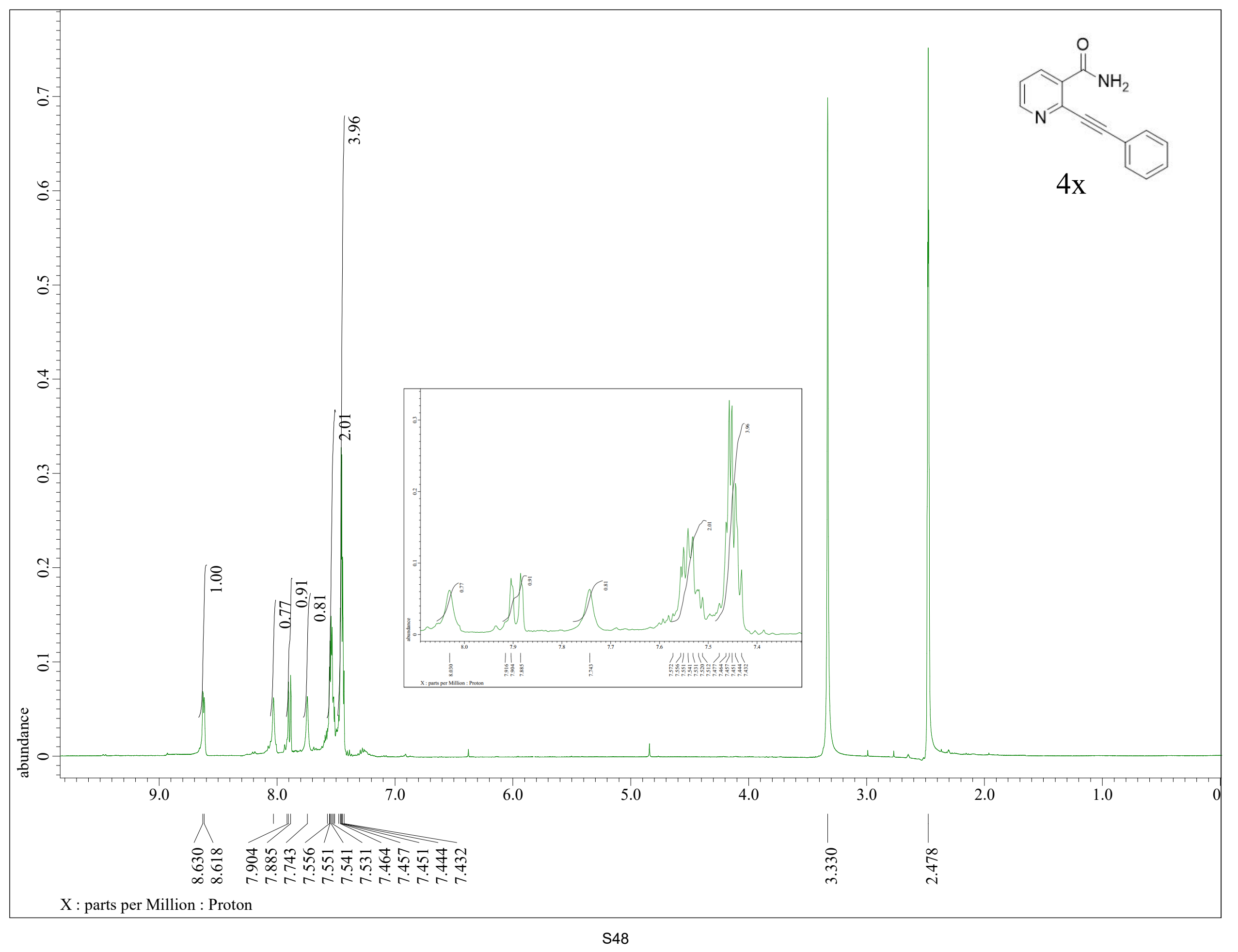




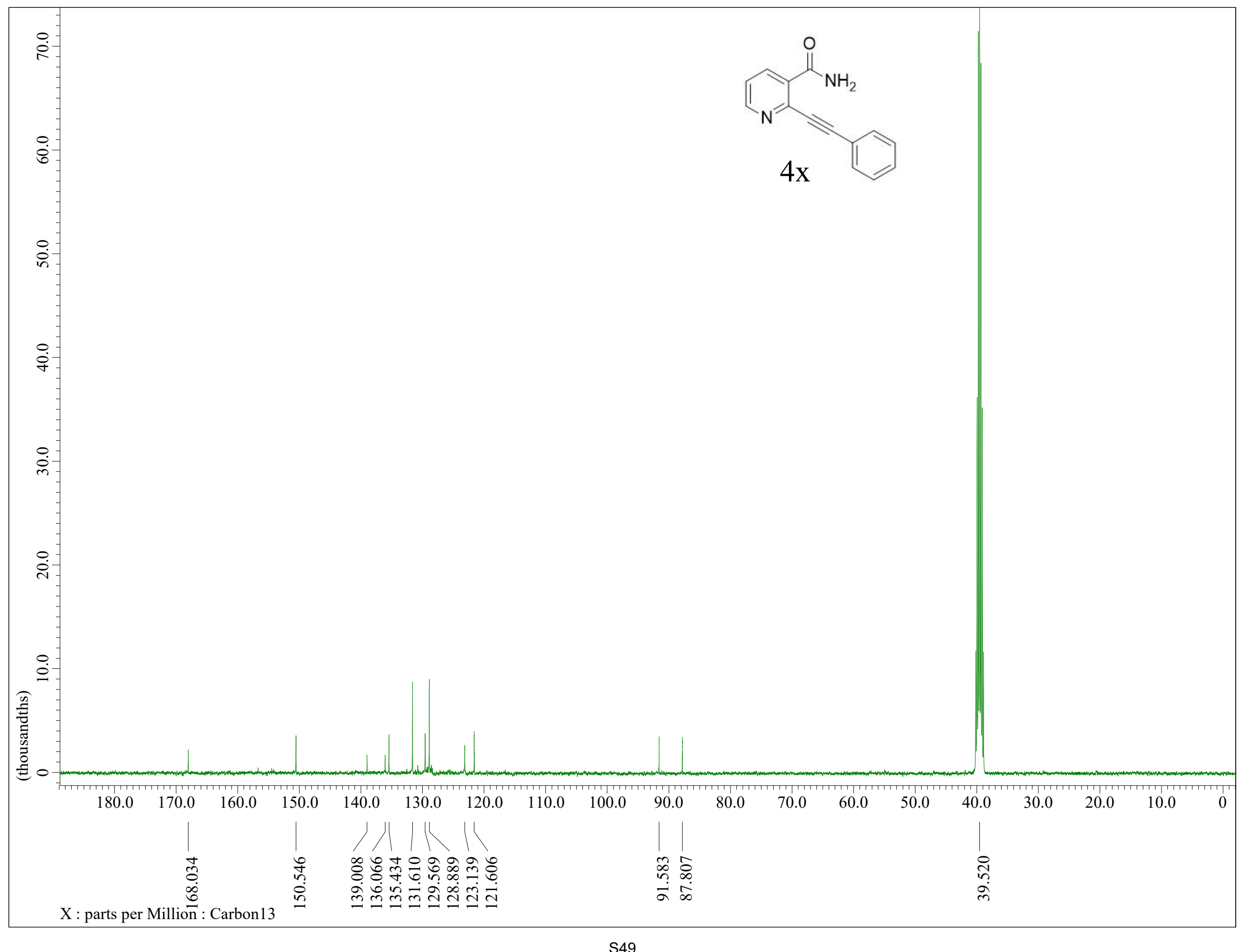




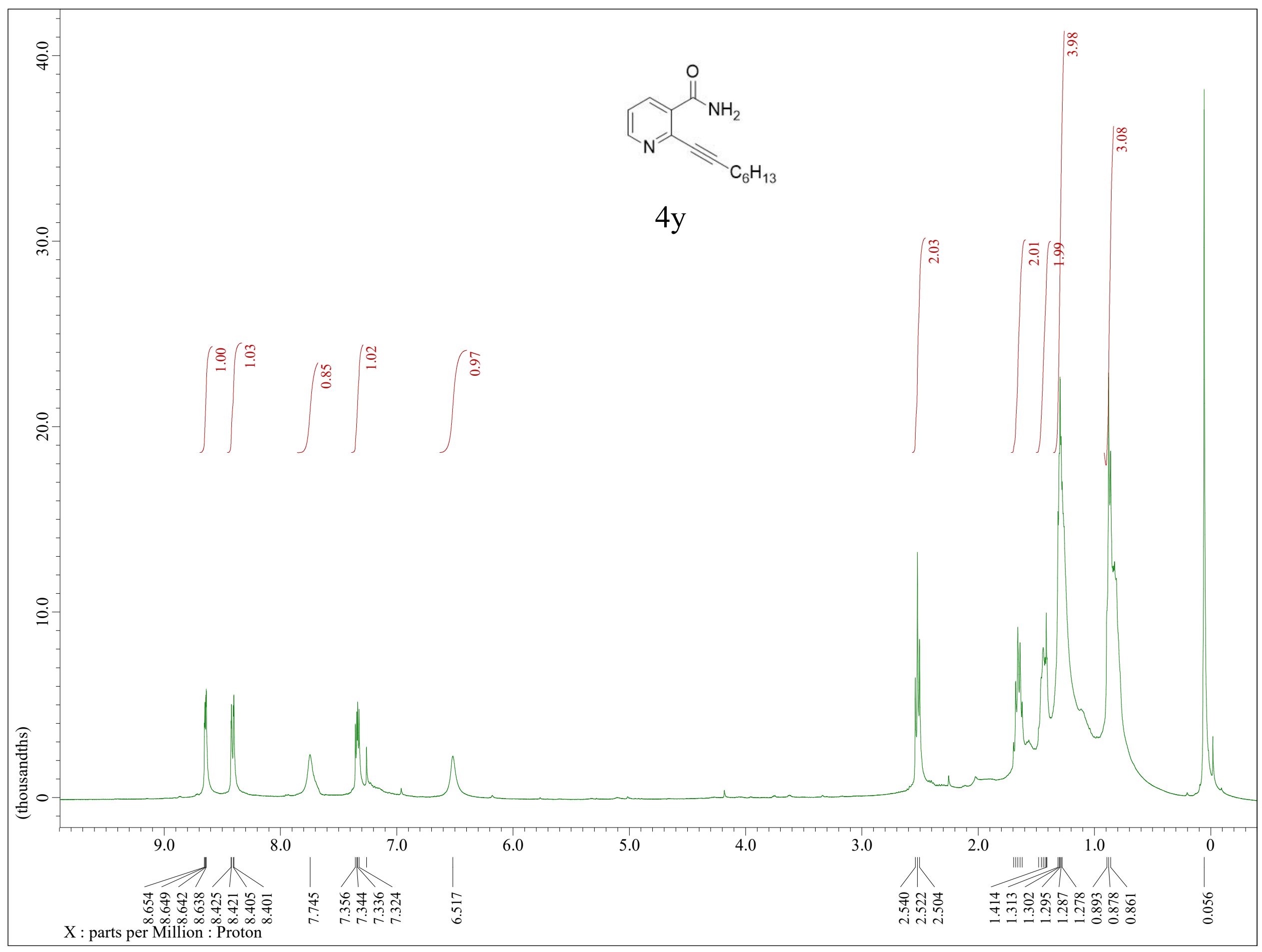




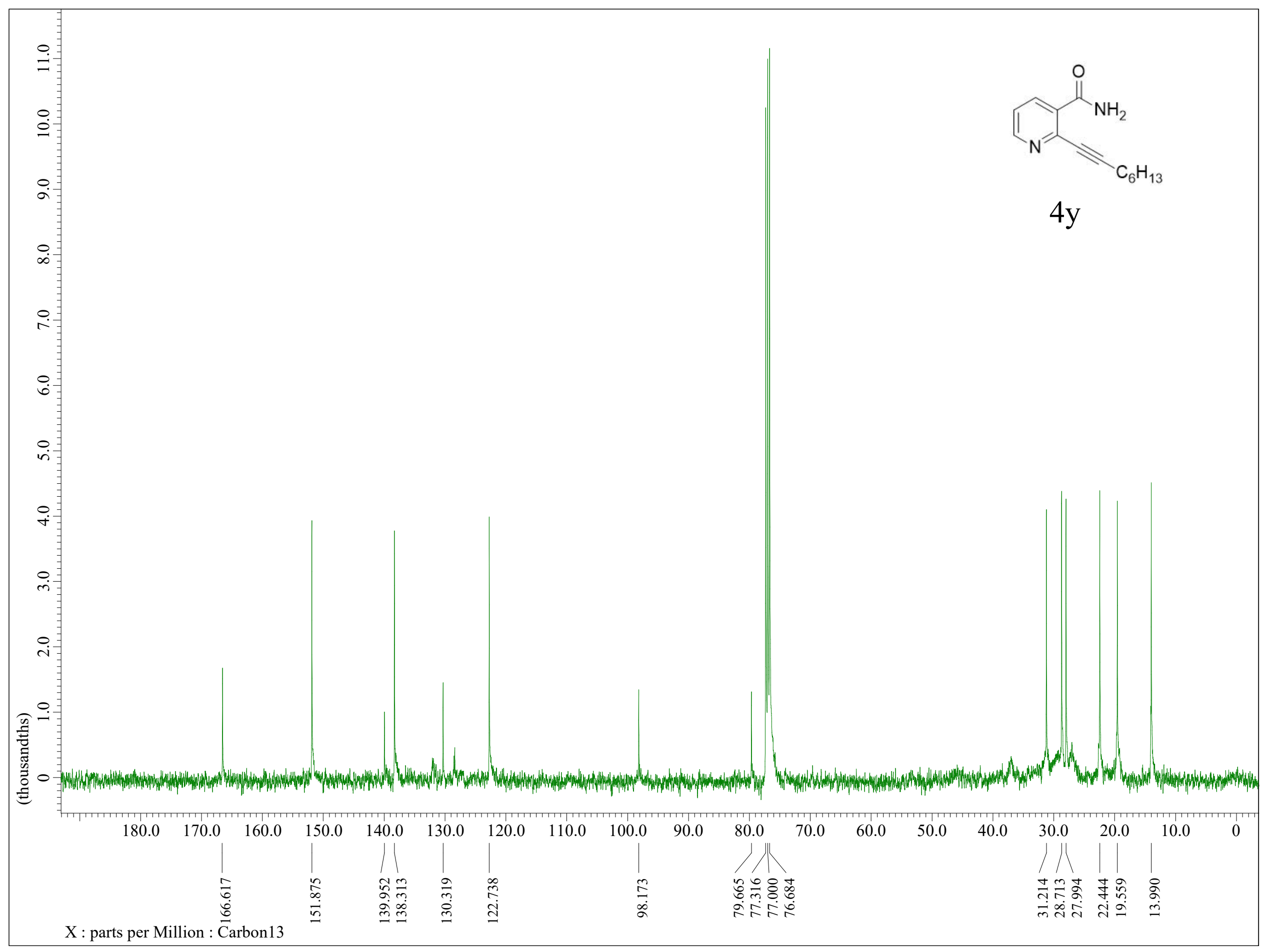




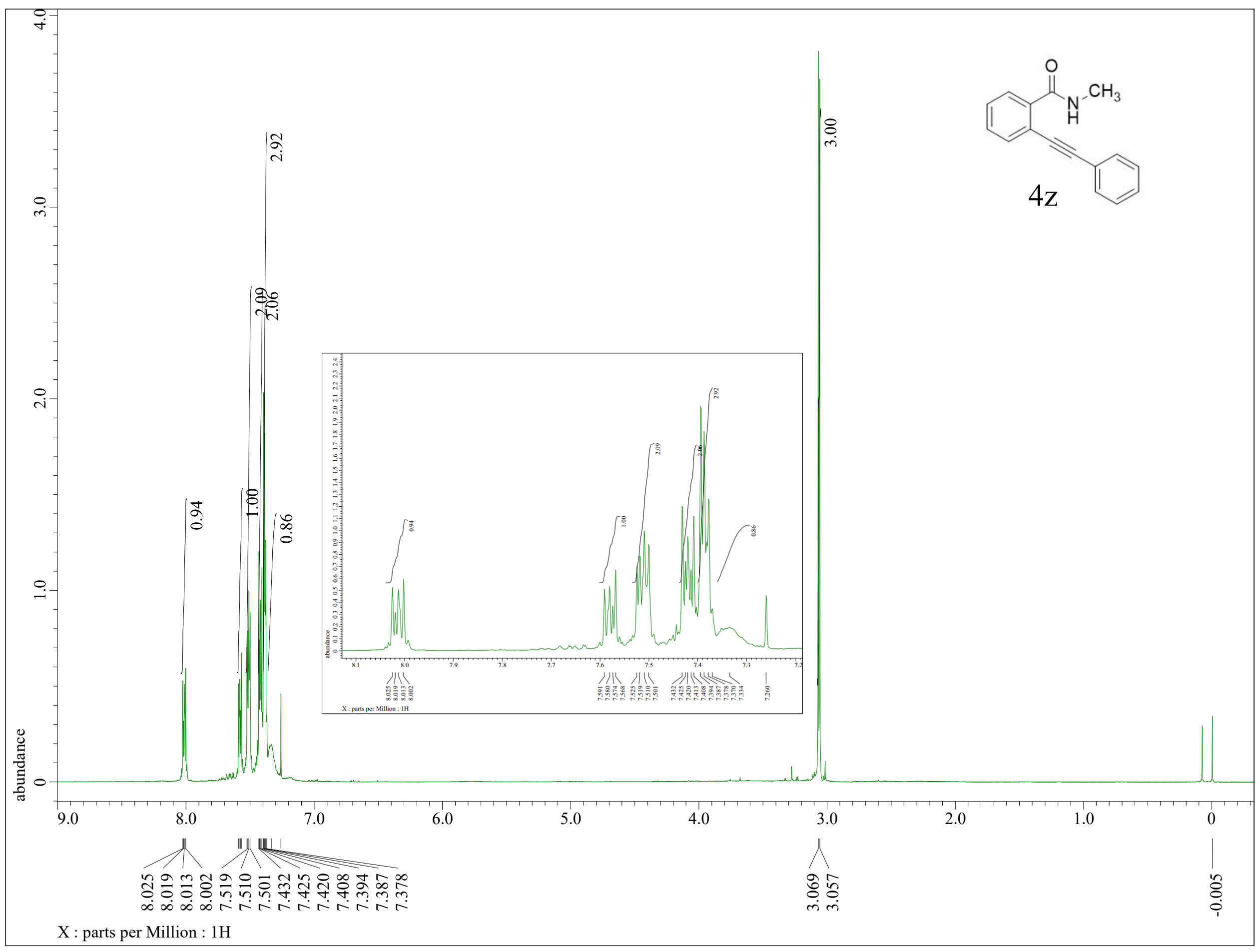




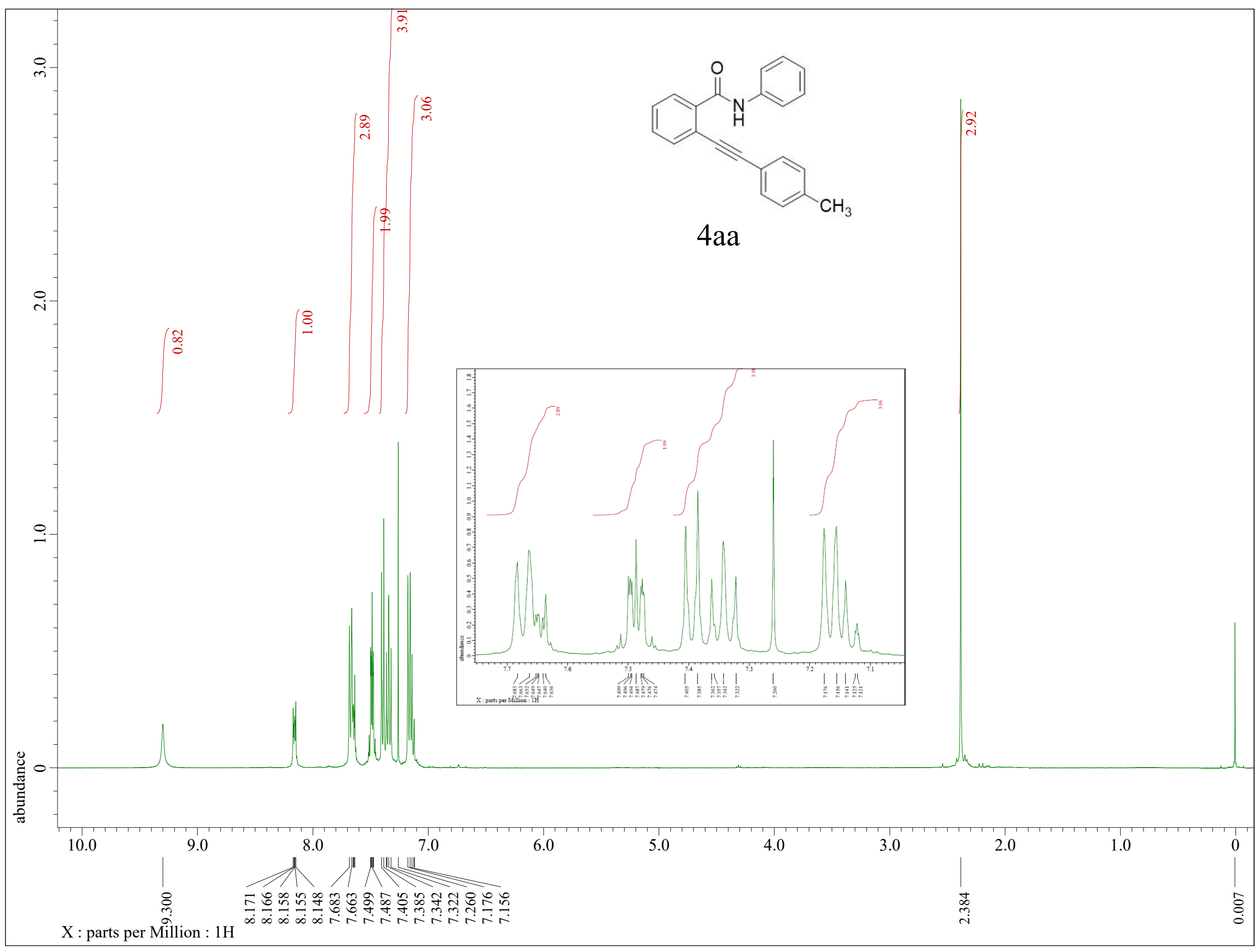




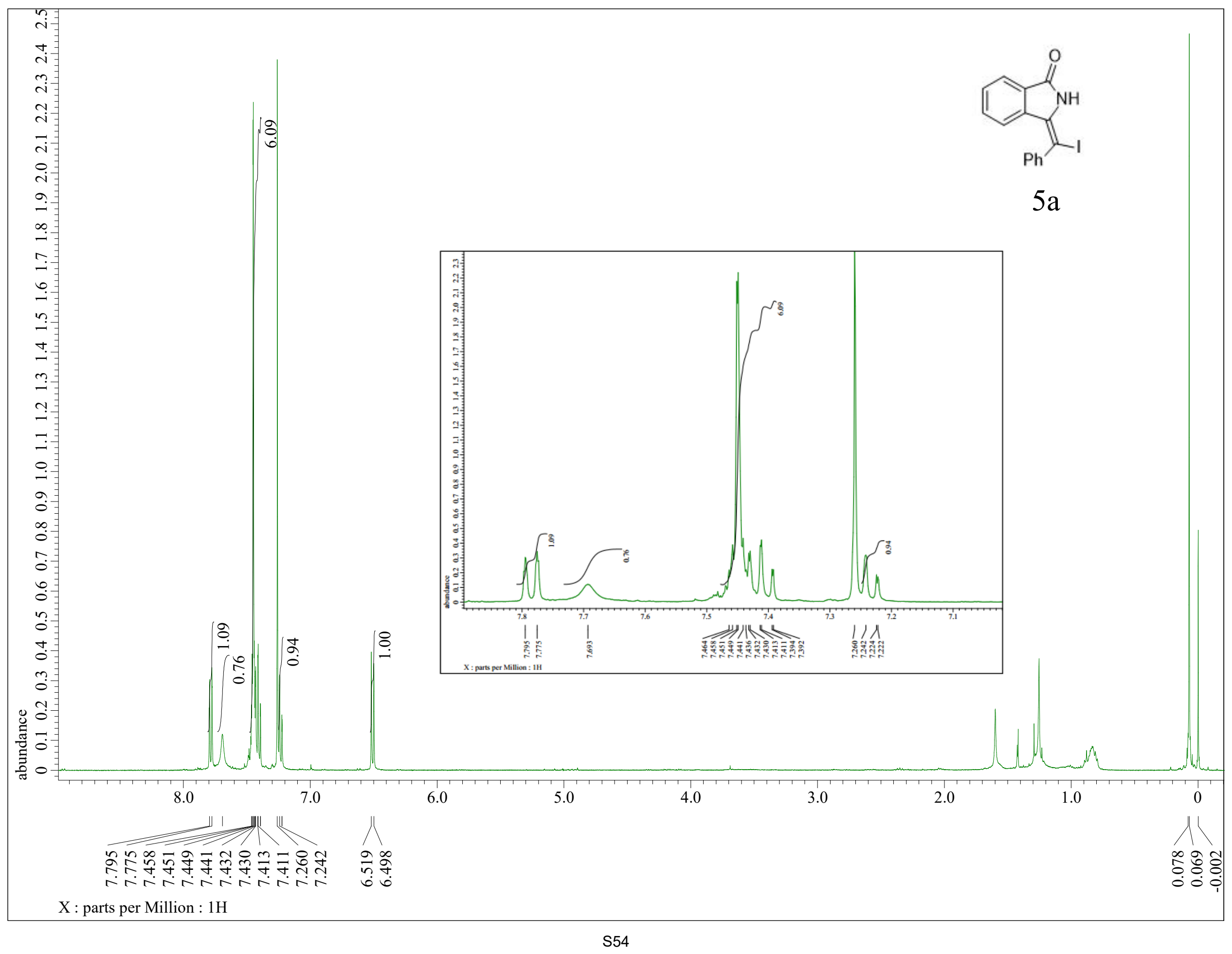




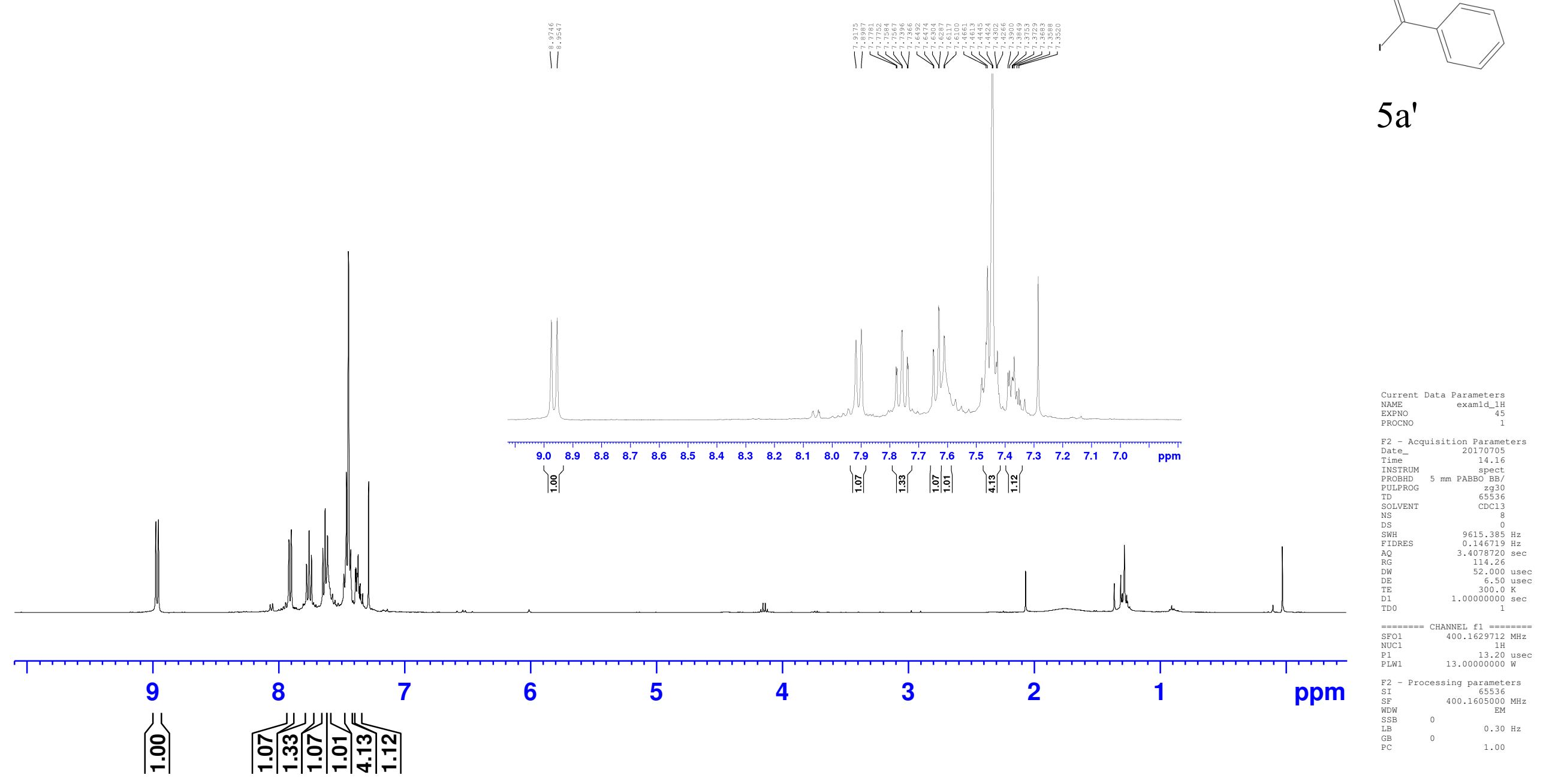




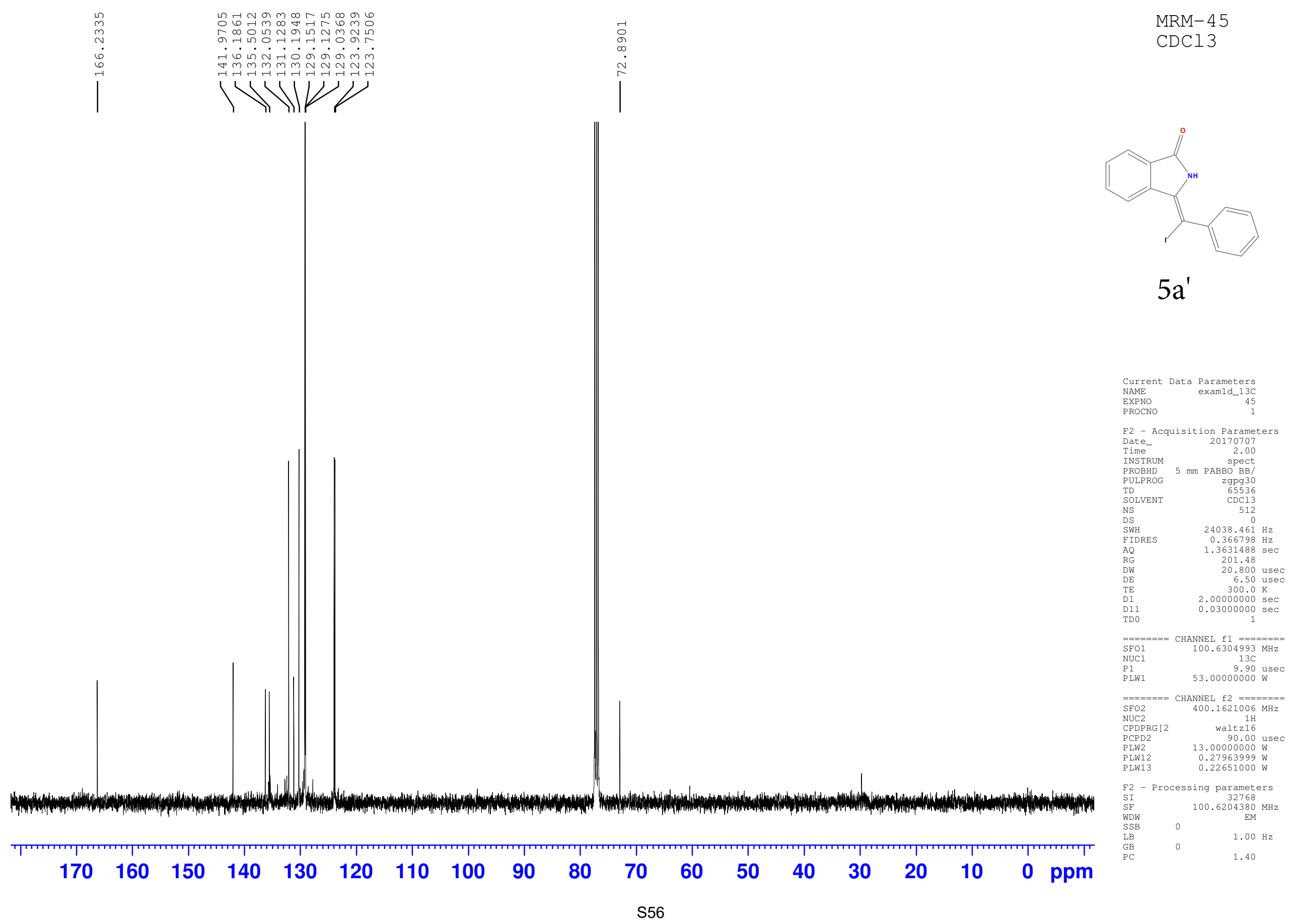




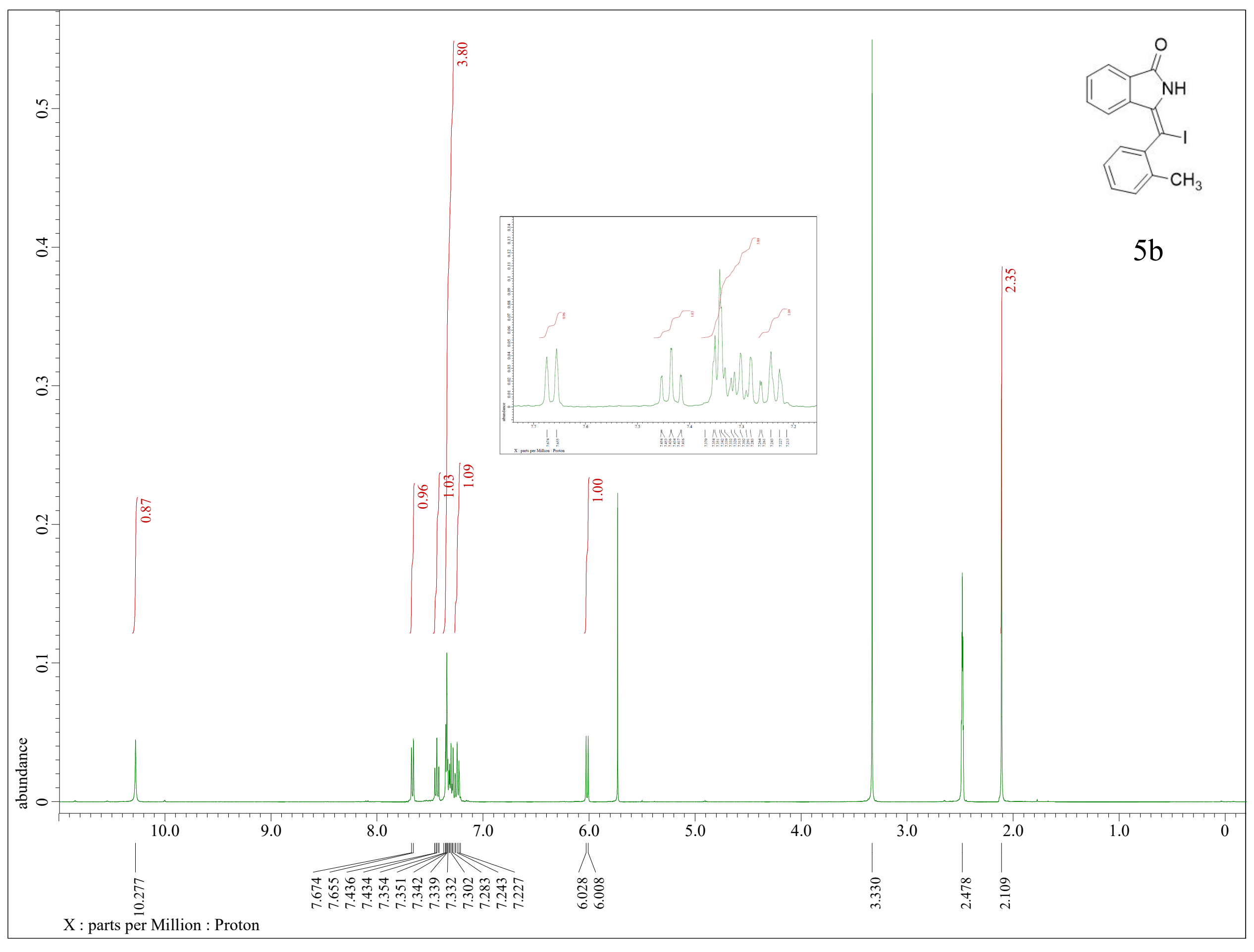




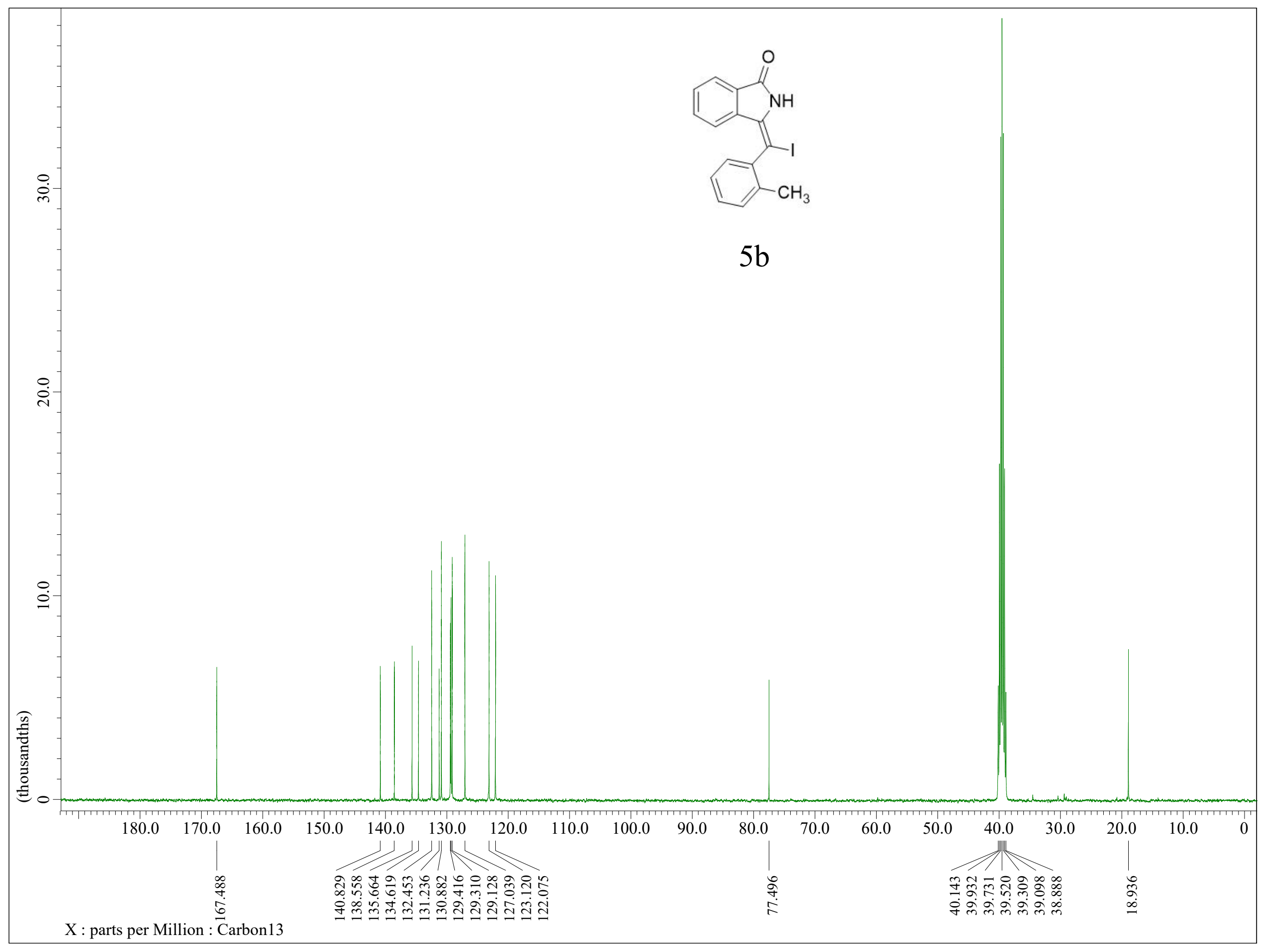




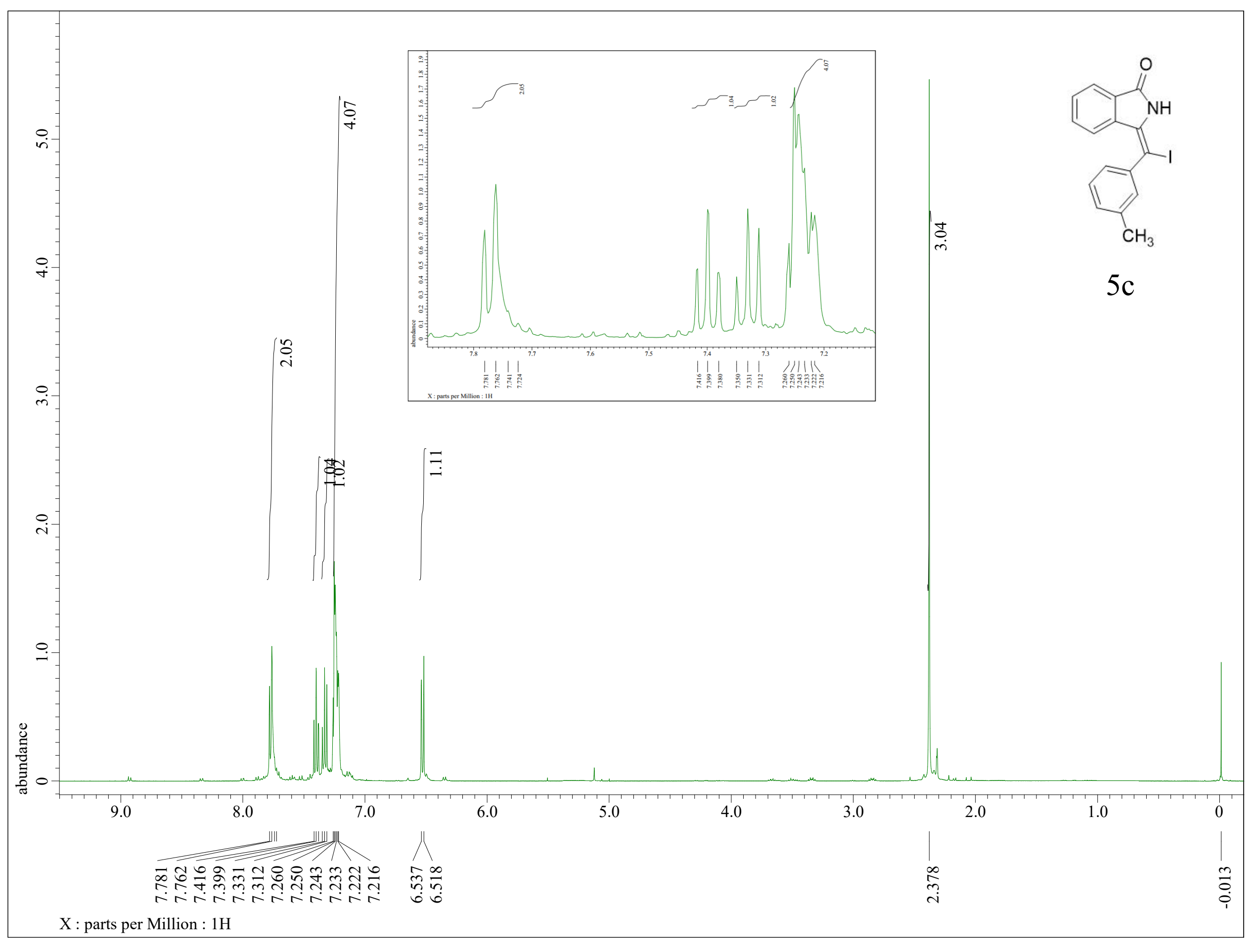




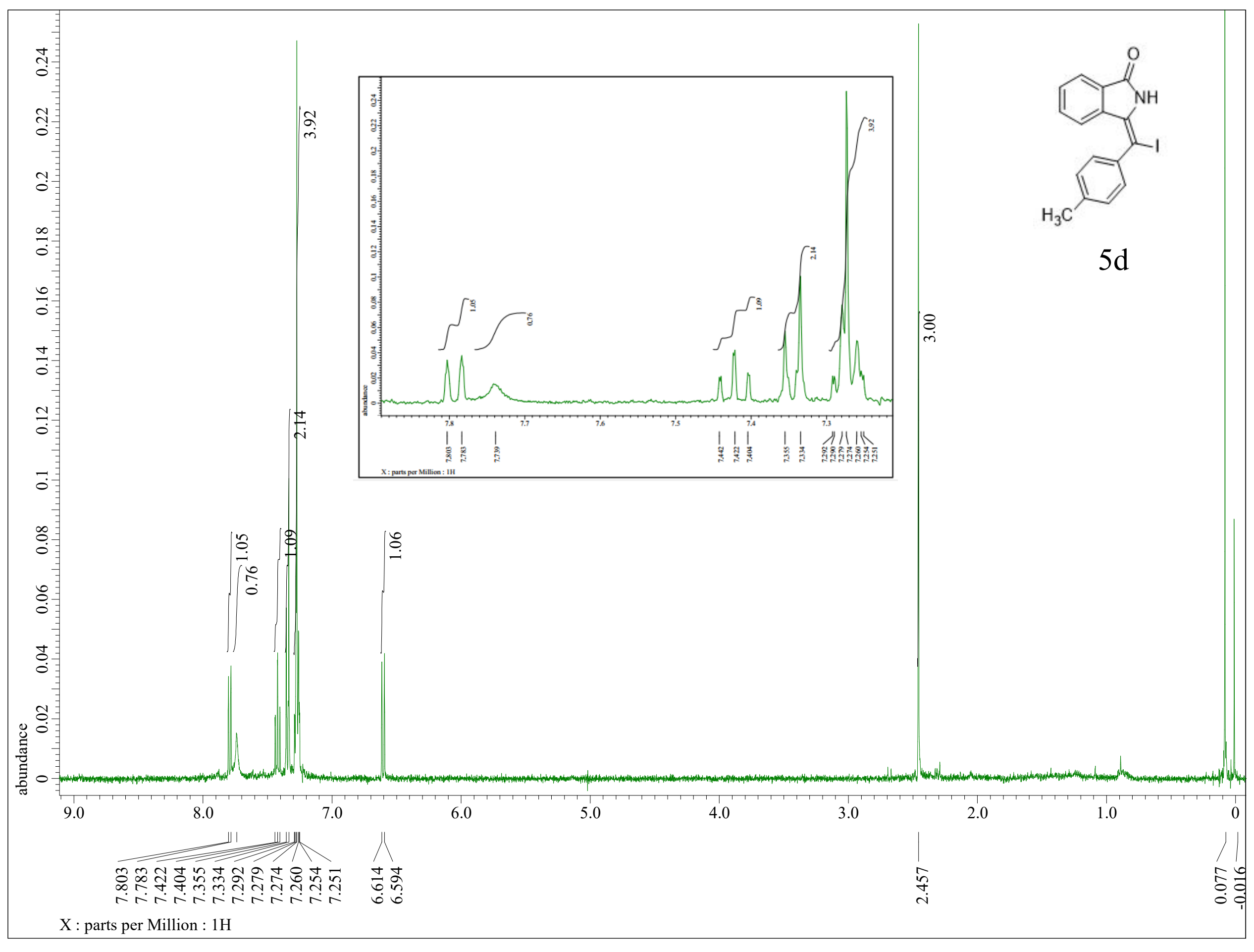




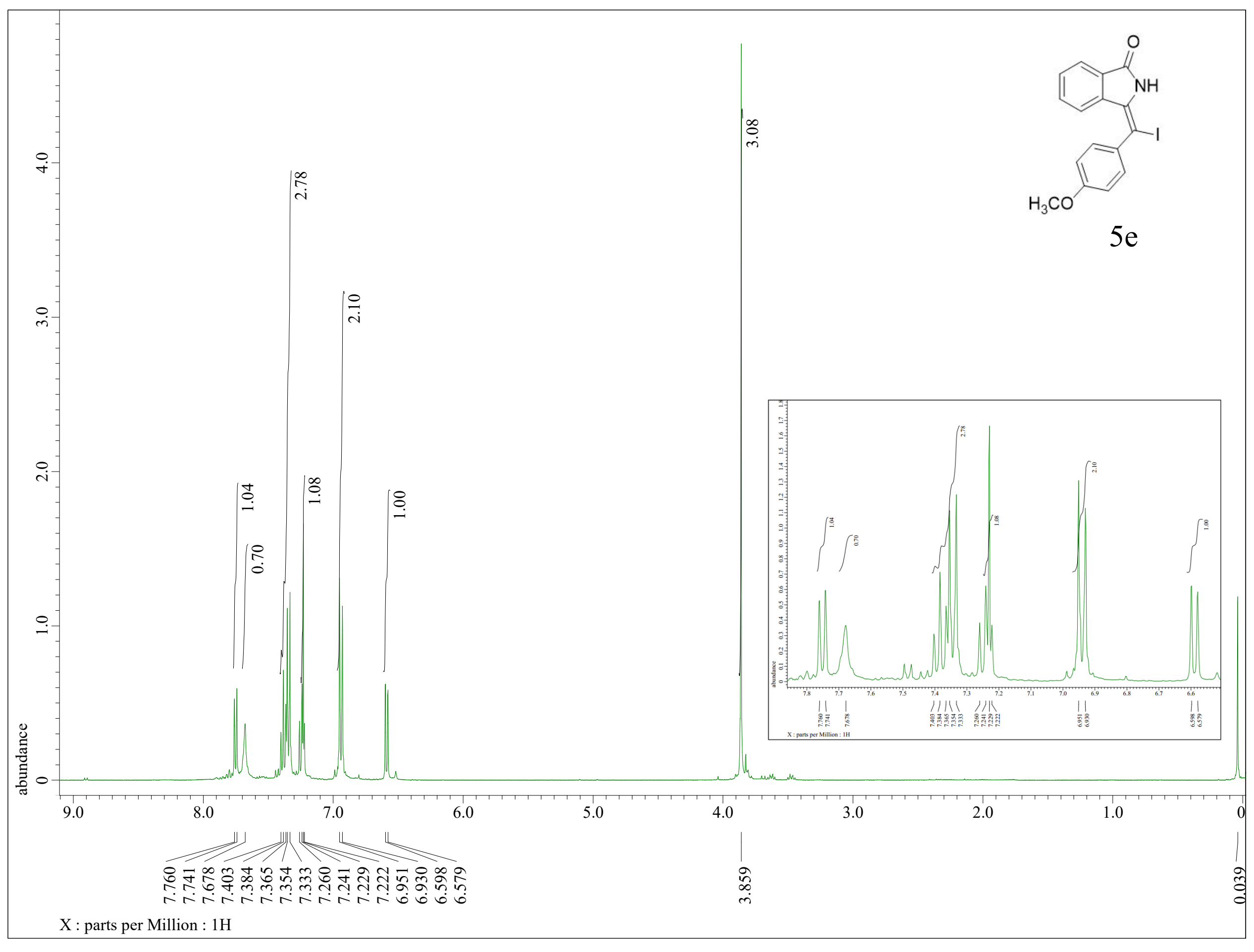




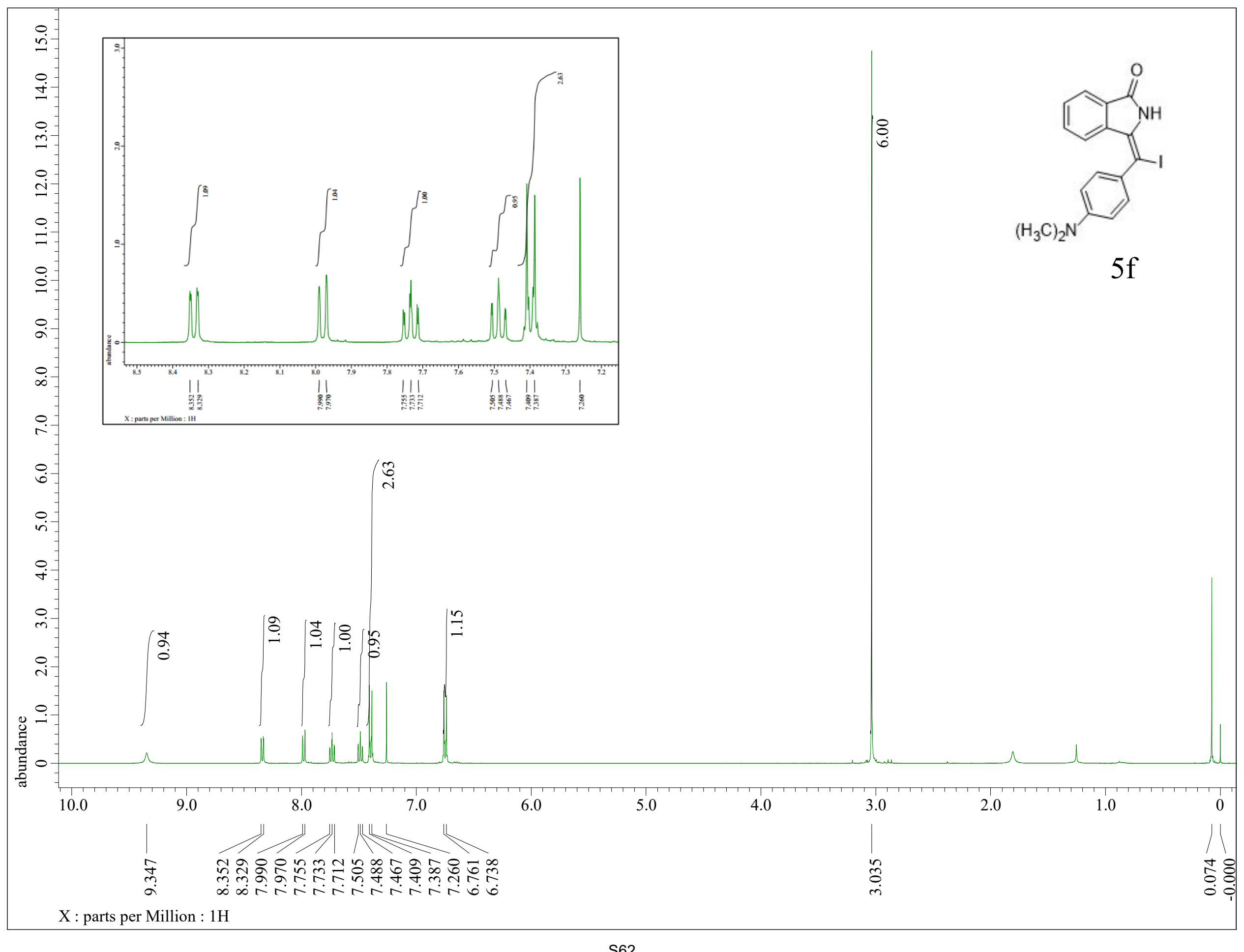




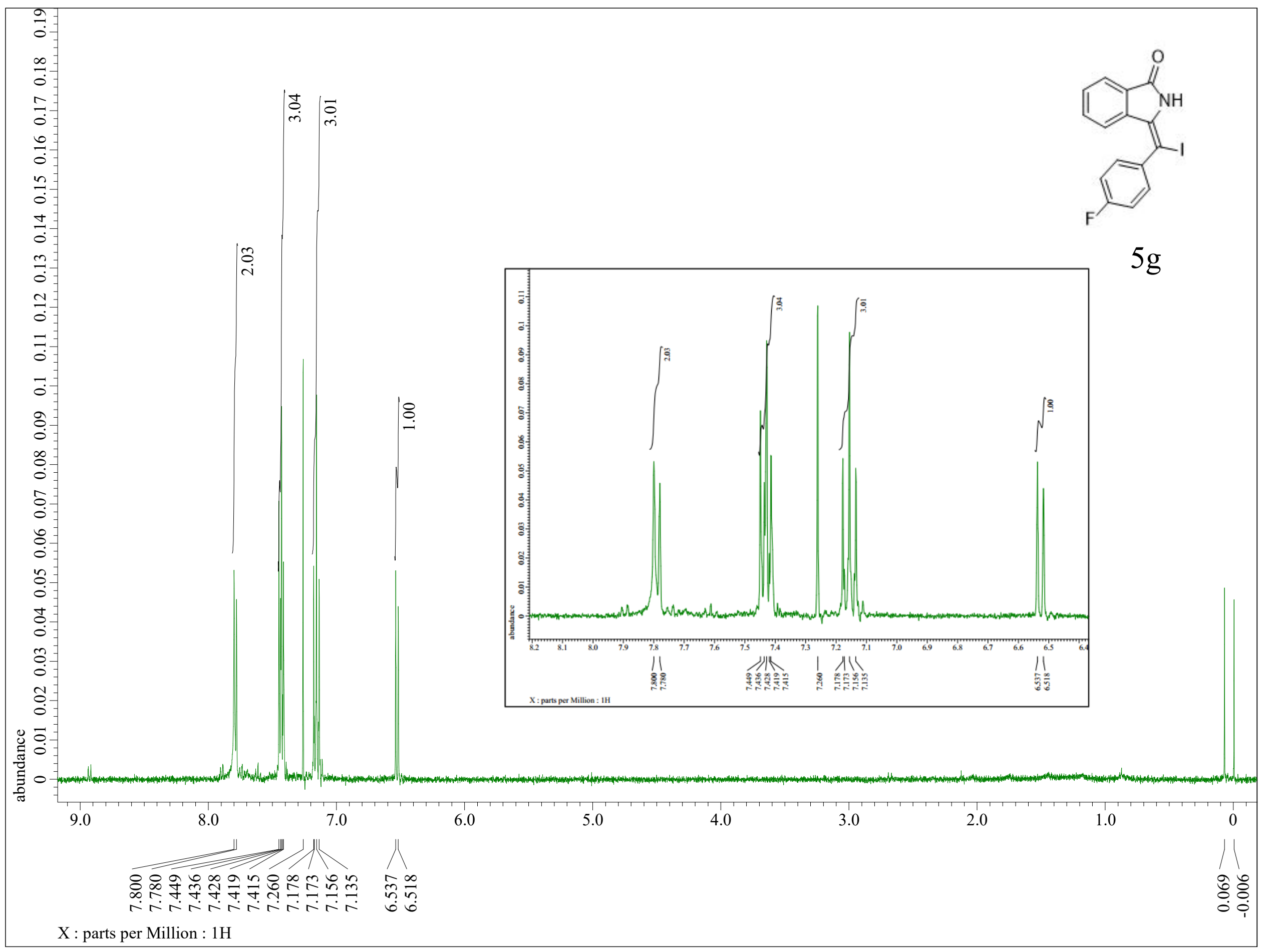




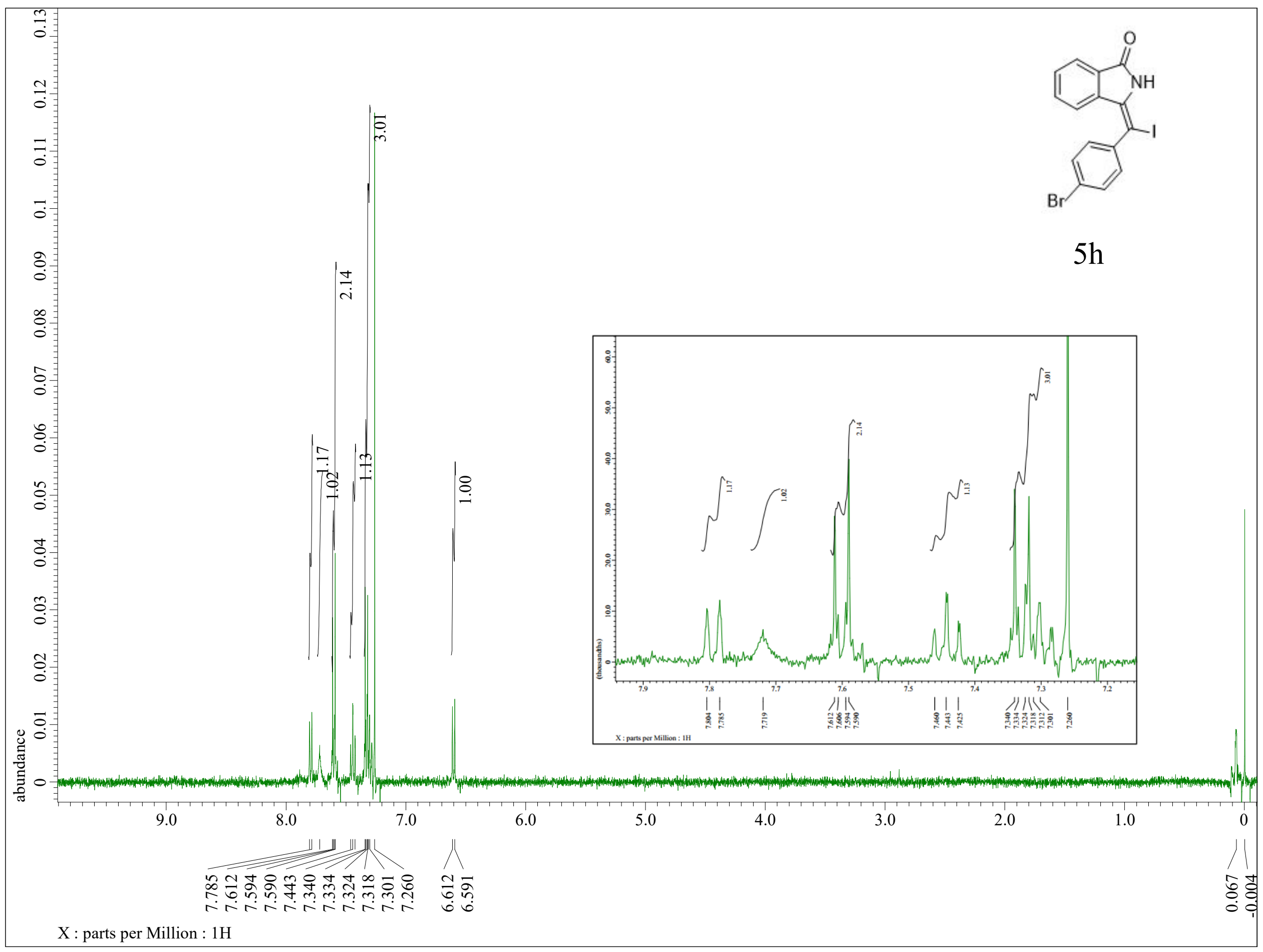




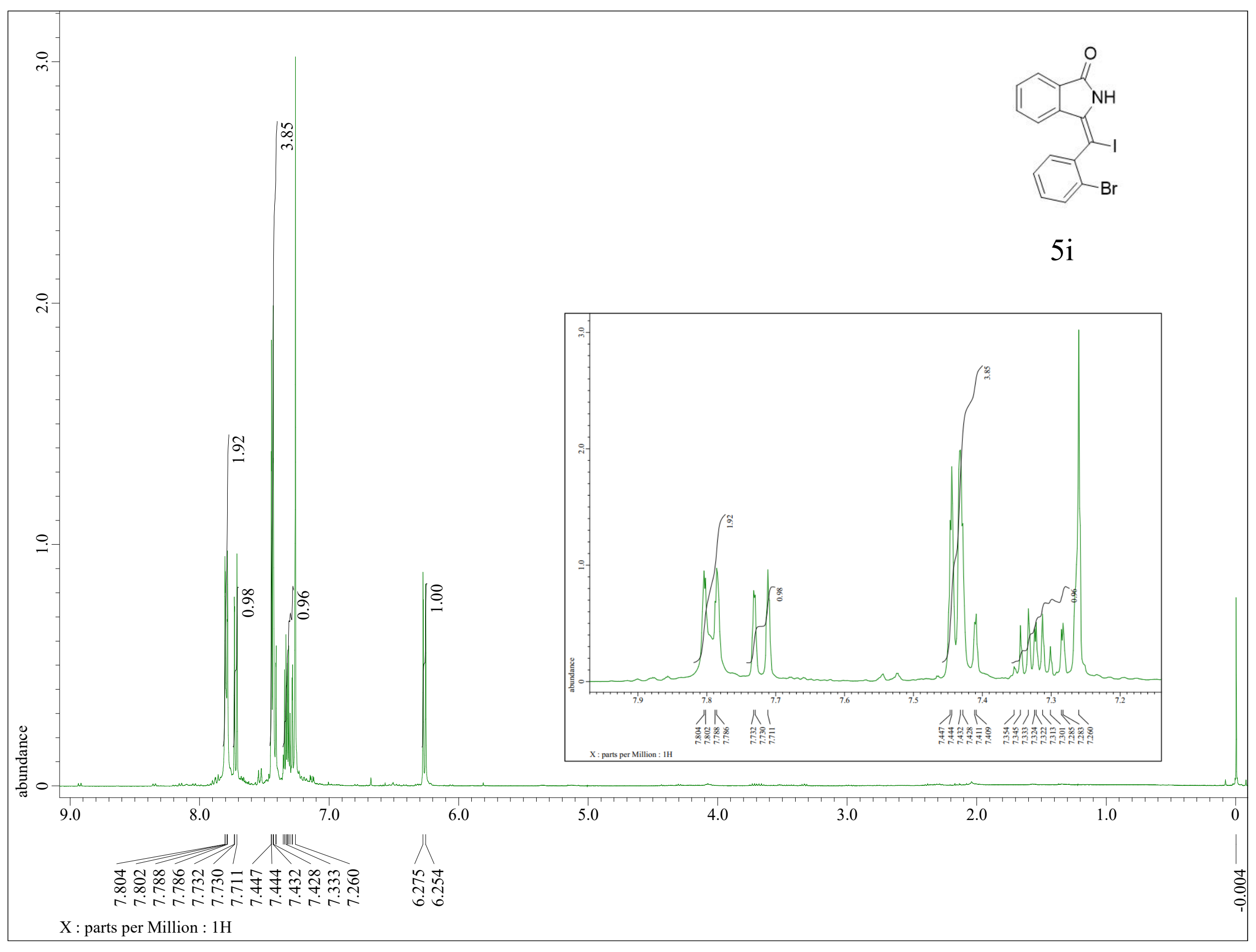




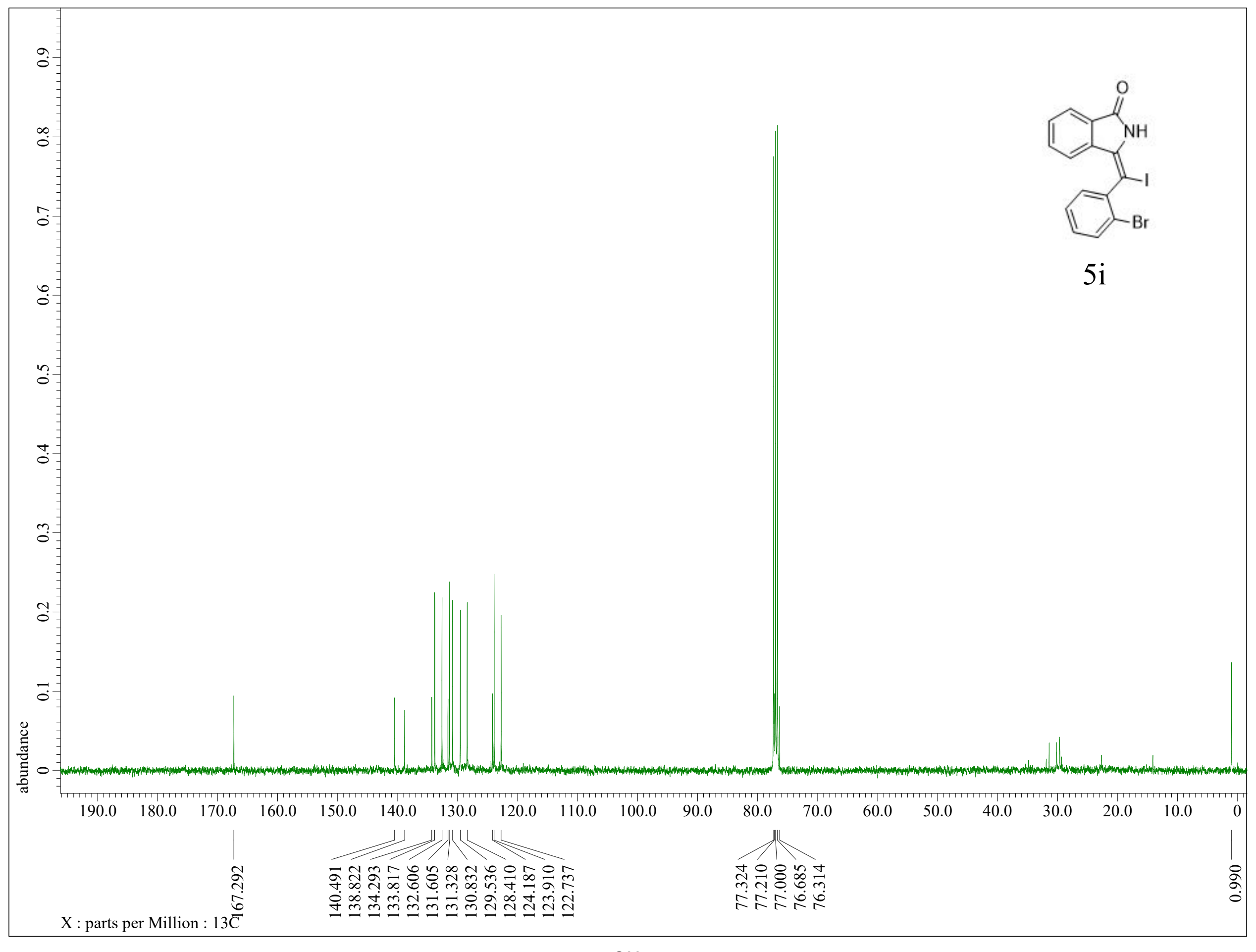




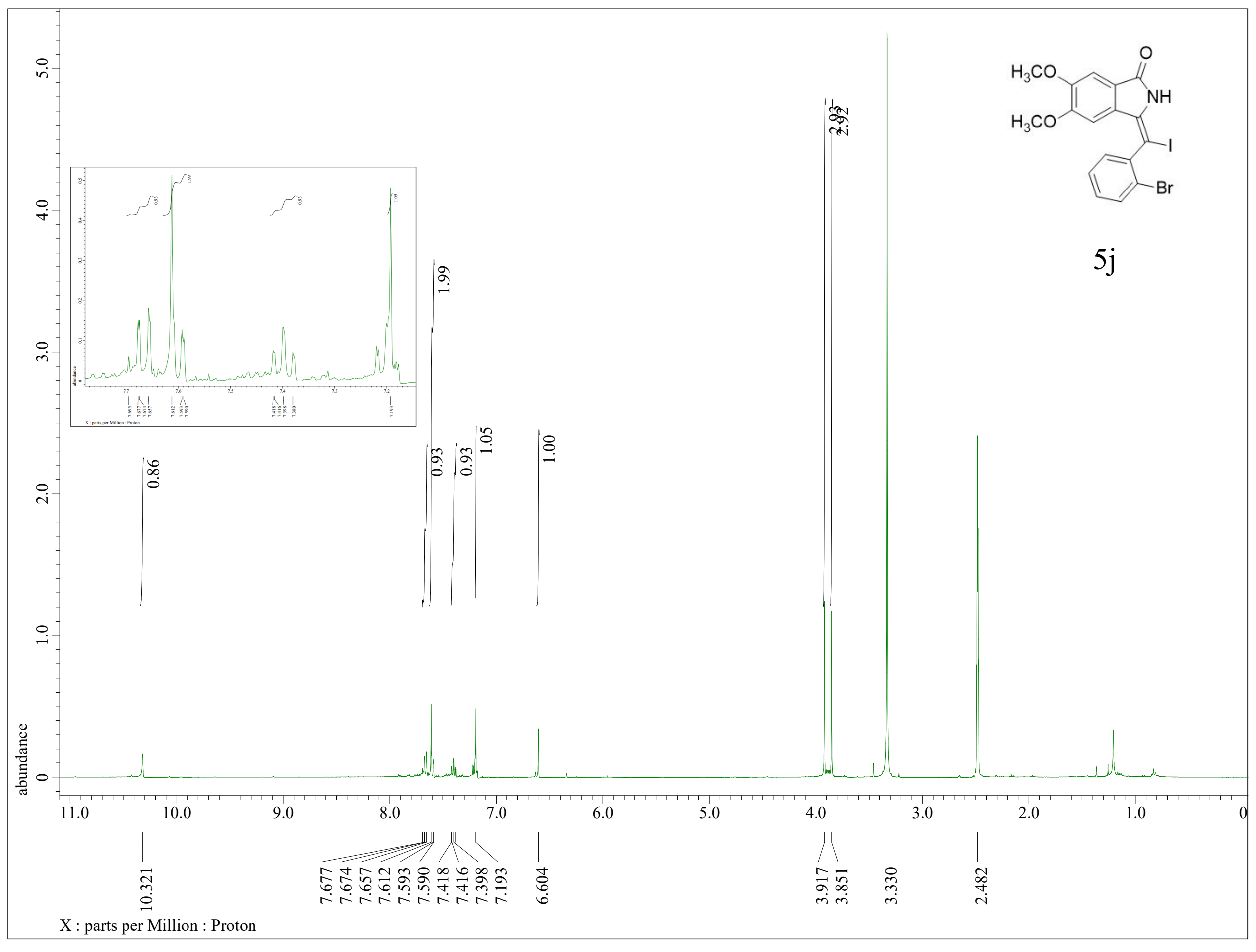




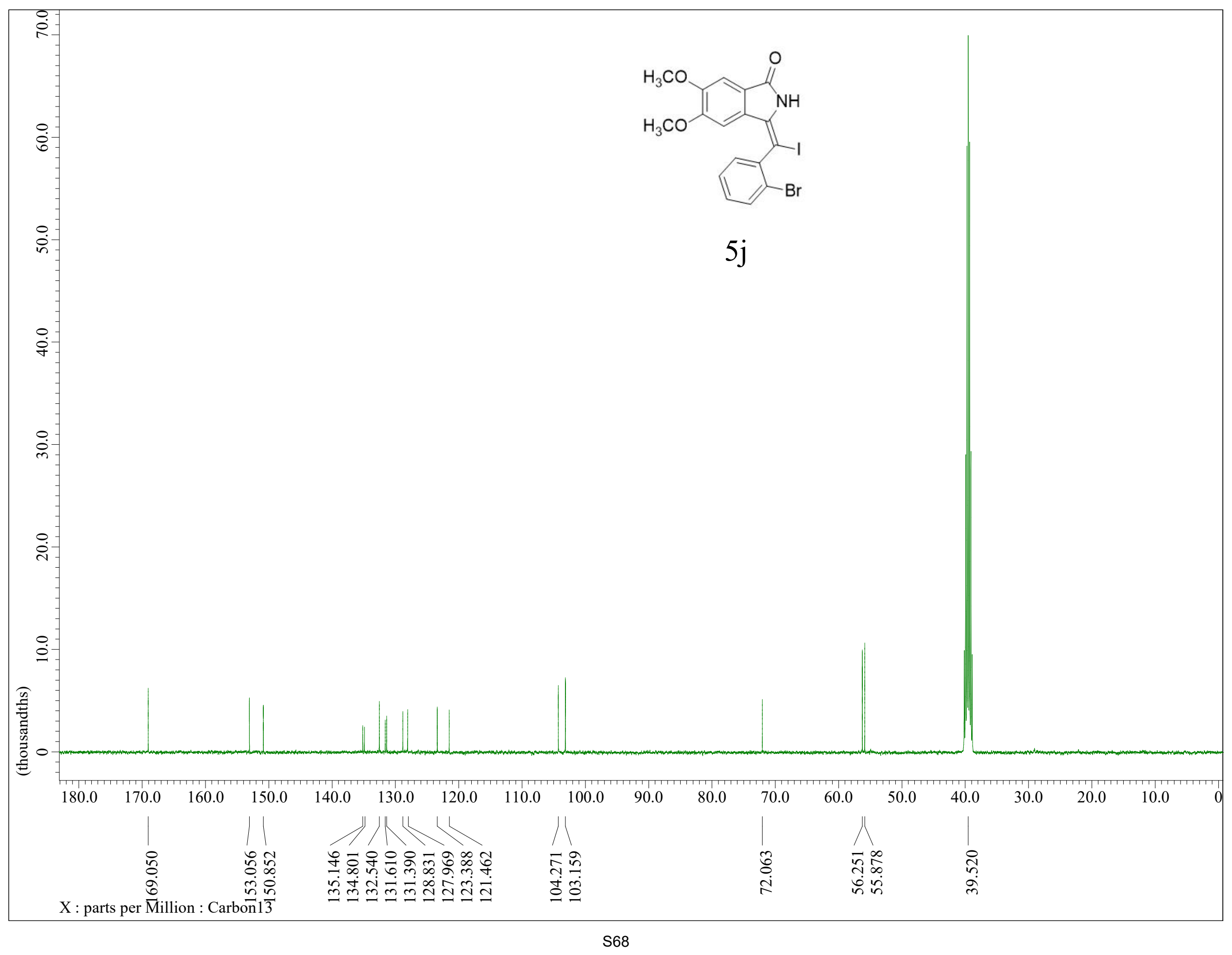




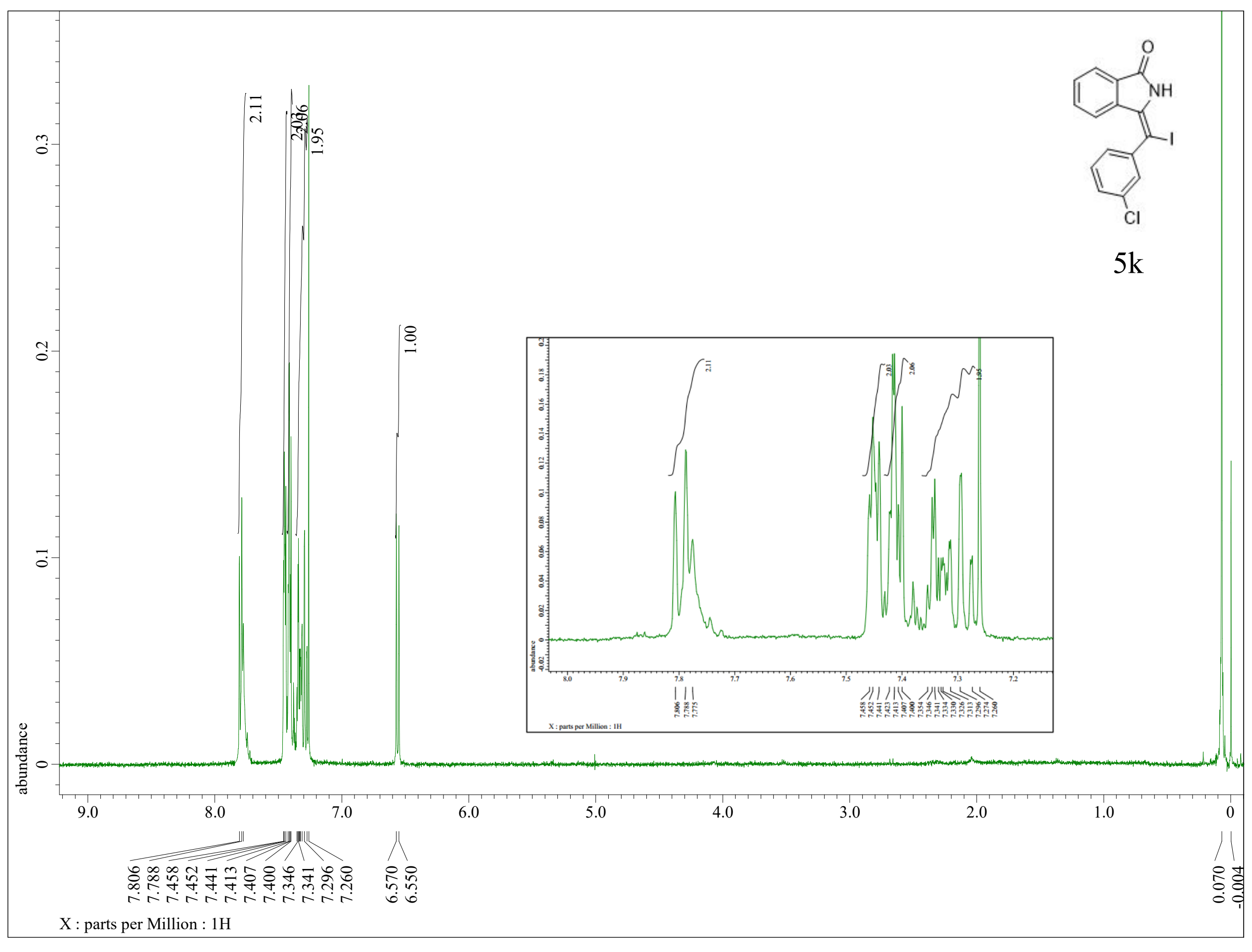




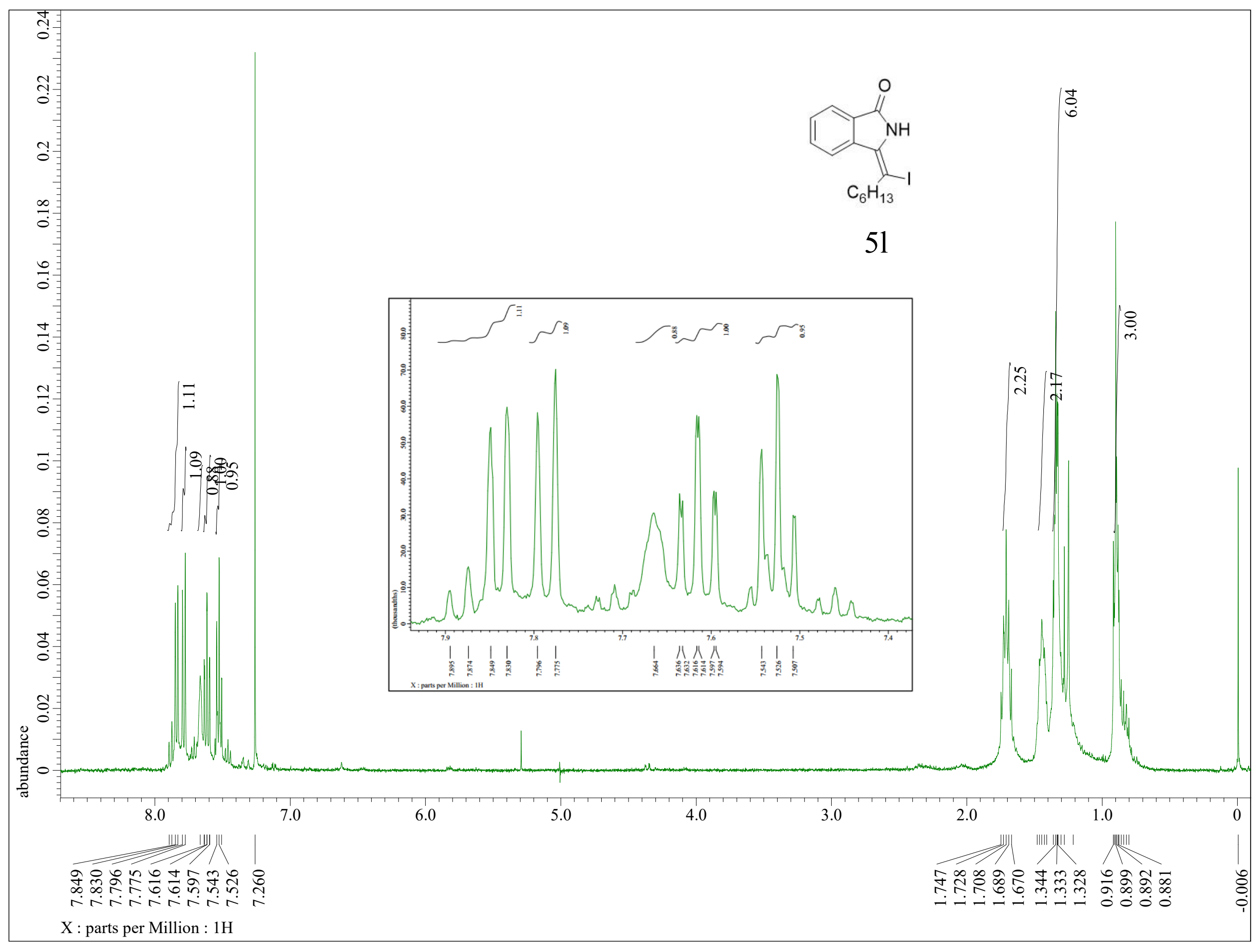




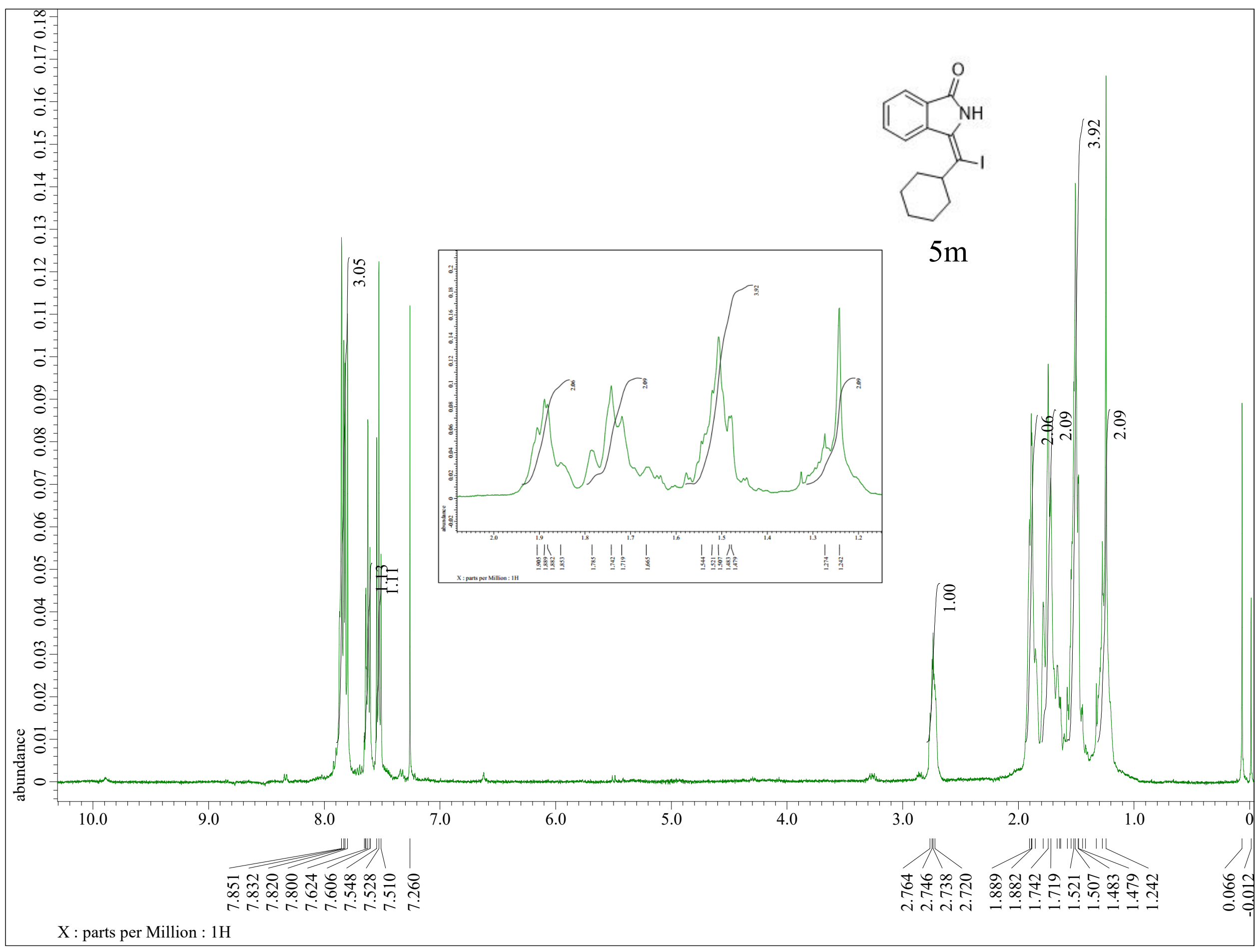




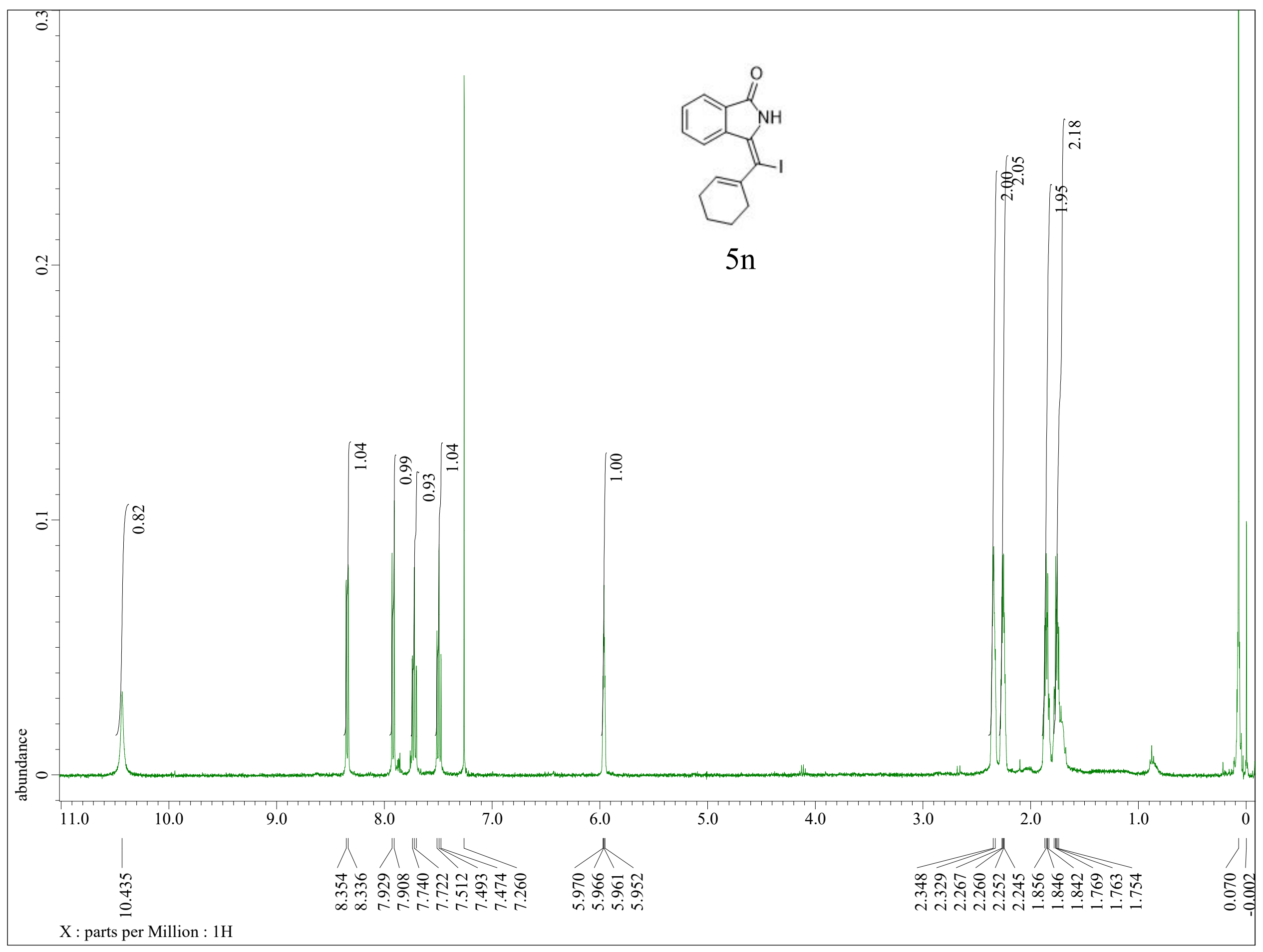




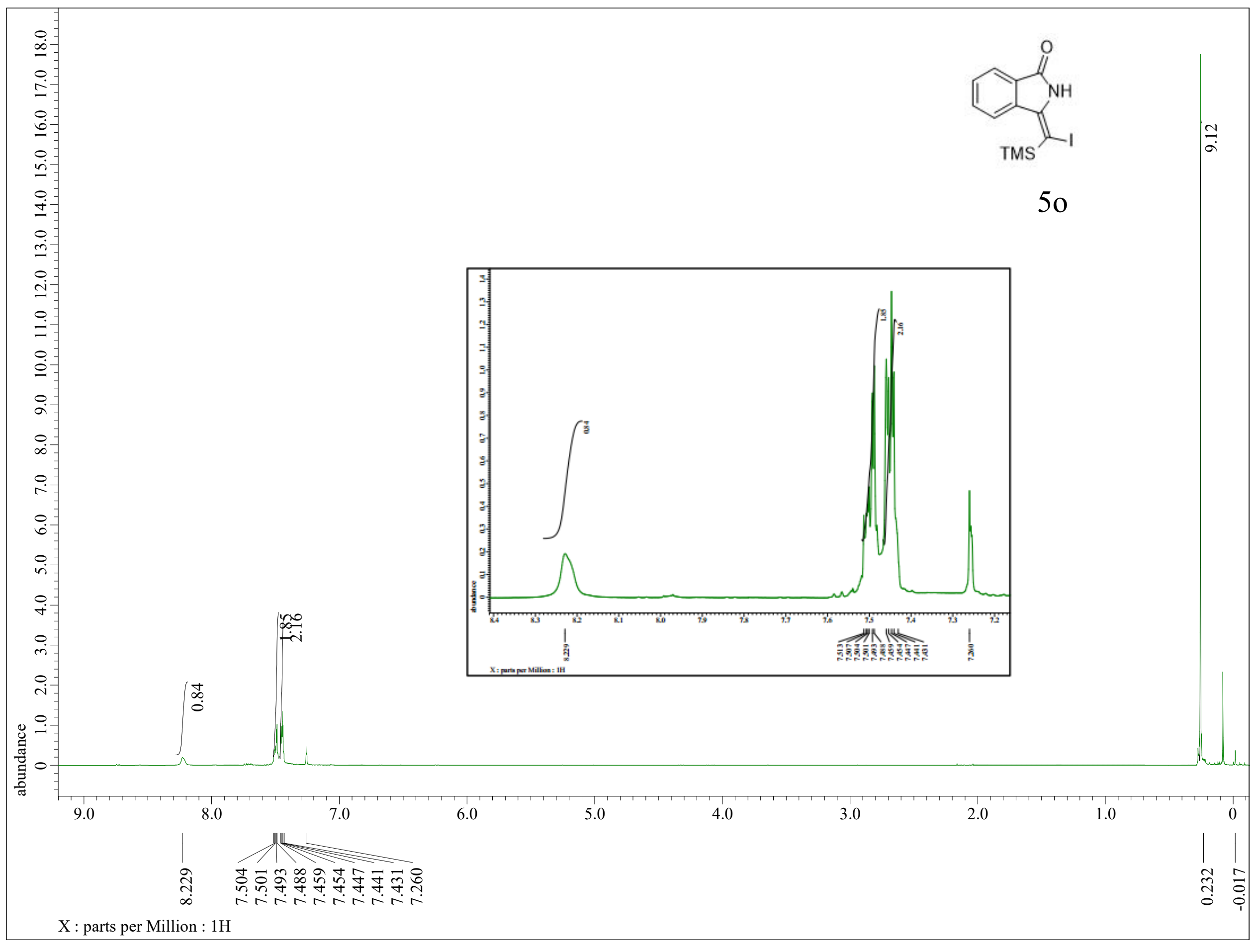




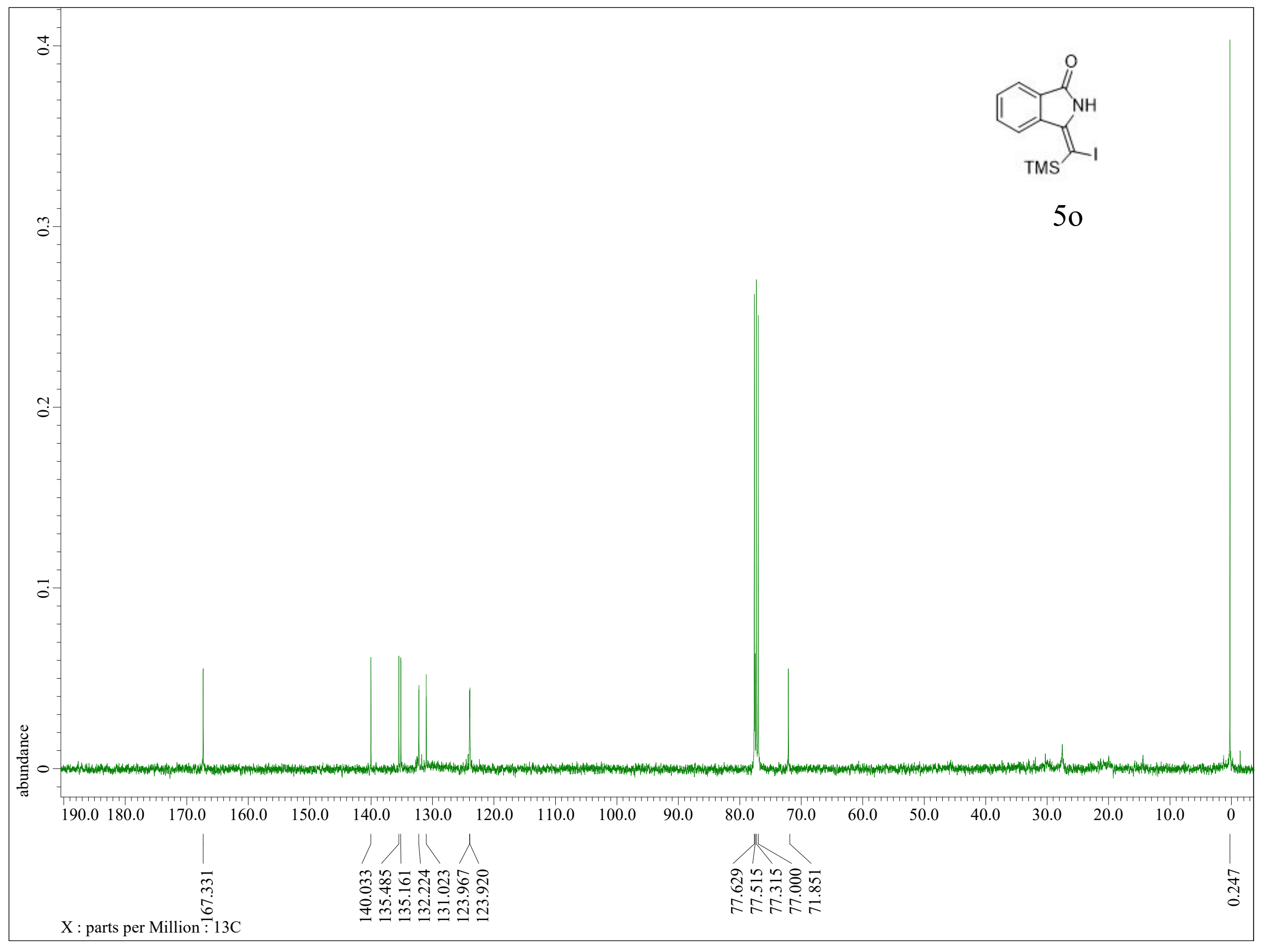




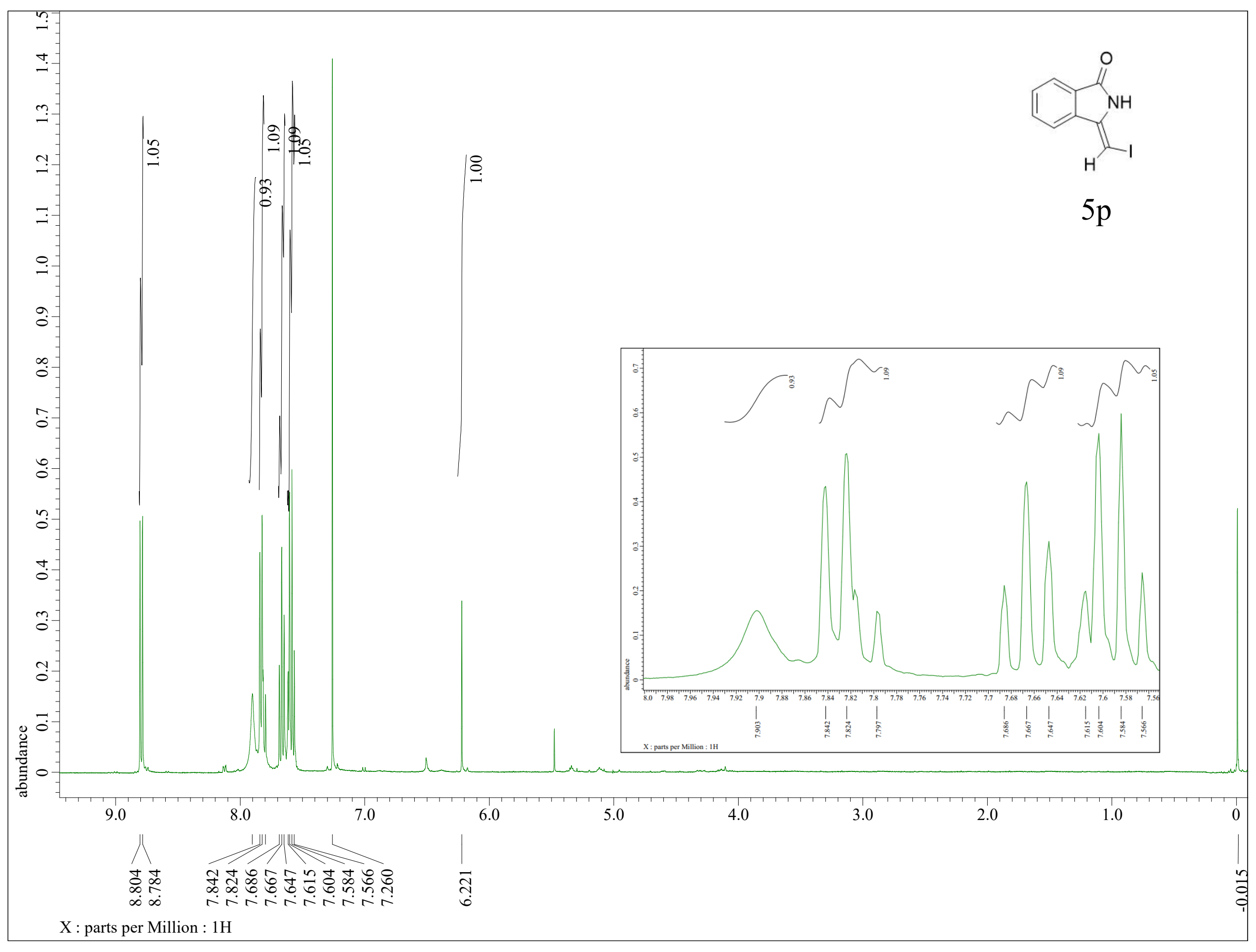




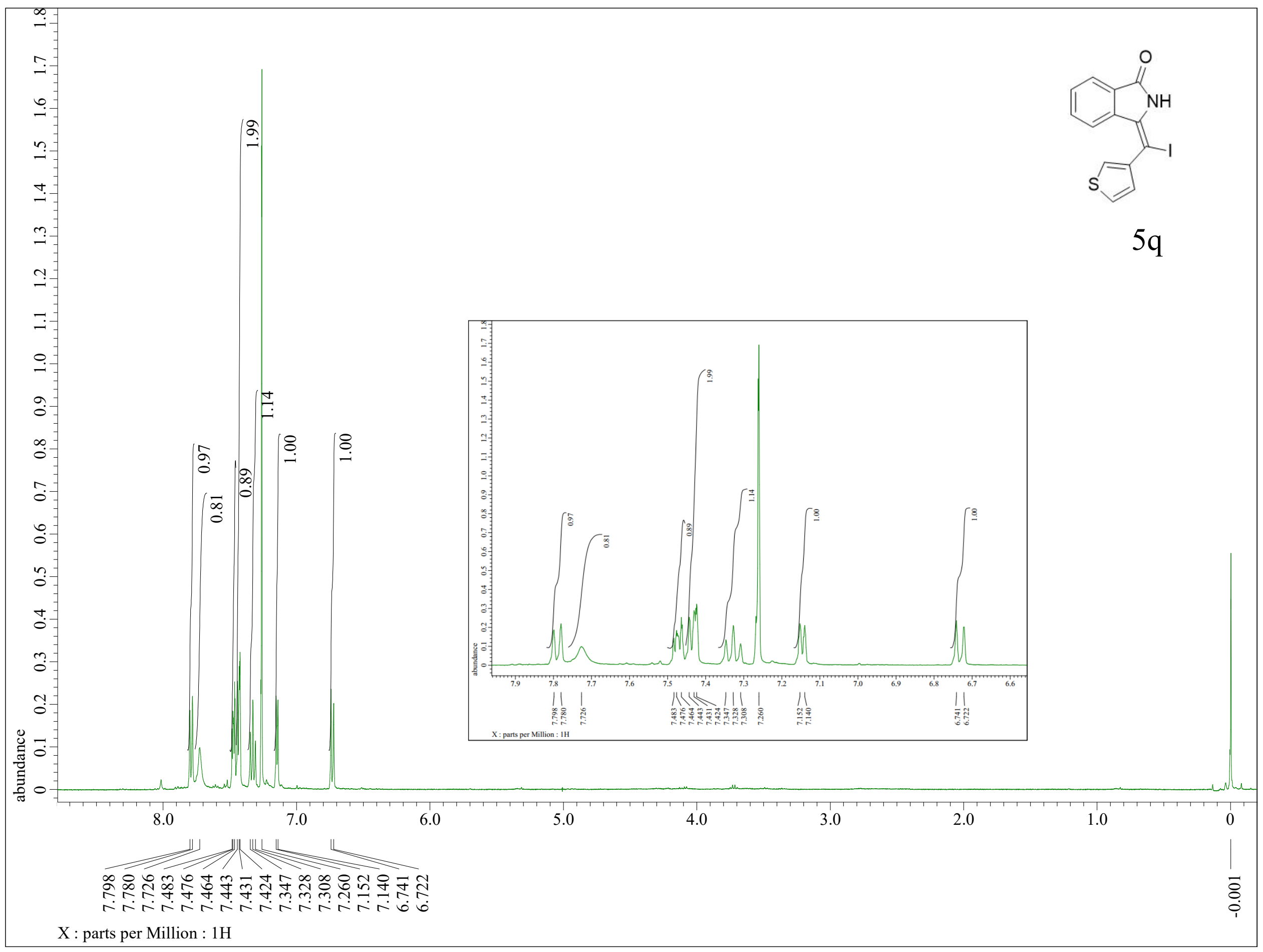




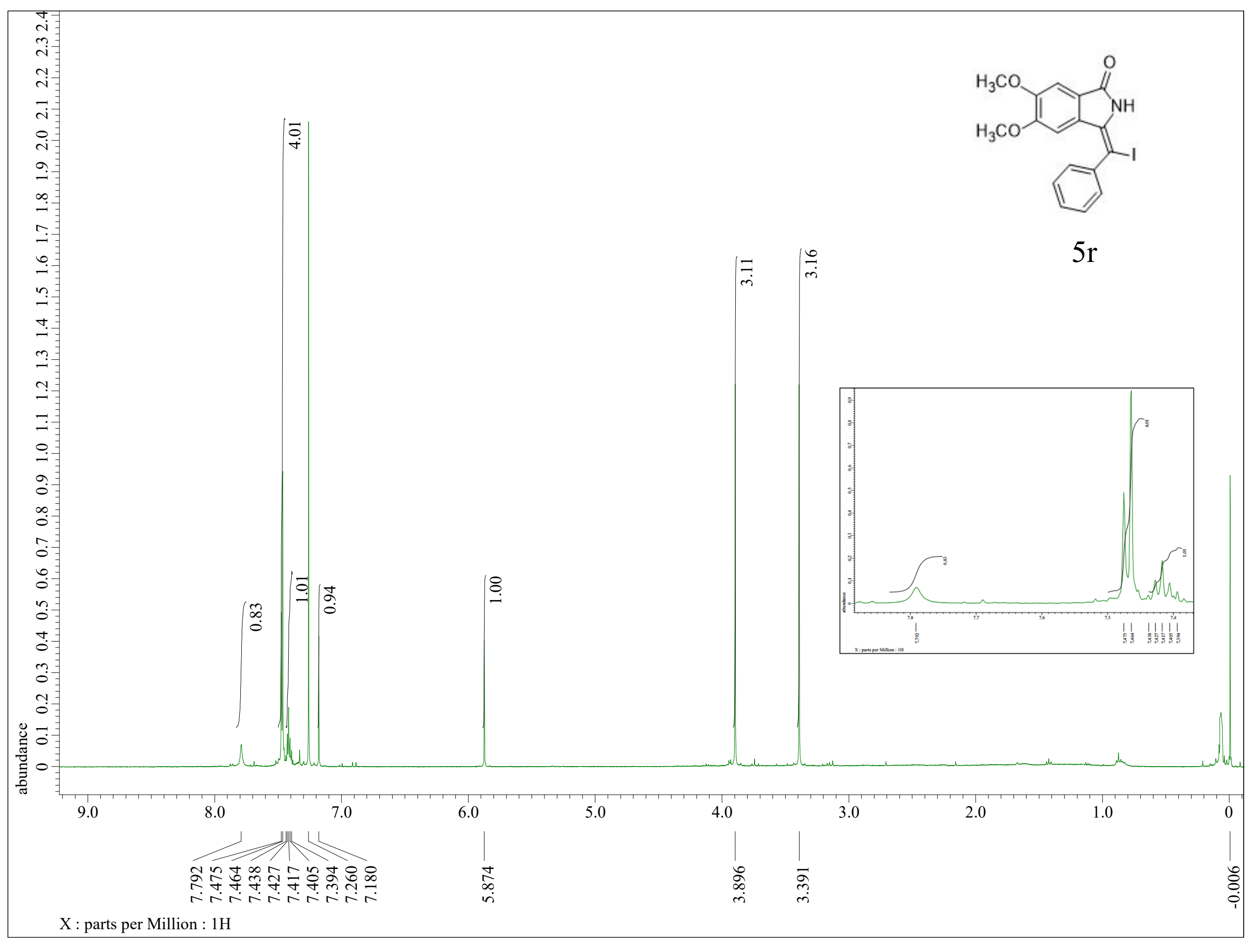




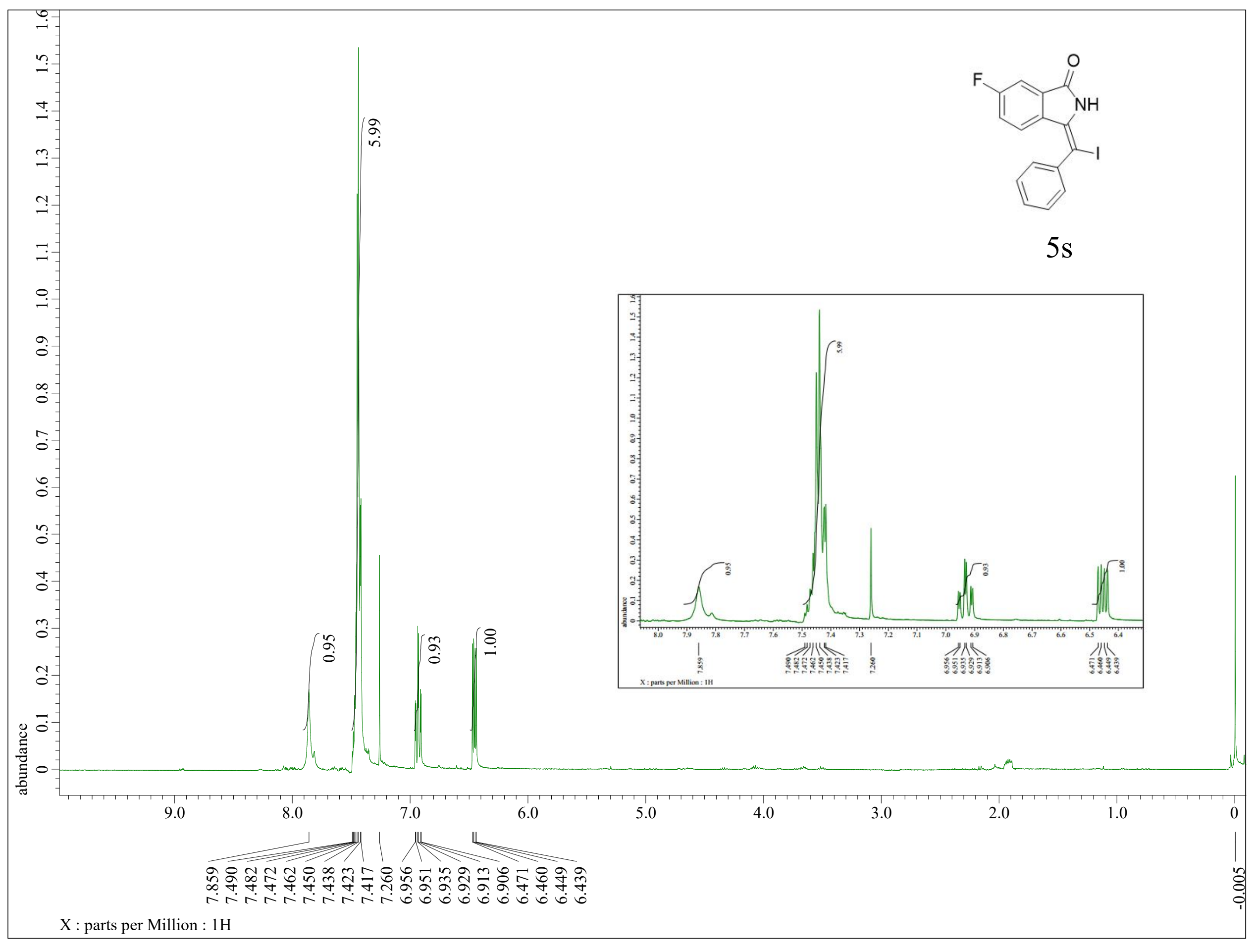




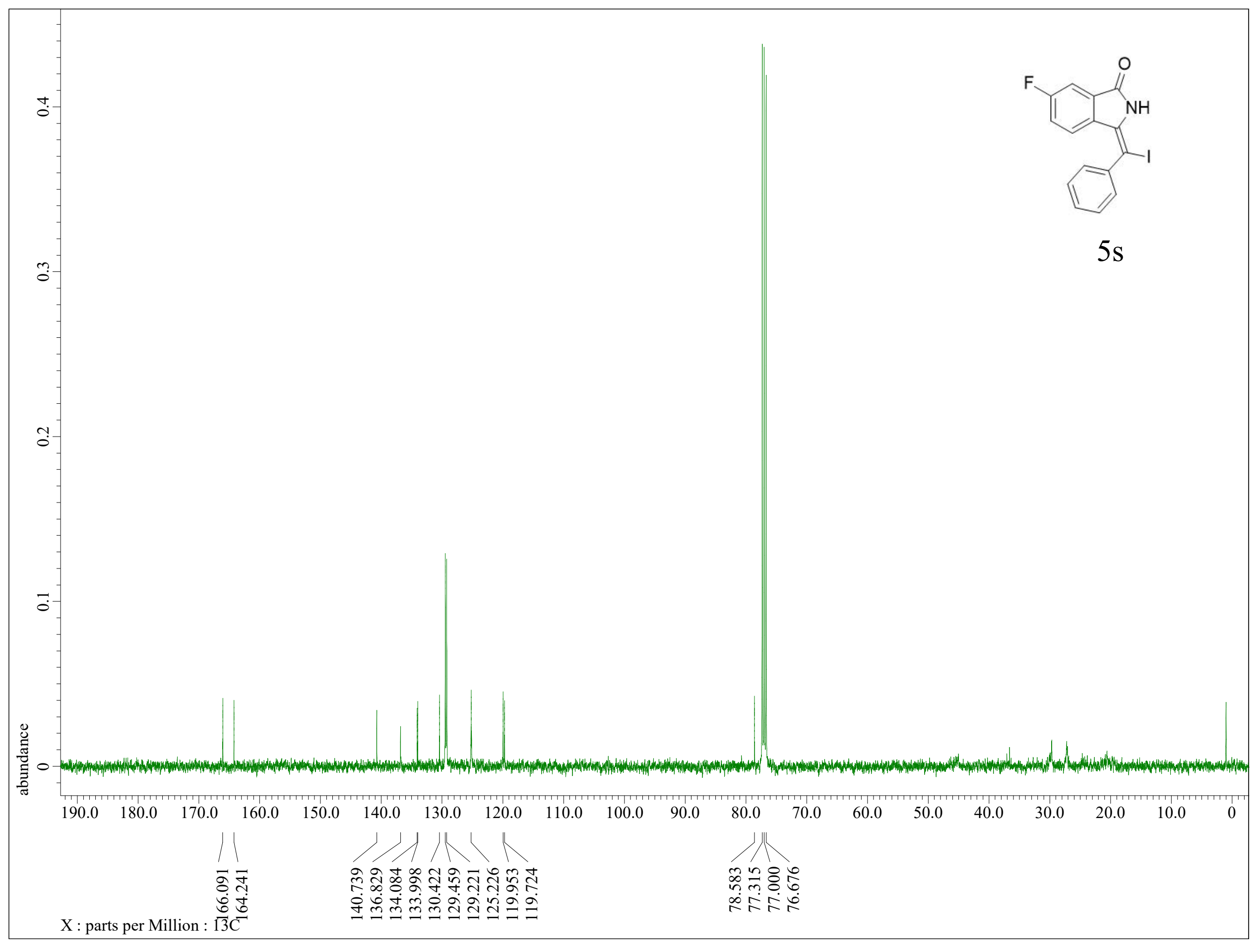




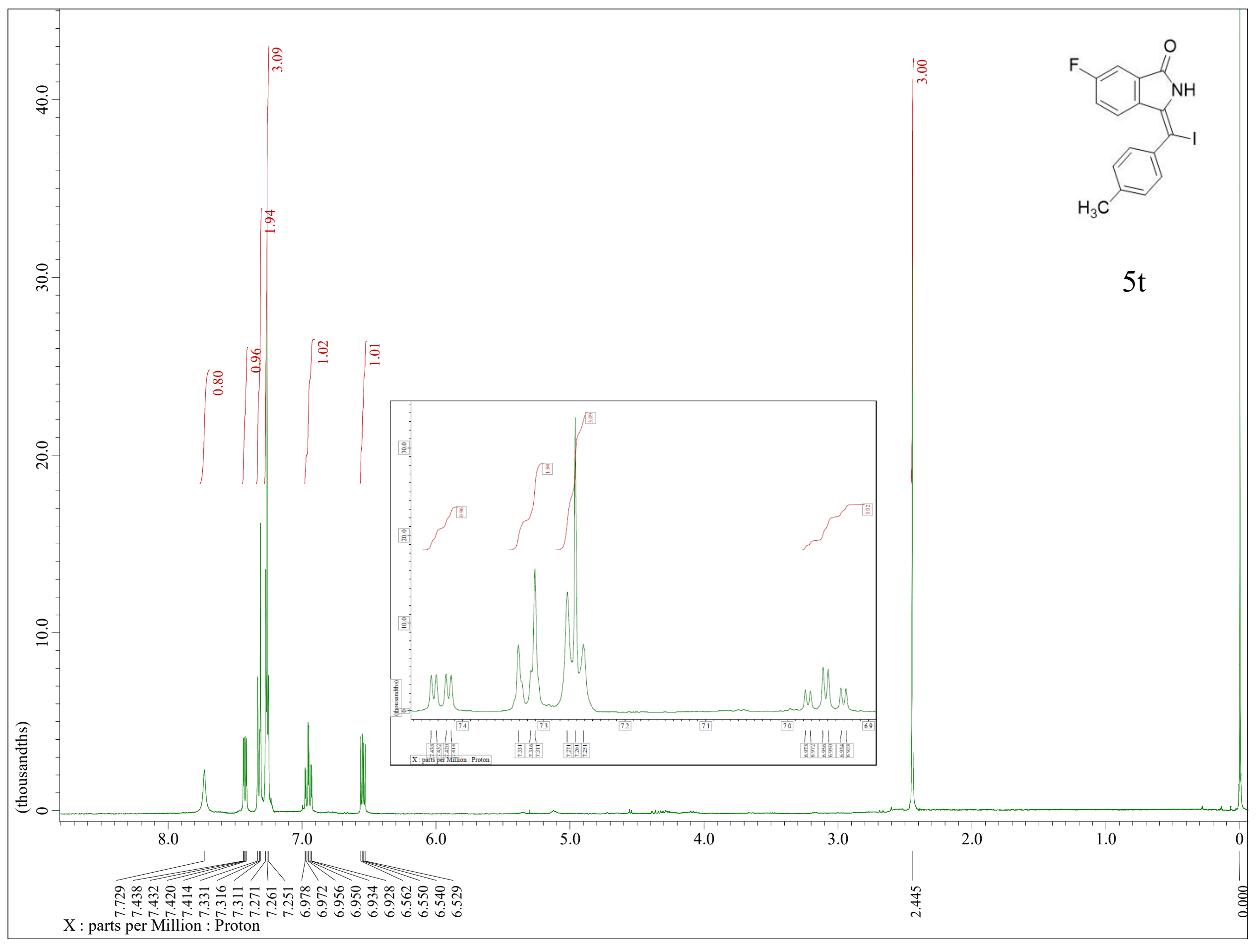




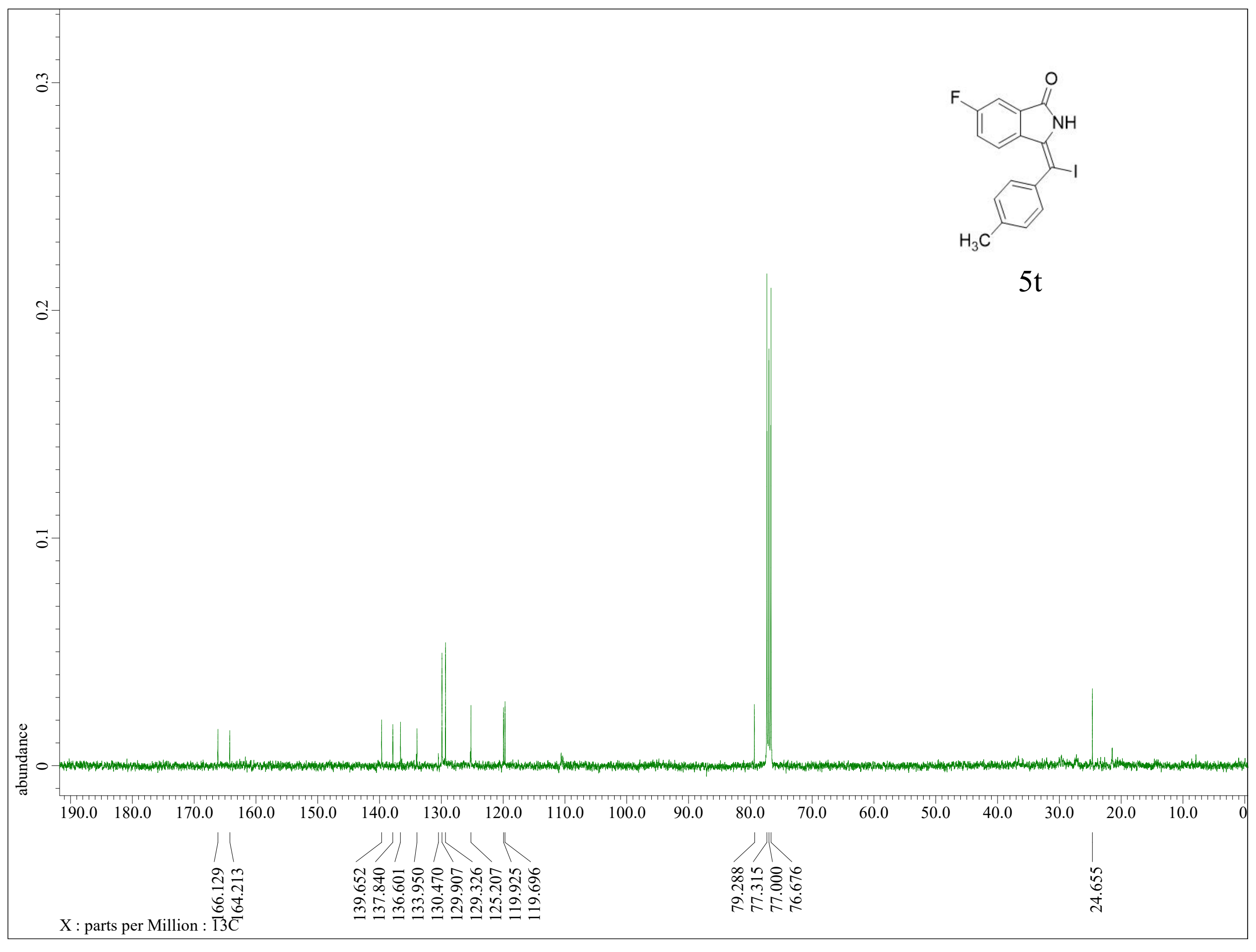




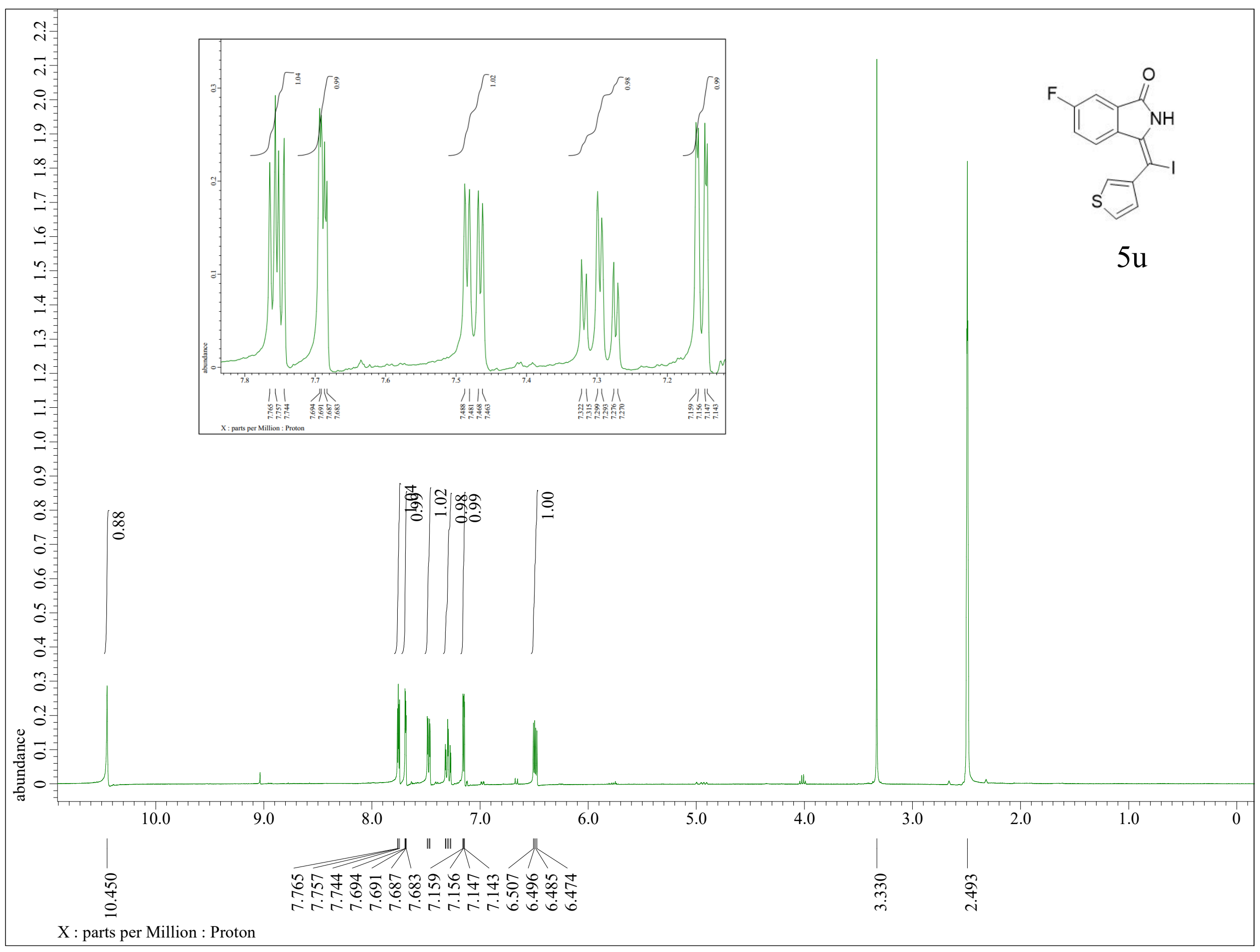




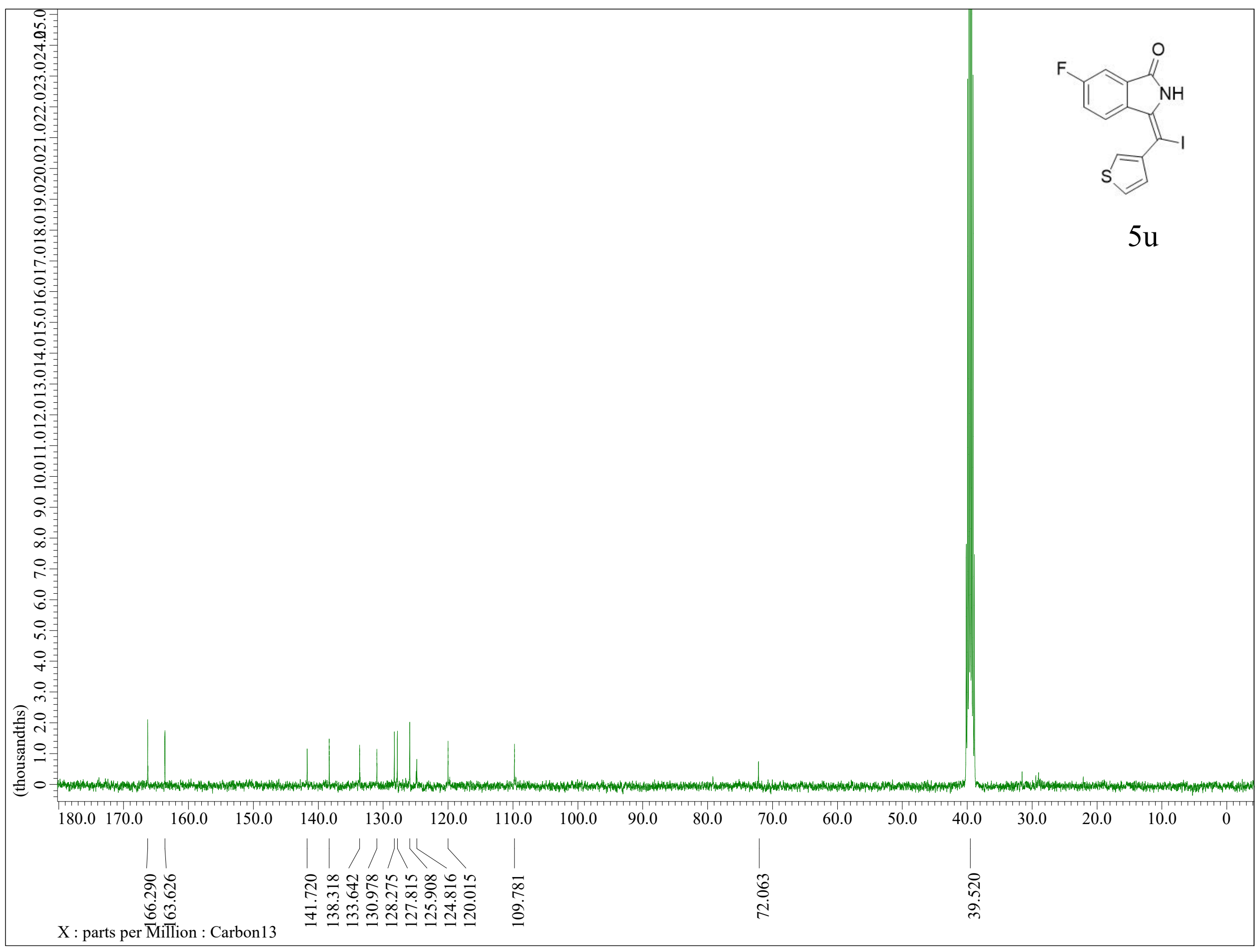




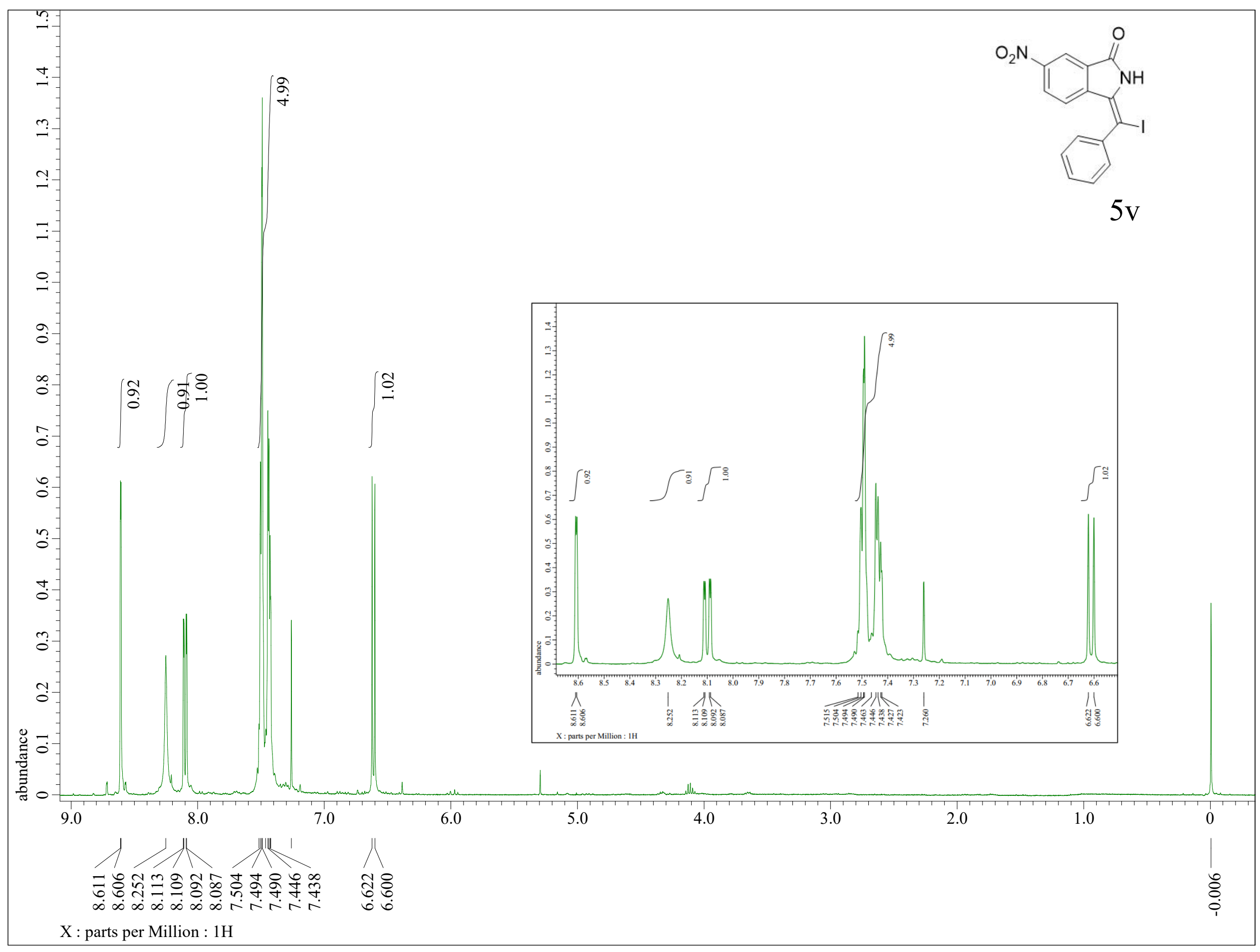




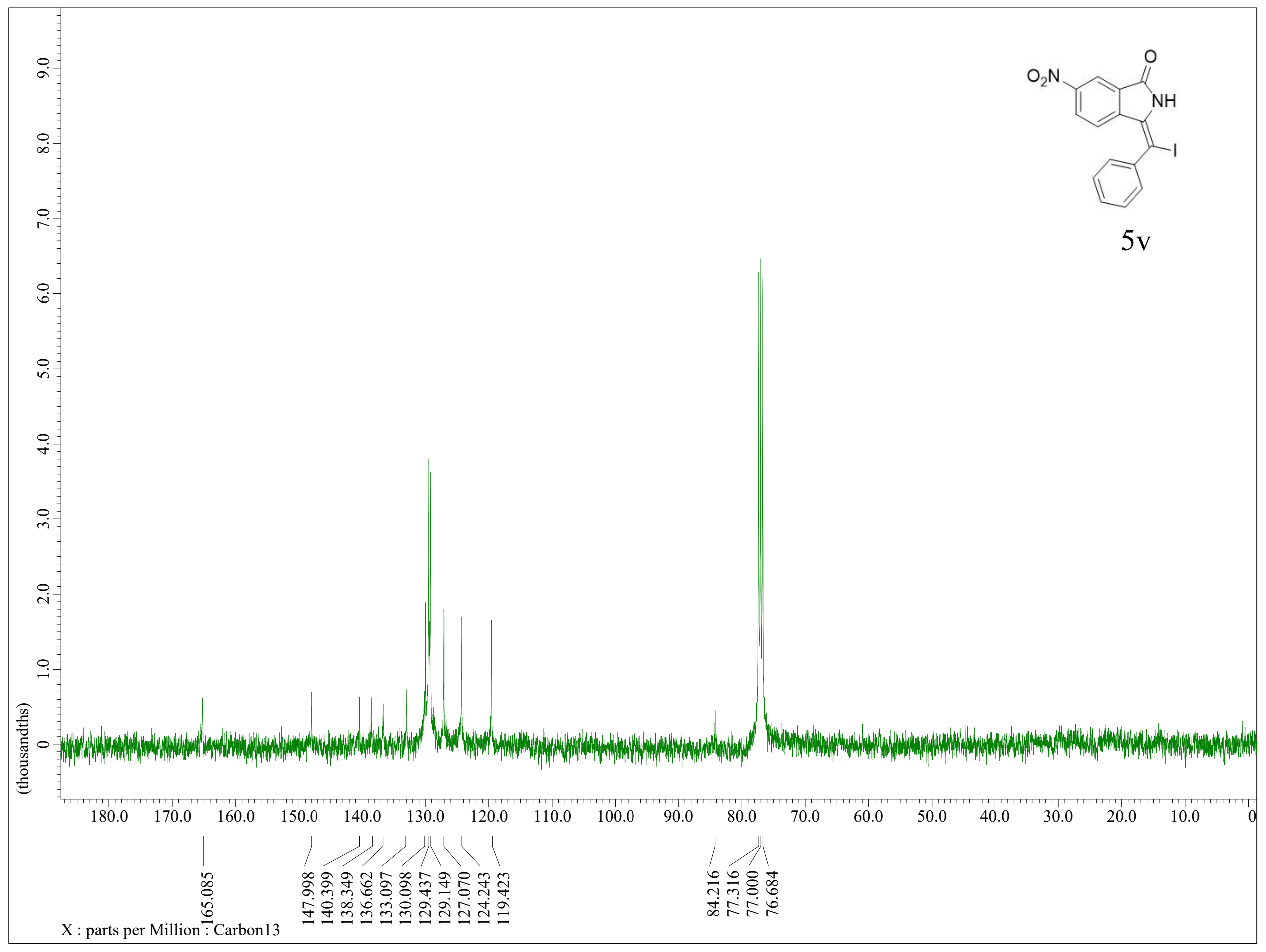




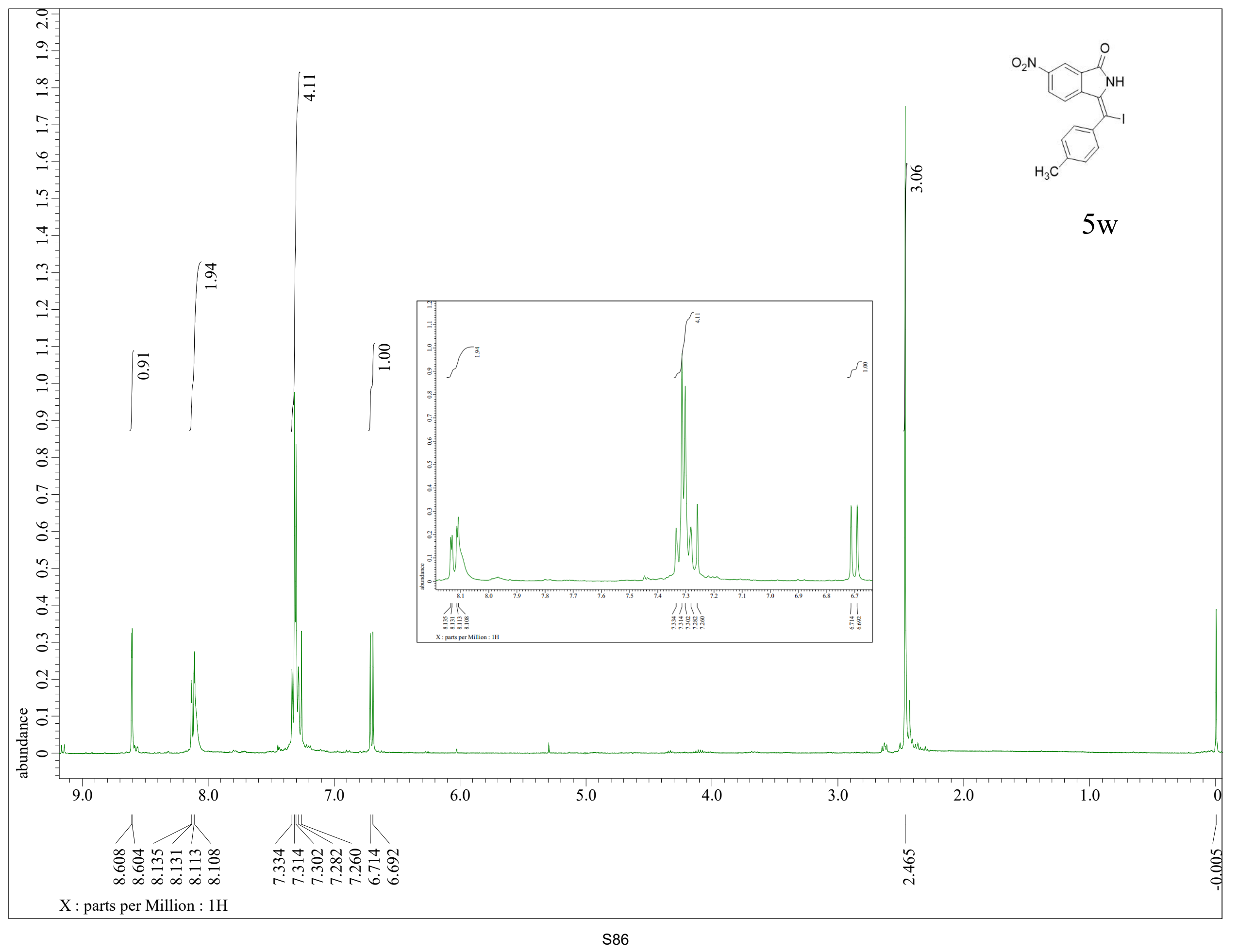




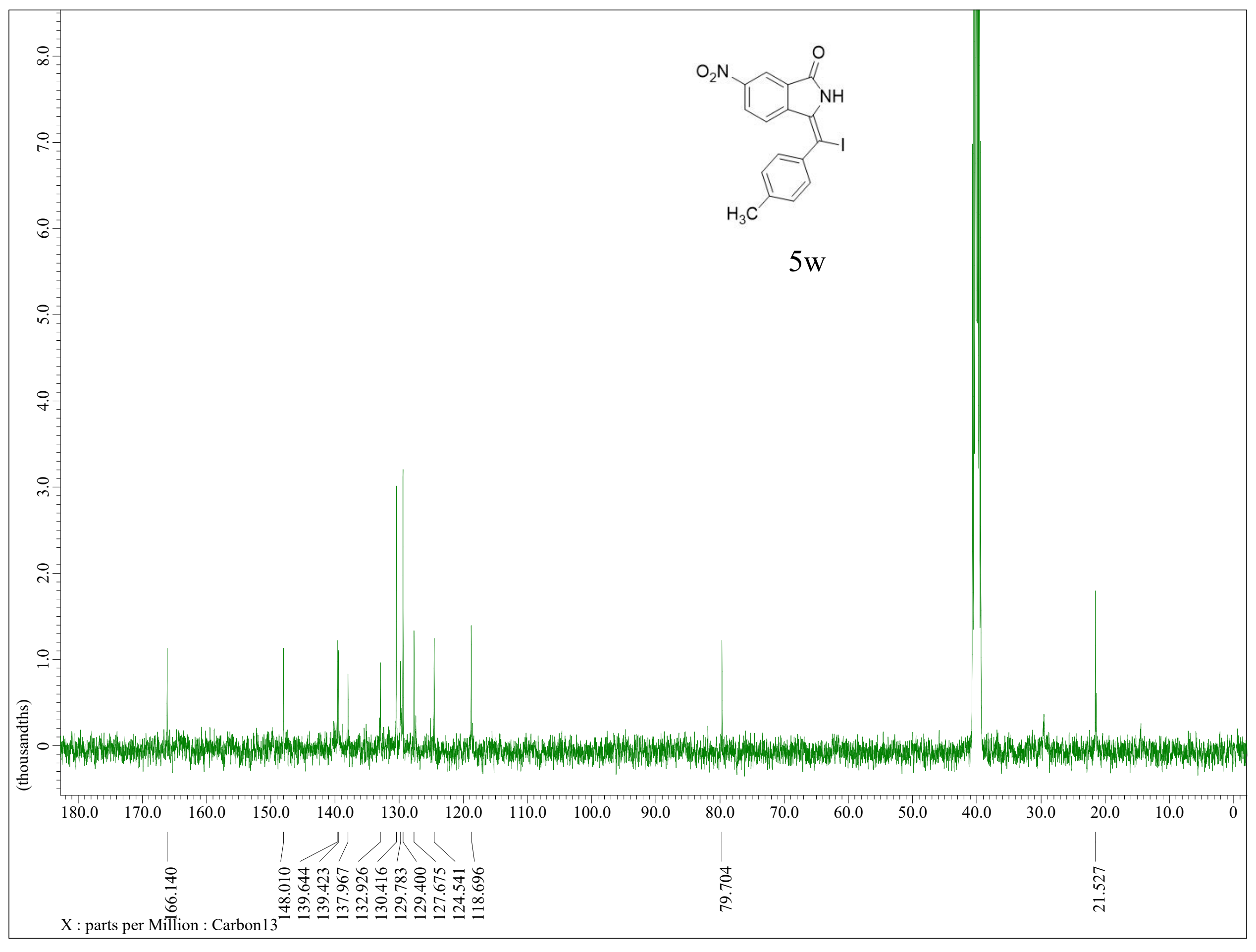




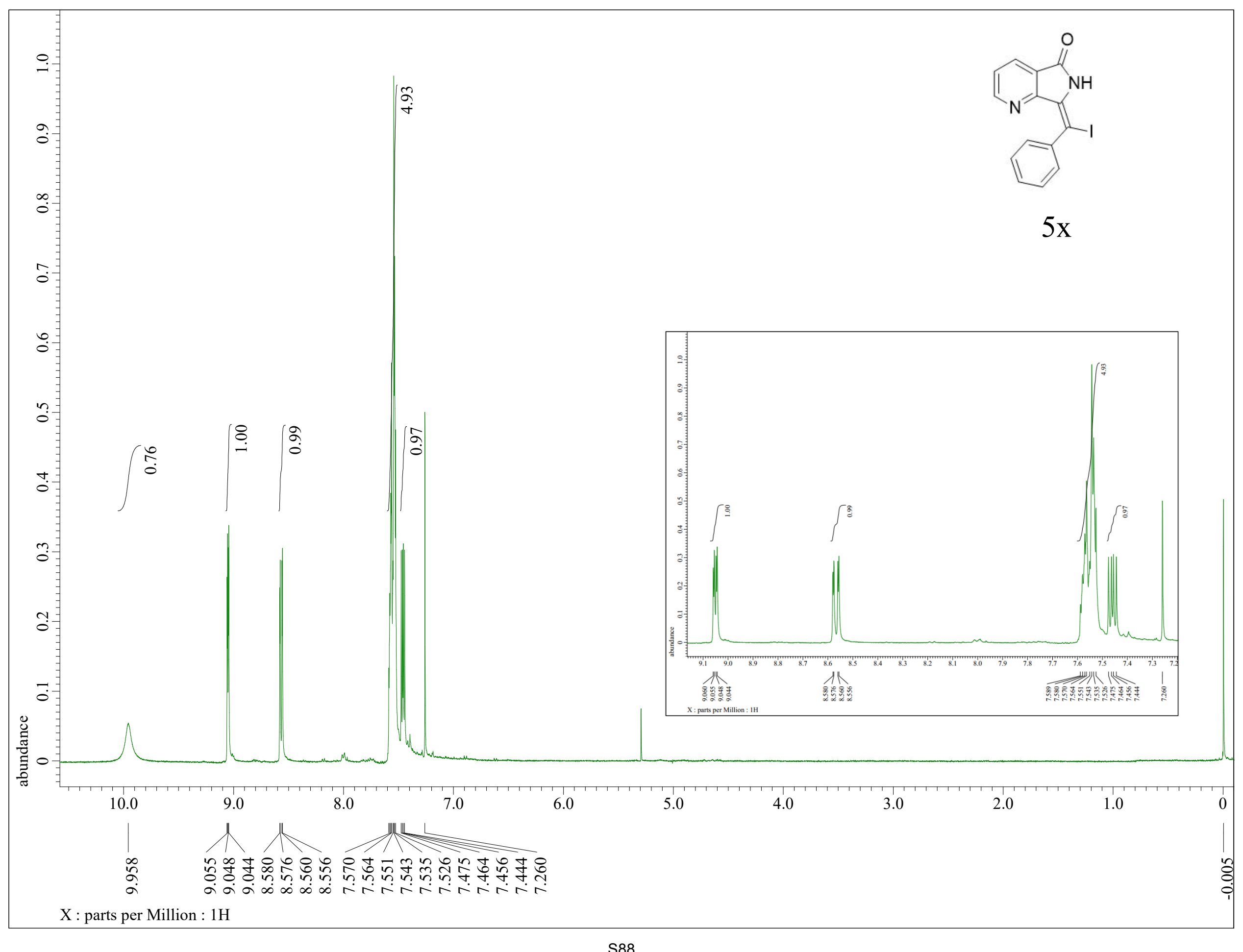




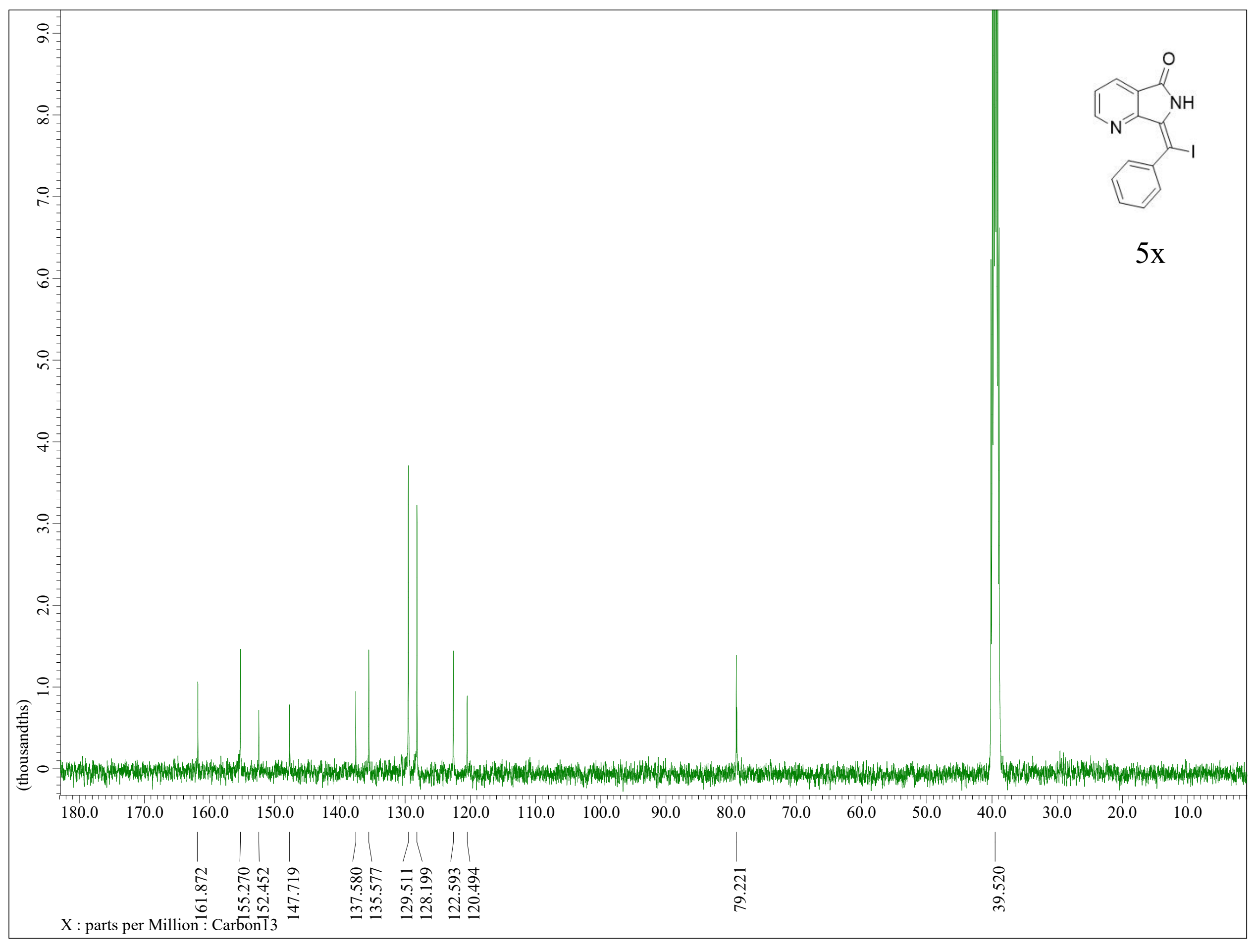




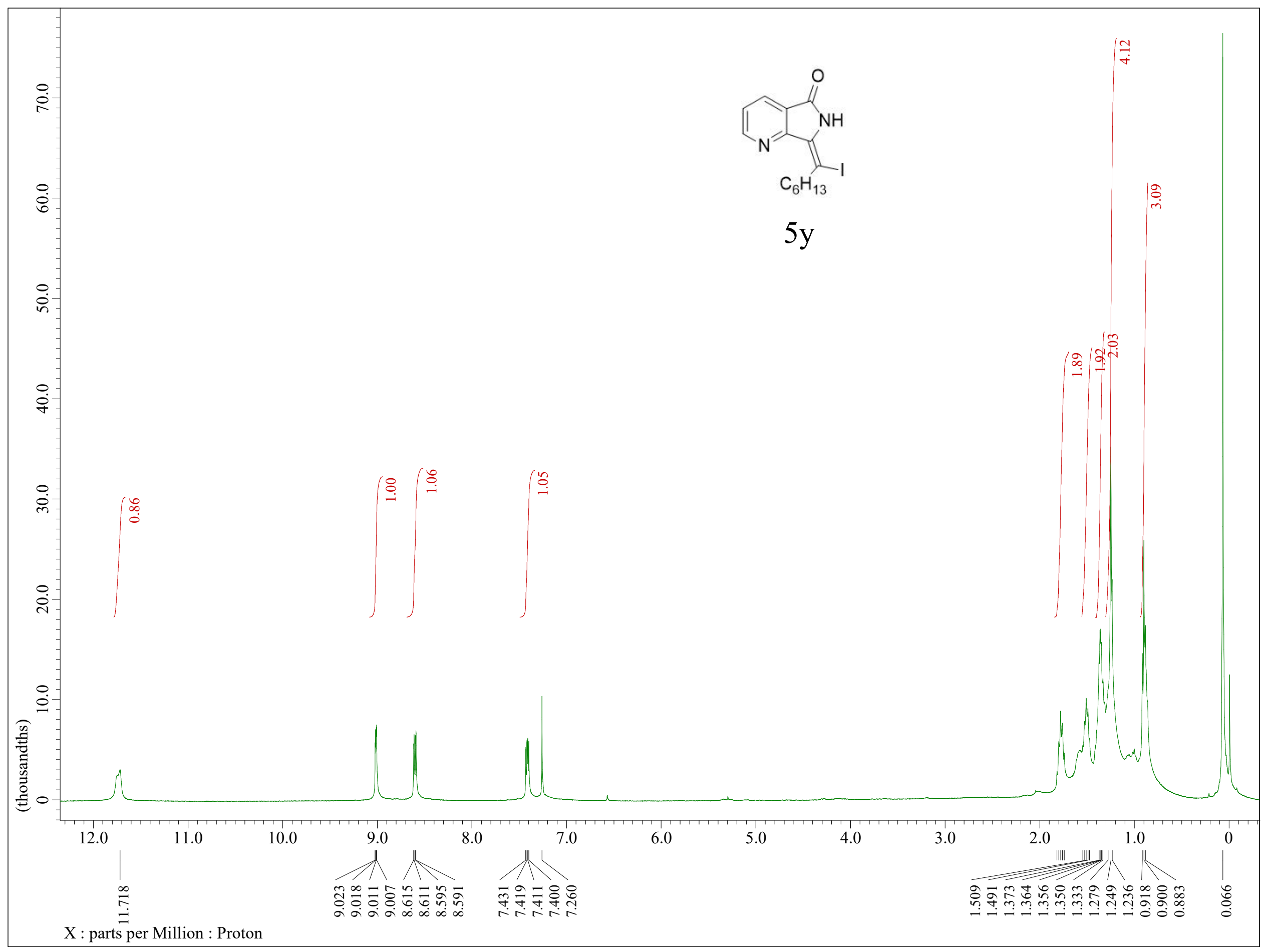




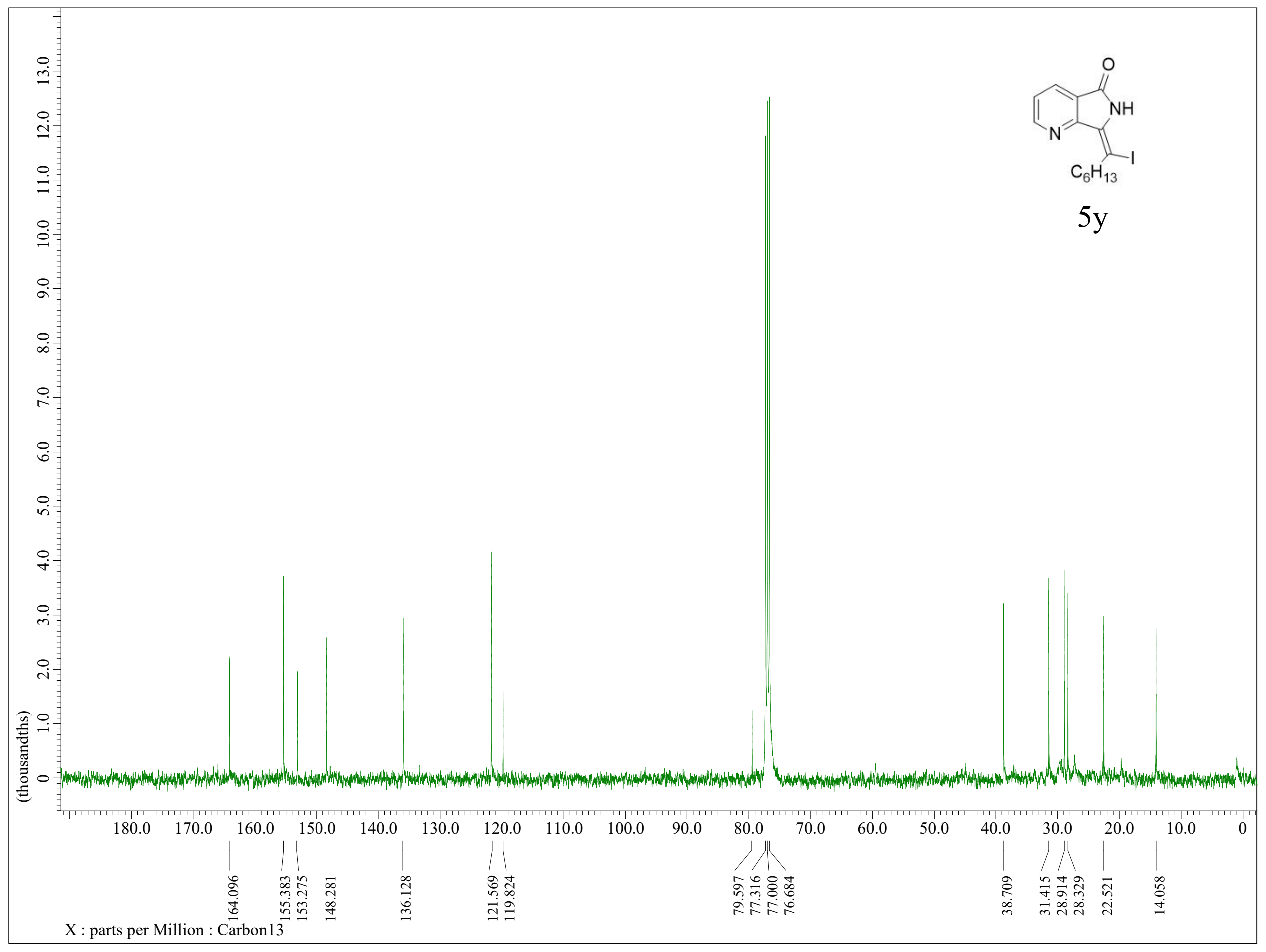




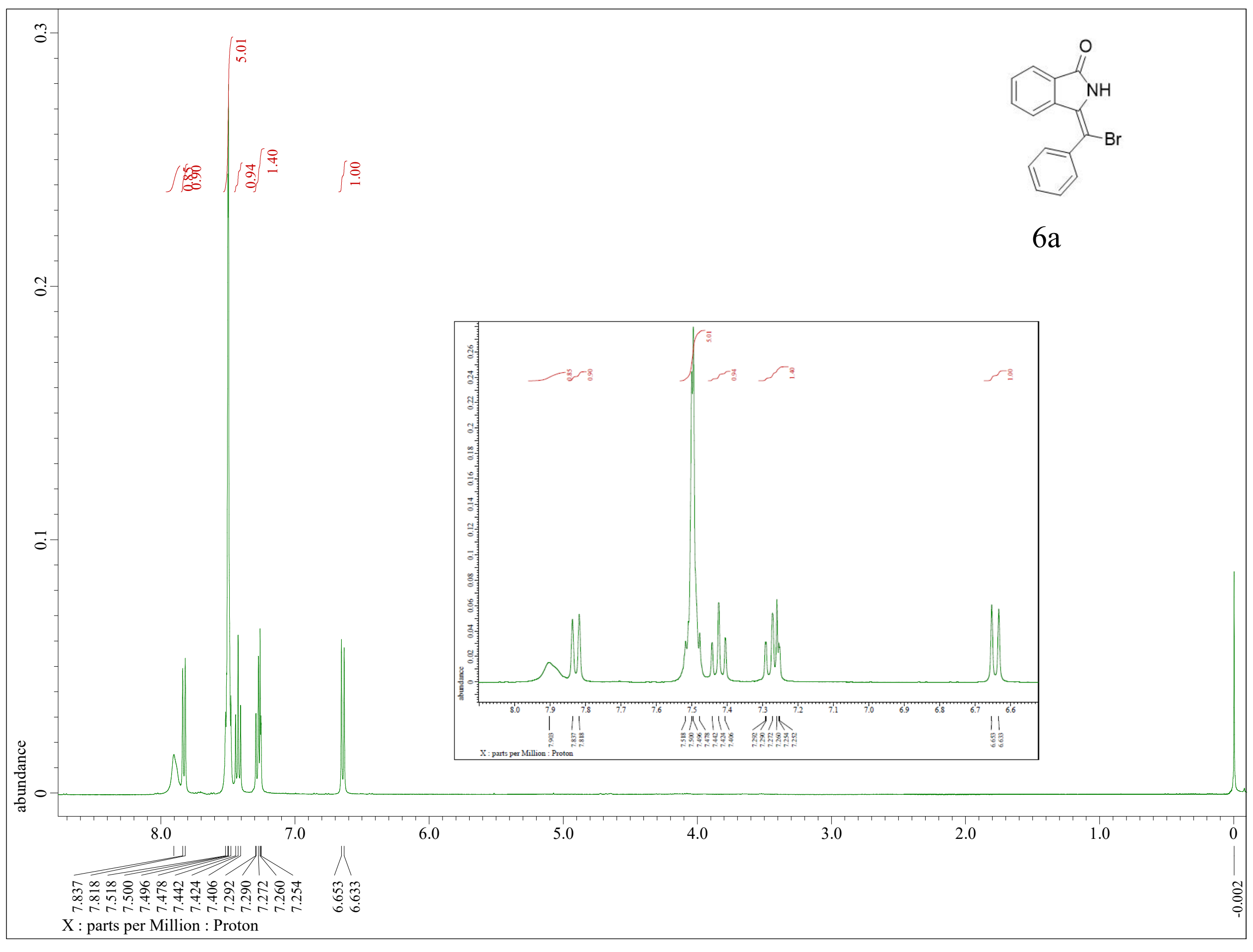




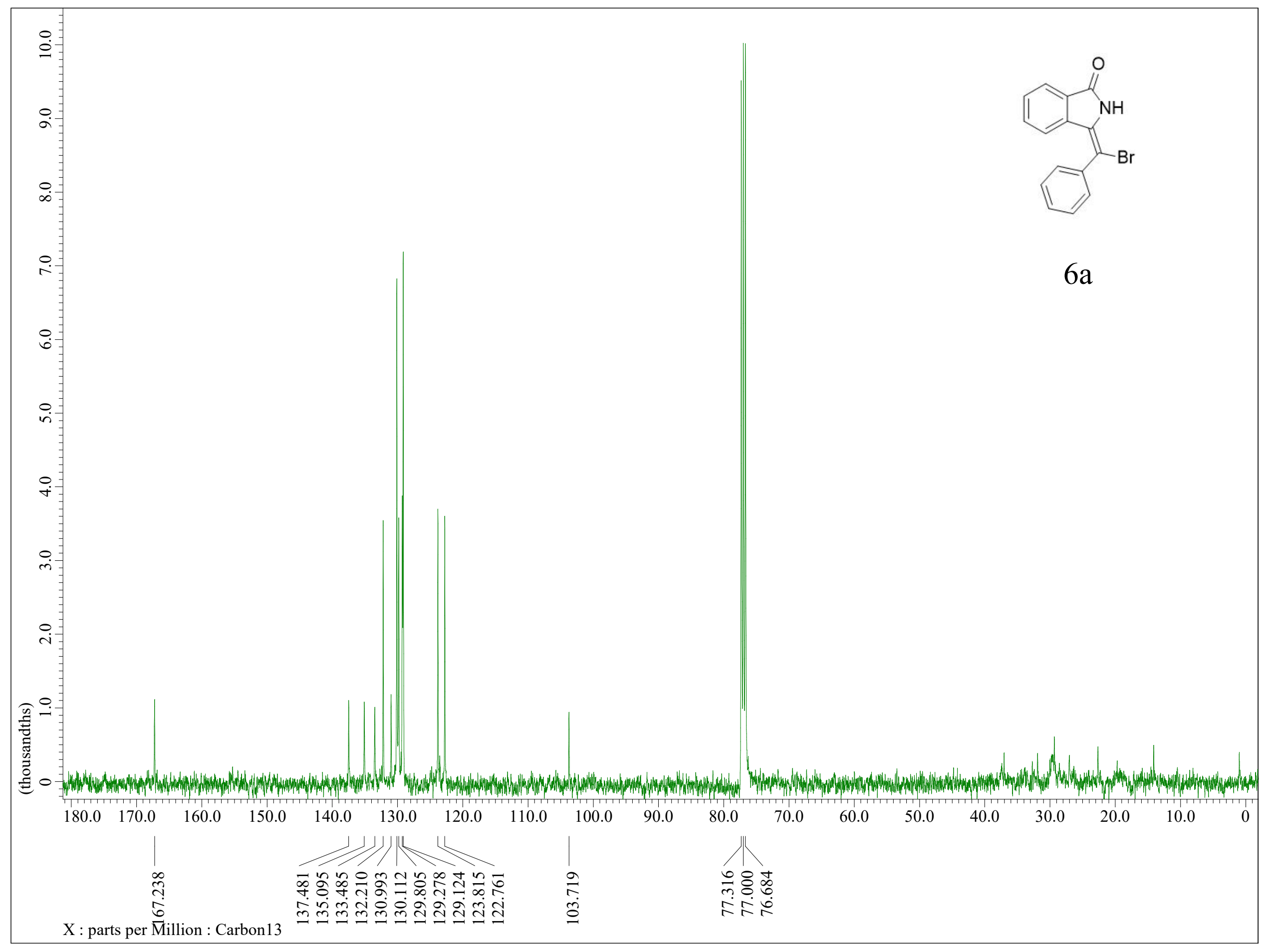




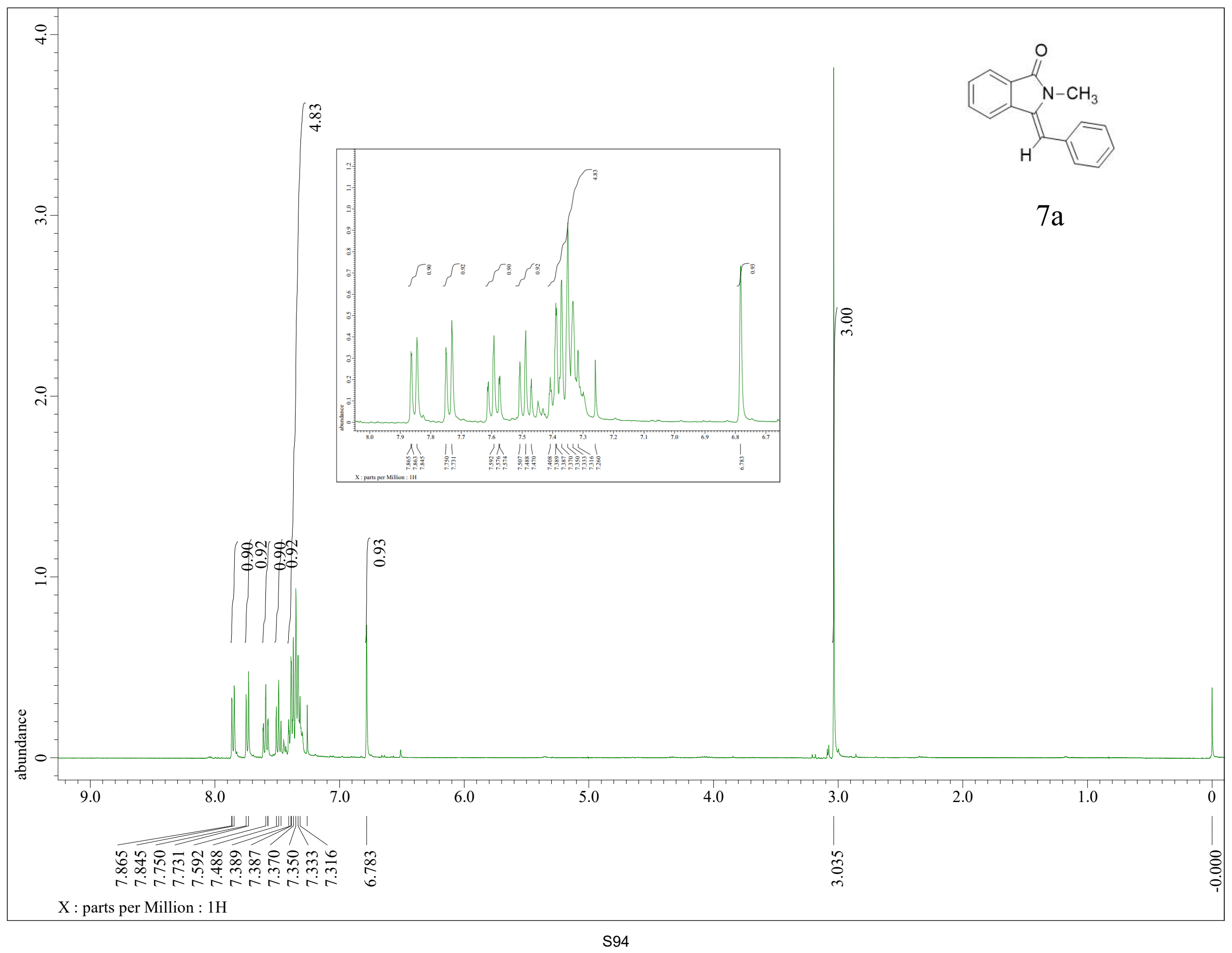




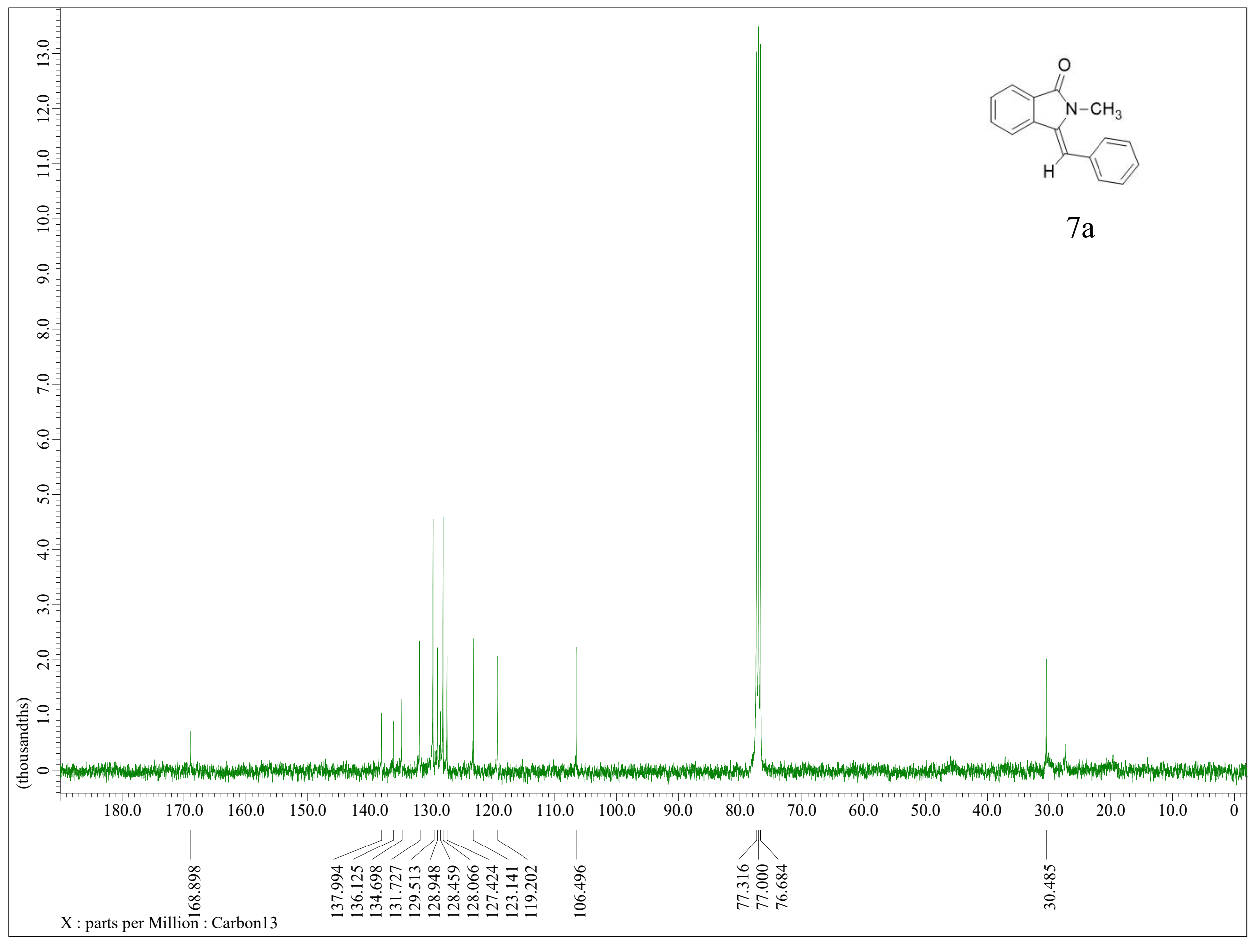




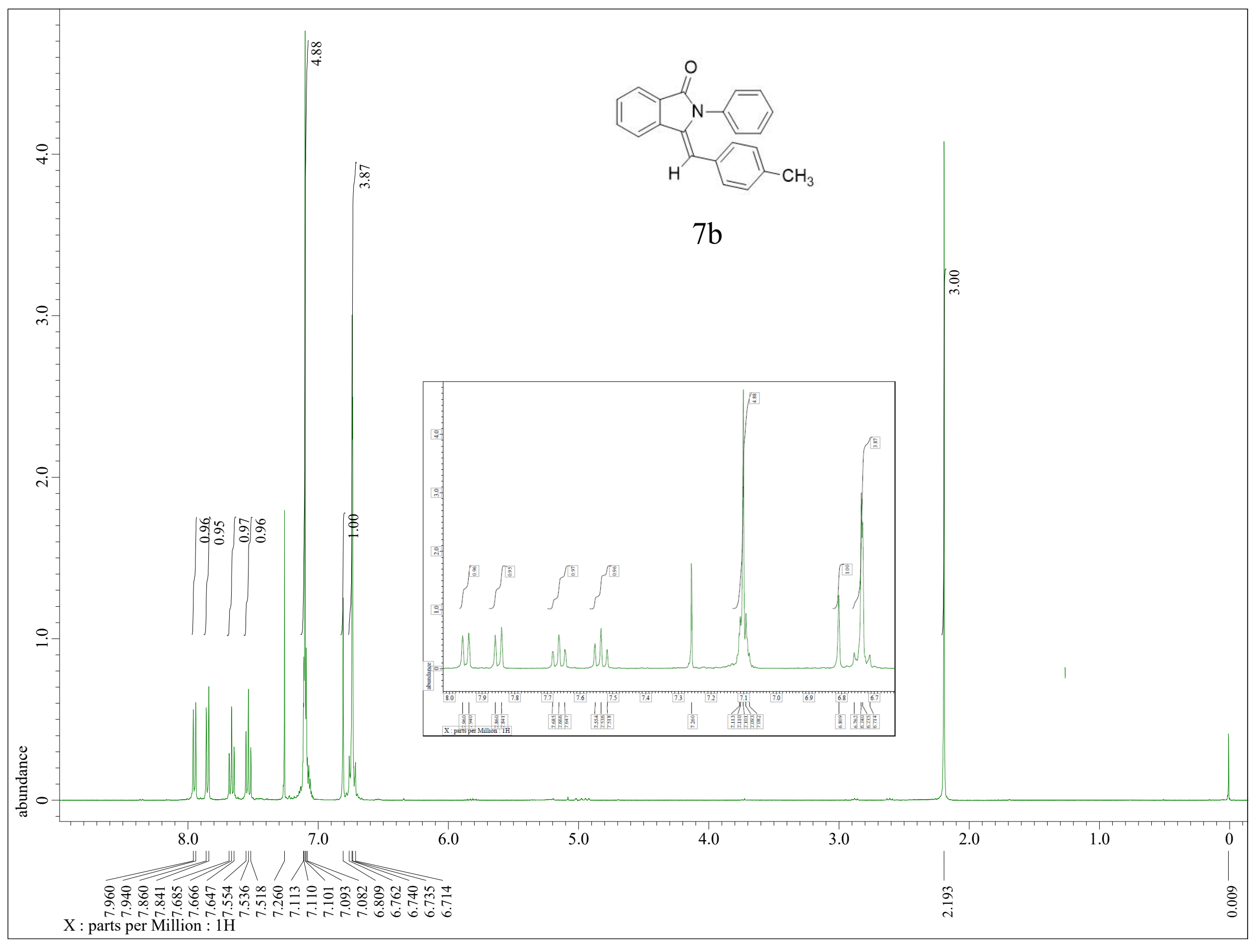




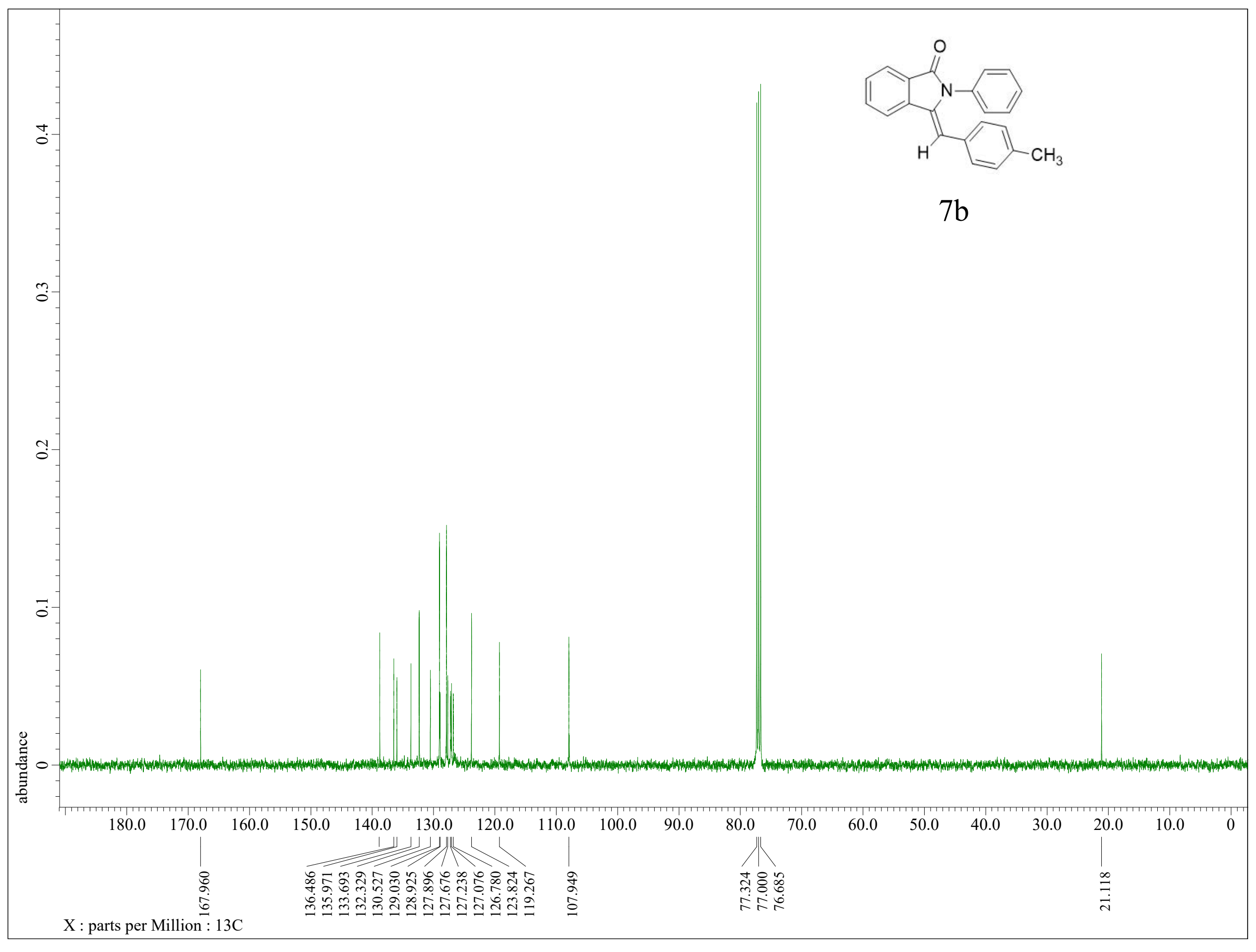




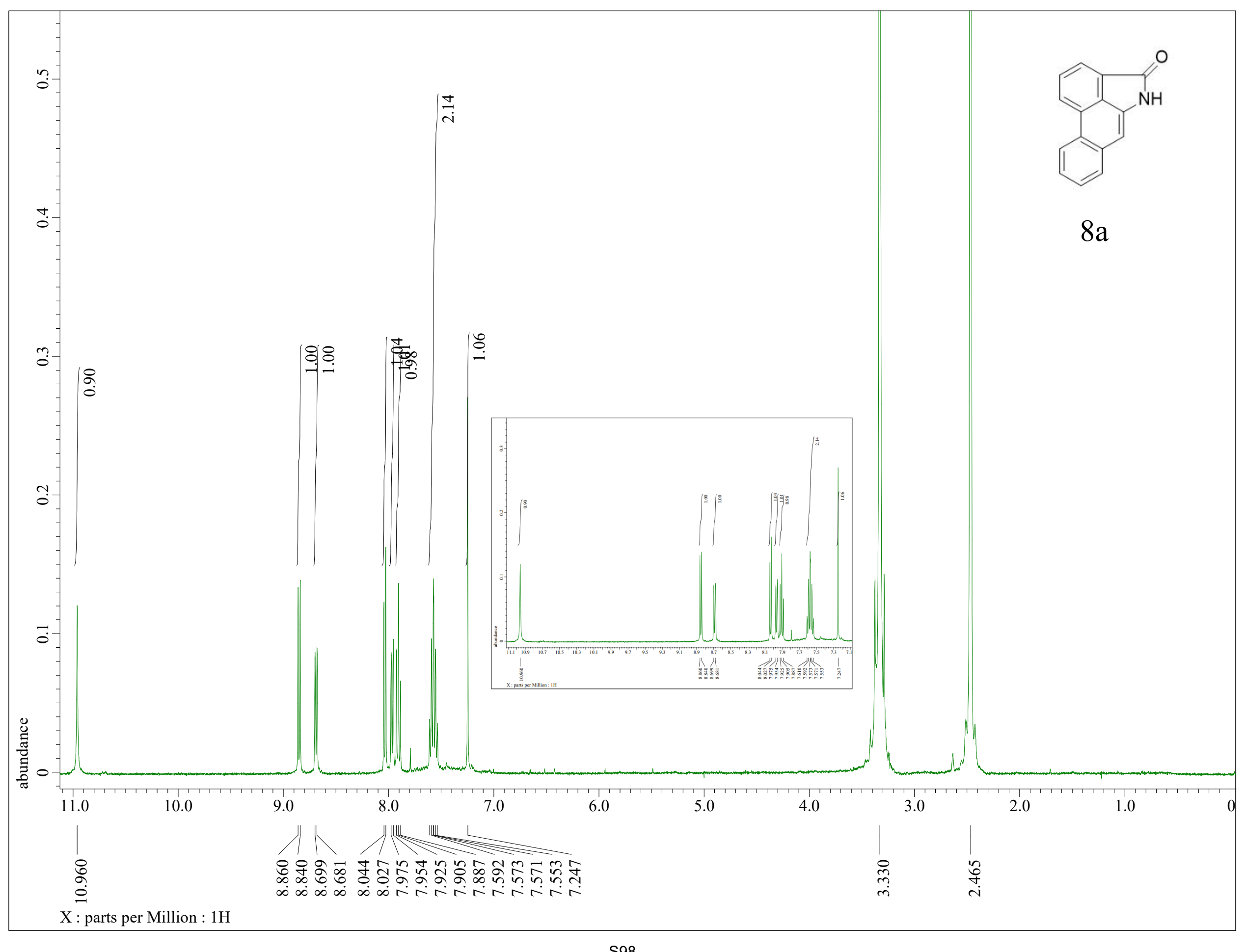




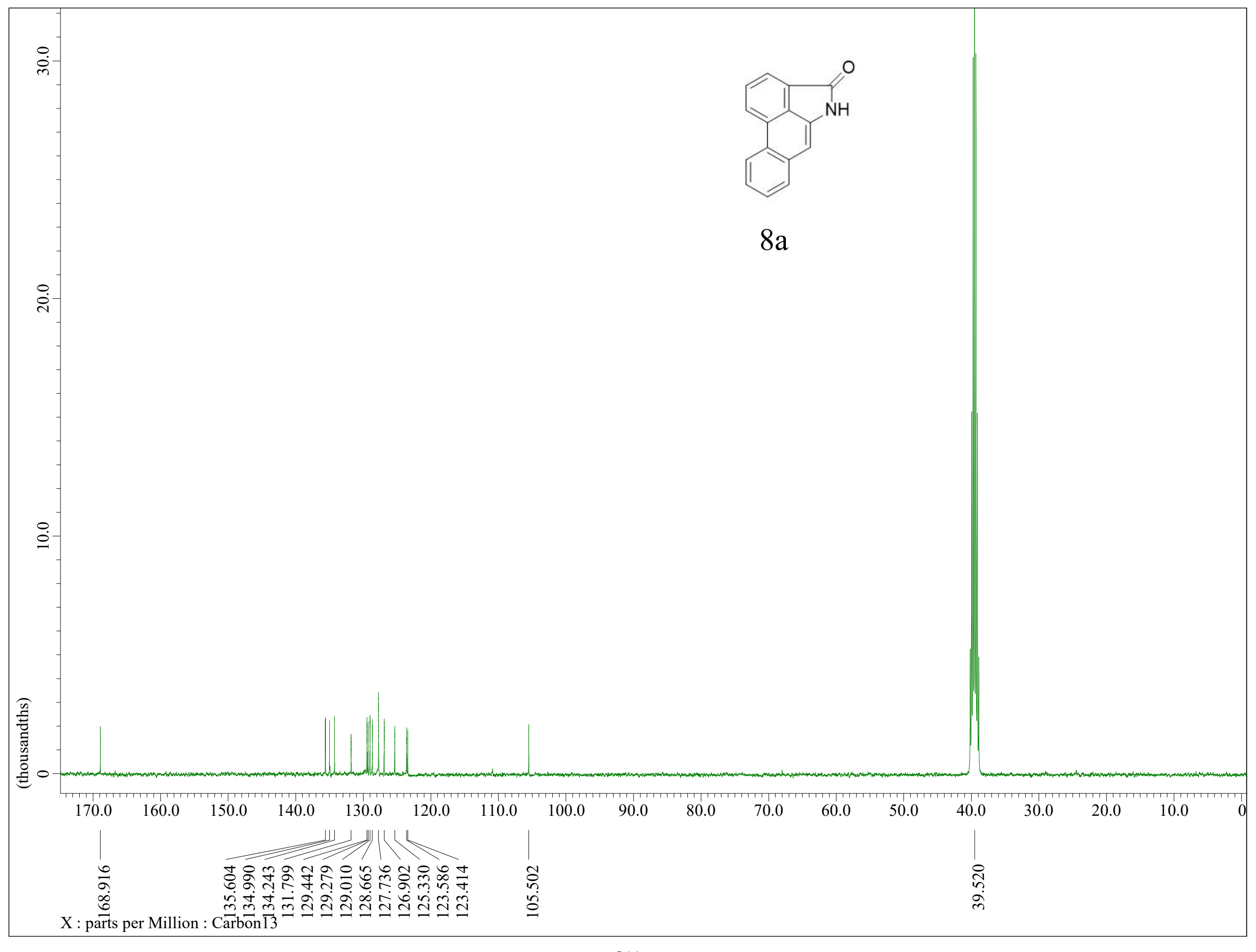




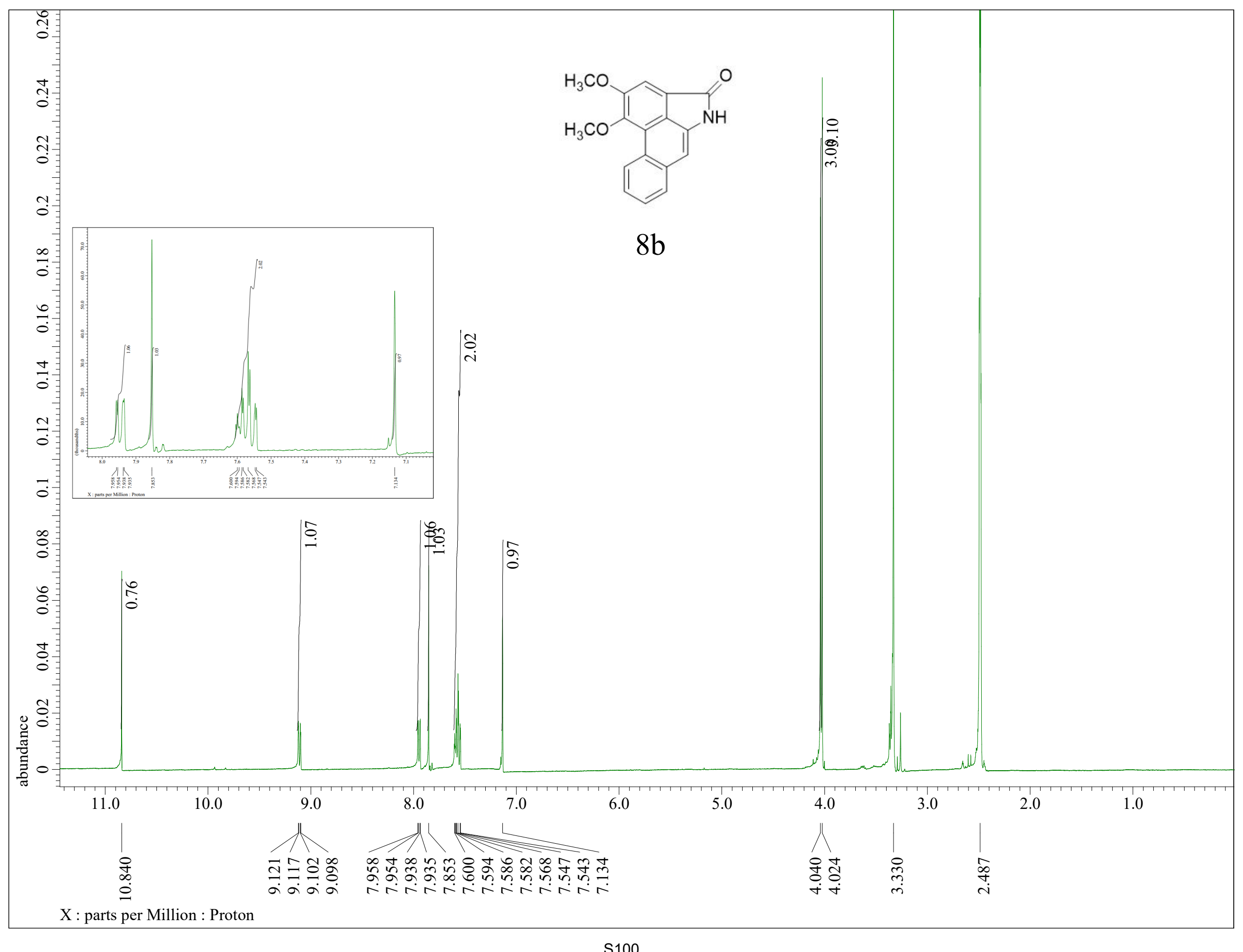




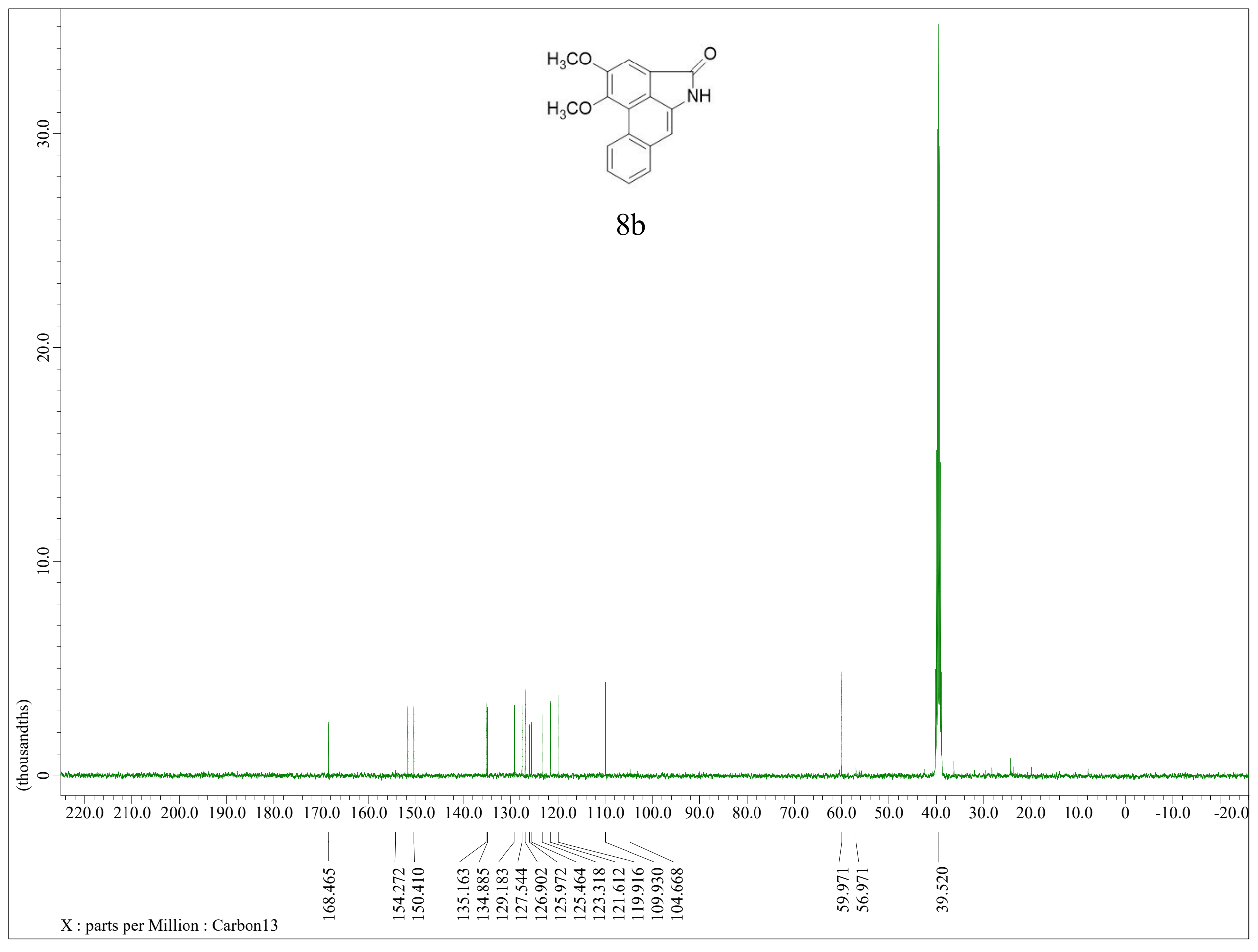

